Universidade de São Paulo - USP

Escola de Engenharia de São Carlos - EESC

Departamento de Engenharia Elétrica

\title{
Proposição e Estudo de Fibras Ópticas Microestruturadas Tipo D: Gerenciamento de Dispersão e Alta Birrefringência
}

\author{
Autor: Danilo Henrique Spadoti \\ Orientador: Prof. Dr. Murilo Araujo Romero \\ Co-orientador: Prof. Dr. Ben-Hur Viana Borges
}

Tese de doutorado apresentada à Escola de Engenharia de São Carlos da Universidade de São Paulo, como parte dos requisitos para obtenção do título de Doutor em Engenharia Elétrica. 



\section{Sumário}

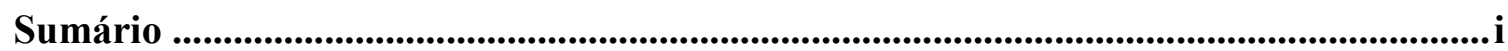

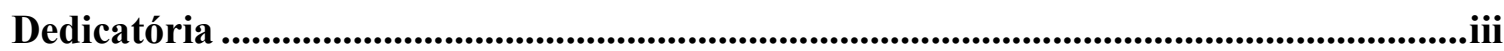

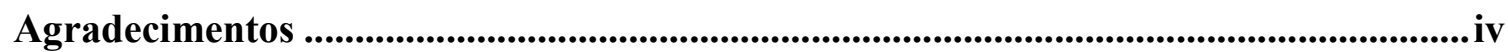

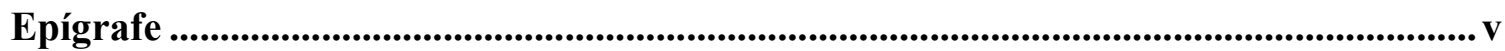

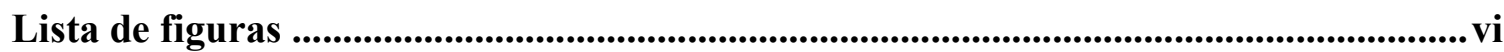

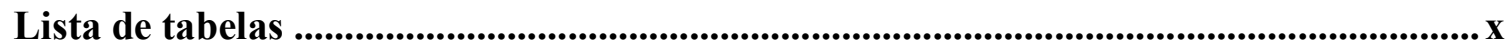

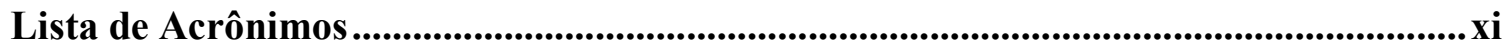

Lista de Símbolos ........................................................................................................................

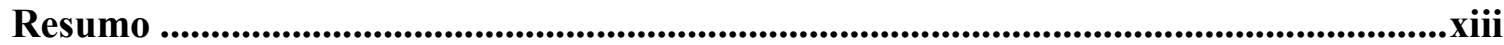

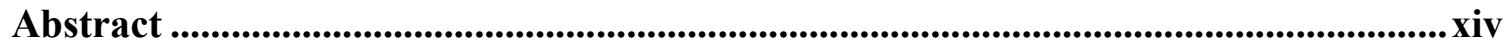

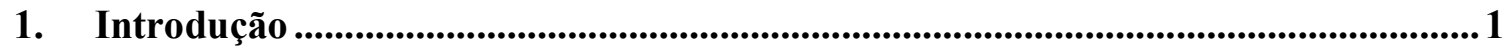

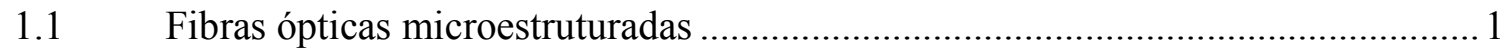

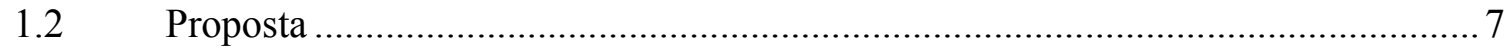

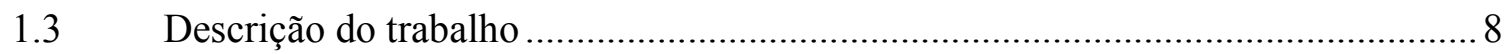

2. Fibras ópticas microestruturadas: compensação de dispersão e alta birrefringência ............................................................................................................................................ 9

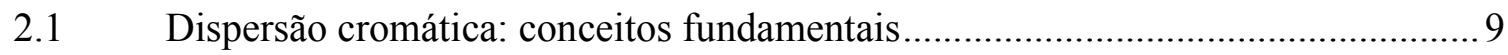

2.2 Fibras ópticas projetadas para compensação de dispersão .................................... 12

A) DCFs - fibras ópticas convencionais compensadoras de dispersão ....... 13

B) MOFs - fibras ópticas microestruturadas compensadoras de dispersão 16

C) DC-MOFs - fibras ópticas microestruturadas de dois núcleos .............. 18

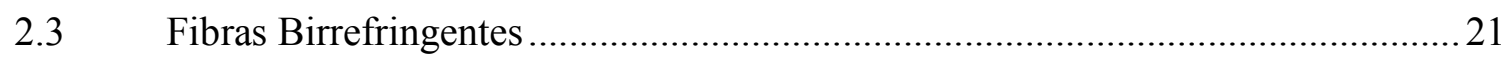

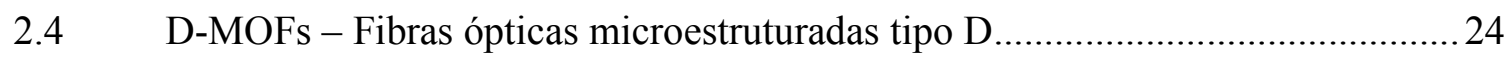

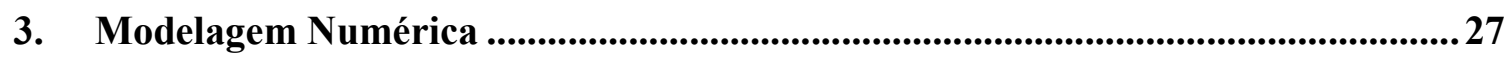

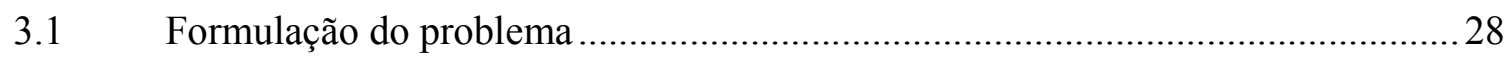

3.2 Método da sobre-relaxação sucessiva - SOR ….................................................... 30

3.3 Método IRAM via sub-rotinas Arpack ................................................................ 34 
3.4 Validação dos métodos SOR e IRAM...... 37

A) Fibra óptica microestruturada monomodo..............................................37

B) Fibra óptica microestruturada de dois núcleos .....................................40

C) Fibra óptica microestruturada HOF ....................................................46

4. Estudos em Fibras Ópticas Microestruturadas Convencionais .................................49

4.1 Fibra óptica microestruturada para compensação de dispersão e amplificação

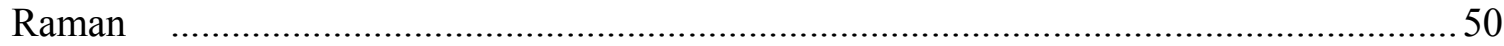

4.2 Acoplamento modal em fibras ópticas microestruturadas de dois núcleos ........... 55

5. Proposição e análise de fibras ópticas microestruturadas tipo $D$.............................65

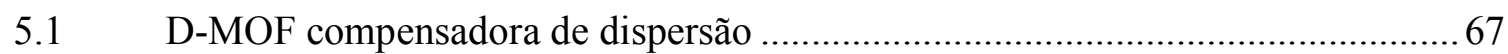

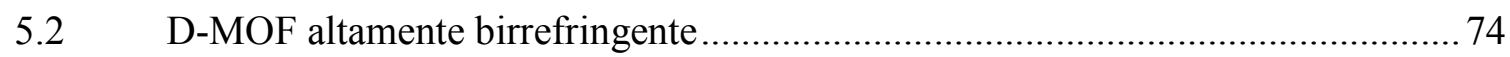

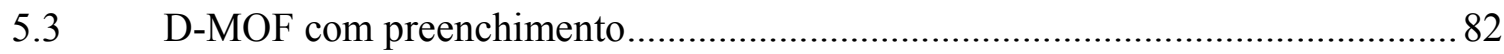

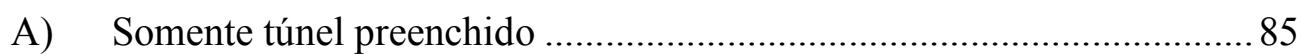

B) Túnel e anéis preenchidos.............................................................. 90

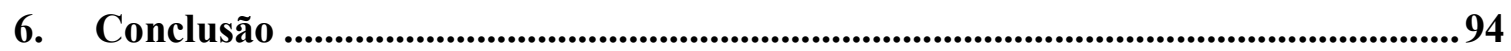

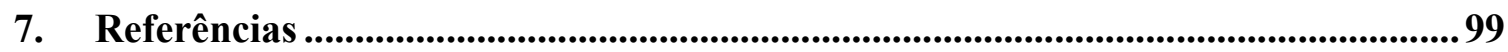

I.1. Apêndice - Obtenção da Equação Vetorial de Helmholtz. ................................... 108 


\section{Dedicatória}

Dedico este trabalho:

a Deus;

a minha esposa Ana Rita;

aos meus pais Luiz e Sueli;

a minha irmã Giovana e avó Zola;

a minha nova família - Gatto 


\section{Agradecimentos}

Agradeço, primeiramente, ao meu orientado professor Dr. Murilo pela sua orientação, paciência e por todos os ensinamentos não só técnicos-científicos como também pelos ensinamentos de vida.

Ao meu co-orientedor, professor Dr. Ben-Hur, agradeço pela forma como ajudou a conduzir este trabalho, pelas longas e valiosas discussões e pelo seu exemplo de dedicação à ciência.

A minha esposa, Ana Rita, sou mais que grato, pois sem seu apoio, paciência e compreenção esse trabalho não sairia. A ela devo mais do que este simples agradecimento, devo tudo o que tenho e conquistei. A ela meu eterno agradecimento, reconhecimento e meu amor.

A minha família: mãe Sueli, avó Zola, minha irmã Giovanna e meu cunhado Pedro, obrigado por fazerem parte da minha vida e por todos os momentos juntos. Agradeço, em particular, ao meu tio Nivaldo pelo apoio e confiança e a toda sua família pelas horas e horas de momentos felizes juntos.

A minha segunda família: meu sogro Paulo e sogra Luzia que me acolheram, apoiaram, contribuíram e oraram por mim e pela Ana Rita. Agradeço e reconheço a importância de vocês nas nossas vidas. A minha irmã-cunhada Stella e meu primo-irmãocunhado Marcelo, obrigado por nos ajudarem tanto e por fazerem parte desta conquista.

Aos meus amigos: de república (Sergio, Rodolfo, Batata, Rall, Amaury, Robertinho, Fião e Gatto) e de Botucatu (João, Binho, Paulo, Marcos e Guga) obrigado pelas horas de 'relaxamento'. Aos amigos da USP: amigos de bandejão - Pedro, Emiliano, Guilherme, Valdemir, Anderson, Clenilson; amigos de 'pelada' - Marcelo, Rafael, Maranhão; aos amigos 'da antiga' - Carlos, Valtemir e Licinius; a todos estes, obrigado pelo convívio diário, pelas aflições e vitórias. 


\section{Epígrafe}

Procure ser uma pessoa de valor ao invés de tentar ser alguém de sucesso -

"Albert Einsten" 


\section{Lista de figuras}

Figura 1. Seção transversal de uma fibra óptica microestruturada com núcleo sólido [2]....2

Figura 2. Fibra óptica com banda fotônica proibida núcleo de ar (PBG) [3] ....................... 3

Figura 3. Esquemático de uma fibra óptica microestruturada ............................................ 3

Figura 4. a) Fibra óptica microestruturada IG, b) Fibra óptica microestruturada PBG....... 4

Figura 5. Coeficientes de dispersão cromática das fibras ópticas convencionais e das fibras ópticas com dispersão deslocada

Figura 6. Diferentes perfis de índice de refração projetados para as fibras DC-DCF, [21], [22] e [26]

Figura 7. Esquemático da fibra óptica microestruturada de dois núcleos; a) ausência dos capilares; b) redução do diâmetro dos capilaeres; c) perfil de índice de refração da estrutura $b$

Figura 8. Esquemático da fibra óptica microestruturada tipo D....................................... 24

Figura 9. Fibra óptica microestruturada tipo D. (a) corte no centro, (b) corte deslocado ... 25

Figura 10. Visualização da equação $\mathrm{Ax}=\lambda \mathrm{x}$ em diferenças finitas .................................. 31

Figura 11. Estrutura da matriz A na forma penta-diagonal ............................................... 35

Figura 12. Comparação entre os valores do índice efetivo calculados pelo método SOR e

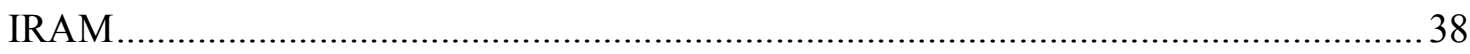

Figura 13. Dispersão cromática em função do comprimento de onda. ............................... 39

Figura 14. Perfil de campo magnético fundamental para dois comprimentos de onda

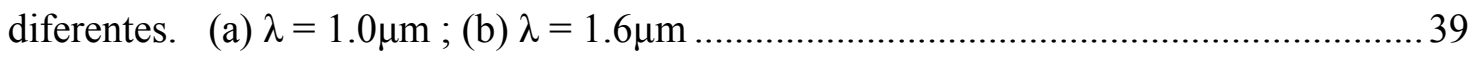

Figura 15. Esquemático da fibra óptica microestruturada de dois núcleos ........................ 40

Figura 16. Variação do índice efetivo em função com comprimento de onda - modo fundamental e terceiro modo.

Figura 17. Componente de campo magnético $H_{x}$ do modo fundamental. a) $\lambda=0,5 \mu \mathrm{m}$, b) $\lambda=1,0 \mu \mathrm{m}, \mathrm{c}) \lambda=1,5 \mu \mathrm{m}$, d) $\lambda=2,0 \mu \mathrm{m}$, e) $\lambda=2,5 \mu \mathrm{m}$, f) $\lambda=3,0 \mu \mathrm{m}$.

Figura 18. Componente de campo magnético $H_{x}$ do terceiro modo. a) $\lambda=0,5 \mu \mathrm{m}, \mathrm{b}$ ) $\lambda=1,0 \mu \mathrm{m}, \quad$ c) $\lambda=1,5 \mu \mathrm{m}$, d) $\lambda=2,0 \mu \mathrm{m}$, e) $\lambda=2,5 \mu \mathrm{m}$, f) $\lambda=3,0 \mu \mathrm{m}$

Figura 19. Comportamento da componente de campo $H_{x}$ para $\lambda<\lambda_{c}$; a) modo fundamental b) terceiro modo. 
Figura 20. Comportamento da componente de campo $\mathrm{H}_{\mathrm{x}}$ para $\lambda>\lambda_{\mathrm{c}}$; a) modo fundamental b) terceiro modo. 45

Figura 21. Esquemático da seção transversal da fibra HOF e o perfil de índice de refração 46

Figura 22. Componentes de campo magnético da fibra HOF. (a) modo fundamental, (b)-(c) primeiro modo $\mathrm{H}_{\mathrm{x}}$ e $\mathrm{H}_{\mathrm{y}}$, (d)-(e) segundo modo $\mathrm{H}_{\mathrm{x}}$ e $\mathrm{H}_{\mathrm{y}}$; (f) contornos da componente de campo $\mathrm{H}_{\mathrm{x}}$ de $\mathrm{a}, \mathrm{b}, \mathrm{d}$, respectivamente.

Figura 23. Parâmetro $d / \Lambda$ como função da pressão aplicada. BOP representa o corte transversal da fibra na posição de puxamento inicial, enquanto que, EOP representa o corte transversal da fibra localizado entre 100-500 metros ao longo do eixo de fibra. A linha azul representa a meta desejada.

Figura 24. Imagem da seção transversal de $125 \mu \mathrm{m}$ da fibra microestruturada fabricada, feita no microscópio eletrônico. No canto superior, a seção transversal da preforma à partir da qual a fibra foi puxada.

Figura 25. Espectro de potência na saída da fibra microestruturada para uma potência de bombeio (em 1480nm) de 1,5 W 54

Figura 26. Esquemático das estruturas com os perfis de índice de refração. a) guia 1 estrutura da DC-PCF completa, b) guia 2 - núcleo interno, c) guia 3 - núcleo externo....56

Figura 27. Variação do índice efetivo dos guias em função do comprimento de onda....... 59

Figura 28. Coeficiente modal em função do comprimento de onda. 60

Figura 29. Evolução do coeficiente modal em função do comprimento de onda para diferentes $\mathrm{f}$. Símbolos cheio $\mathrm{f}=0,45$, símbolos vazados $\mathrm{f}=0,85$.

Figura 30. Componente de campo $H_{x}$ do supermodo par. (a) $\lambda=1500 \mathrm{~nm}$, (b) $\lambda=1550 \mathrm{~nm}$ e (c) $\lambda=1600 \mathrm{~nm}$

Figura 31. Componente de campo $H_{x}$ do supermodo ímpar. (a) $\lambda=1500 \mathrm{~nm}$, (b) $\lambda=$ $1550 \mathrm{~nm} \mathrm{e} \quad$ (c) $\lambda=1600 \mathrm{~nm}$.

Figura 32. Fibra óptica microestruturada. (a) MOF convencional; (b) D-MOF ..................66 66

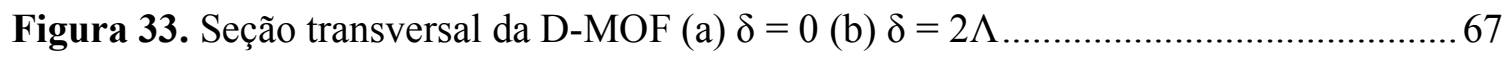

Figura 34. Área efetiva em função do comprimento de onda. Fibra MOF convencional linhas pontilhadas e símbolos vazados, D-MOF linhas sólidas com símbolos cheios. 
Figura 35. Dispersão em função do comprimento de onda para polarização-x. D-MOF com $\Lambda=1,6 \mu \mathrm{m}, \mathrm{d} / \Lambda=0,6875$ e sem o capilar central (linha em preto). D-MOF com $\Lambda=1,6 \mu \mathrm{m}$, $\mathrm{d} / \Lambda=0,6875$ e $\mathrm{r}_{\mathrm{c}}=0,10 \mathrm{r}$ (linha em azul). D-MOF com $\Lambda=1,6 \mu \mathrm{m}, \mathrm{d} / \Lambda=0,6875$ e $\mathrm{r}_{\mathrm{c}}=0,25 \mathrm{r}$ (linha em vermelho). D-MOF com $\Lambda=1,3 \mu \mathrm{m}, \mathrm{d} / \Lambda=0,846$ e $\mathrm{r}_{\mathrm{c}}=0,25 \mathrm{r}$ (linha em verde).... 71

Figura 36. Compensação da dispersão nas bandas S, C e L. Linha azul - fibra convencional SMF-28, linha verde - D-MOF otimizada, linha preta - cancelamento resultante da compensação de dispersão em um enlace de $40 \mathrm{~km}$ com dispersão residual abaixo de $1,0 \mathrm{ps} /(\mathrm{nmkm})$.

Figura 37. Dispersão cromática em função do comprimento de onda. Polarização na direção $x$ linhas em preto com símbolos cheios e polarização na direção y linhas em azul com símbolos vazados; $\mathrm{f}=0,875$ (quadrados) $\mathrm{f}=0,75$ (estrelas) e $\mathrm{f}=0,6875$ (círculos) 73

Figura 38. Cálculo da birrefringência para $D-M O F \operatorname{com} d / \Lambda=0,875$ e a posição do corte em $\delta=0$ (linhas em preto e símbolos cheios ) e $\delta=$ raio (linhas em azul e símbolos vazados), respectivamente, para: $\Lambda=1,0 \mu \mathrm{m}$ (quadrado), $\Lambda=1,2 \mu \mathrm{m}$ (triângulo), $\Lambda=1,6 \mu \mathrm{m}$ (estrela) e $\Lambda=2,3 \mu \mathrm{m}$ (diamante) .75

Figura 39. Cálculo da birrefringência para D-MOF com posição do corte em $\delta=0$ e: $\Lambda=1,3 \mu \mathrm{m}$ (preta), $\Lambda=1,2 \mu \mathrm{m}$ (verde), $\Lambda=1,0 \mu \mathrm{m}$ (azul) para $\mathrm{d} / \Lambda=0,90$ (símbolos cheios) e $\mathrm{d} / \Lambda=0,95$ (símbolos vazados).

Figura 40. (a) Fibra x-ED-MOF - capilares elípticos dispostos horizontalmente; (b) Fibra y-ED-MOF - capilares elípticos dispostos verticalmente. .78

Figura 41. Cálculo da birrefringência para x-ED-MOF linhas em preto e símbolos vazados e para $\mathrm{y}$-ED-MOFs linhas em vermelho com símbolos cheios; $\Lambda=1,0 \mu \mathrm{m}$ (quadrado), $\Lambda=1,2 \mu \mathrm{m}$ (triângulo), $\Lambda=1,6 \mu \mathrm{m}$ (estrela) e $\Lambda=2,3 \mu \mathrm{m}$ (diamante).

Figura 42. Distribuição da componente de campo magnético fundamental; $\Lambda=1,6 \mu \mathrm{m}$, $\mathrm{d} / \Lambda=0,875$ e $\lambda=1,0 \mu \mathrm{m} \quad$ (a) $\mathrm{x}$-ED-MOF $\quad$ (b) $\mathrm{y}$-ED-MOF . .80

Figura 43. Cálculo da birrefringência para as D-MOFs linhas em azul com símbolos vazados e $\mathrm{x}$-ED-MOFs linhas em preto com símbolos cheios; $\Lambda=1,2 \mu \mathrm{m}$ (triangulo), $\Lambda=1,6 \mu \mathrm{m}$ (estrela) e $\Lambda=2,0 \mu \mathrm{m}$ (circulo).

Figura 44. Perfil de índice de refração da D-MOF com a região do túnel preenchida e anéis vazados .85 
Figura 45. Índice efetivo em função do comprimento de onda para a D-MOF com apenas a região do túnel preenchida

Figura 46. Componente de campo magnético $H_{x}$ do modo fundamental. (a) $\lambda=1000 \mathrm{~nm}$; (b) $\lambda=1800 \mathrm{~nm}$ 88

Figura 47. Dispersão cromática para a fibra D-MOF com túnel preenchido 88

Figura 48. Dispersão cromática para a fibra D-MOF com túnel preenchido com $n=1,40$ e $\mathrm{n}=1,38$.

Figura 49. Perfil de índice de refração da D-MOF com a região do túnel e os anéis preenchidos 90

Figura 50. Índice efetivo em função do comprimento de onda para a D-MOF com $d / \Lambda=$ $0,8, \delta=\mathrm{d} / 2$ e região do túnel e anéis preenchidos com material de índice de refração igual a 1,40 (quadrado), 1,38 (estrela) e 1,30 (triângulo). 91

Figura 51. Dispersão cromática em função do comprimento de onda. $\Lambda=2$ linhas com símbolos cheios e $\Lambda=3$ linhas com símbolos vazados. Índice de refração do material de preenchimento igual a 1,40 (quadrado), 1,38 (triângulo) e 1,30 (estrela). 92

Figura 52. (a) Dispersão cromática em função do comprimento de onda. (b) Birrefringência em função do comprimento de onda. Linhas: preto $d / \Lambda=0,90$, verde $\mathrm{d} / \Lambda=0,80$, azul $\mathrm{d} / \Lambda=0,73$ e vermelho $\mathrm{d} / \Lambda=0,66$. 93 


\section{Lista de tabelas}

Tabela 1: Parâmetros físicos e geométricos da MOF 37

Tabela 2: Comparação entre os valores do índice efetivo obtidos para a fibra HOF da componente de campo $\mathrm{H}_{\mathrm{x}}$ pelo método IRAM com os valores obtidos em [86]. 48

Tabela 3: Projeto para compensação em banda larga. Bandas C e L (1530-1610nm) ........ 70

Tabela 4: Projeto de uma D-MOF com capilar central ................................................... 71

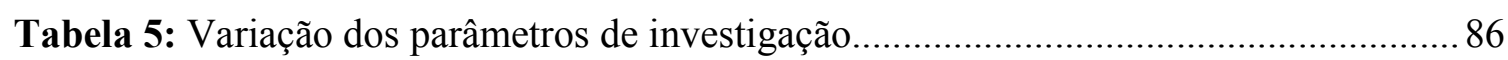




\section{Lista de Acrônimos}

\begin{tabular}{|c|c|c|}
\hline Acrônimos & Português & Inglês \\
\hline B & Birrefringência & Birefringence \\
\hline $\mathrm{D}$ & Dispersão cromática & Chromatic Dispersion \\
\hline DCF & $\begin{array}{l}\text { Fibra óptica compensadora de } \\
\text { dispersão }\end{array}$ & Dispersion compensating fiber \\
\hline DC-MOF & $\begin{array}{l}\text { Fibra óptica microestruturada de } \\
\text { dois núcleos }\end{array}$ & $\begin{array}{l}\text { Dual-core microstructured optical } \\
\text { fiber }\end{array}$ \\
\hline D-MOF & Fibra óptica microestruturas tipo D & $\begin{array}{l}\text { D-shape microstructured optical } \\
\text { fiber }\end{array}$ \\
\hline DSF & $\begin{array}{l}\text { Fibra óptica com dispersão } \\
\text { deslocada }\end{array}$ & Dispersion shifted fiber \\
\hline ED-MOF & $\begin{array}{l}\text { Fibra óptica microestrutura tipo D } \\
\text { com capilares elípticos }\end{array}$ & $\begin{array}{l}\text { Elliptical air-holes D-shape } \\
\text { microstructured optical fiber }\end{array}$ \\
\hline $\mathrm{HF}$ & Fibra perfurada & Holey fiber \\
\hline IRAM & $\begin{array}{l}\text { Método de Arnoldi Implicitamente } \\
\text { Reiniciado }\end{array}$ & $\begin{array}{l}\text { Implicitly Restarted Arnoldi } \\
\text { Method }\end{array}$ \\
\hline MOF & Fibra óptica microestruturada & Microstructured optical fiber \\
\hline NZ-DSF & $\begin{array}{l}\text { Fibra óptica com dispersão } \\
\text { deslocada não-nula }\end{array}$ & Non-zero shifted fiber \\
\hline PCF & Fibra de cristal fotônico & Photonic crystal fiber \\
\hline SOR & Sobre-relaxação sucessiva & Successive over relaxation \\
\hline
\end{tabular}




\section{Lista de Símbolos}

\begin{tabular}{|l|l|l|}
\hline \multicolumn{1}{|c|}{ Símbolo } & \multicolumn{1}{|c|}{ Nomenclatura } & \multicolumn{1}{c|}{ Unidade } \\
\hline $\mathrm{A}_{\text {eff }}$ & Área efetiva & {$\left[\mathrm{m}^{2}\right]$} \\
\hline$\beta$ & Constante de propagação & {$[1 / \mathrm{m}]$} \\
\hline $\mathrm{d}$ & Diâmetro dos capilares & {$[\mathrm{m}]$} \\
\hline $\mathrm{D}$ & dispersão & {$[\mathrm{ps} /(\mathrm{nm} \mathrm{km})]$} \\
\hline$\delta$ & Corte & {$[\mathrm{m}]$} \\
\hline$\lambda$ & Comprimento de onda & {$[\mathrm{m}]$} \\
\hline$\Lambda$ & $\begin{array}{l}\text { Espaçamento entre os centros dos } \\
\text { capilares (pitch) }\end{array}$ & {$[\mathrm{m}]$} \\
\hline $\mathrm{n}_{\mathrm{cl}}$ & Índice de refração da casca & \\
\hline $\mathrm{n}_{\mathrm{co}}$ & Índice de refração do núcleo & \\
\hline $\mathrm{n}_{\mathrm{eff}}$ & Índice efetivo & {$[\mathrm{m}]$} \\
\hline $\mathrm{r}$ & Raio dos capilares & \\
\hline
\end{tabular}




\section{Resumo}

\section{SPADOTI, D.H., "Proposição e Estudo de Fibras Ópticas Microestruturadas Tipo D:} Gerenciamento de Dispersão e Alta Birrefringência", 2008. Tese (doutorado) - Escola de Engenharia de São Carlos, Universidade de São Paulo, 2008.

Este trabalho de doutoramento propôs investigar novas configurações geométricas para as fibras ópticas microestruturadas à base de sílica. Aproveitando-se da flexibilidade que sua geometria proporciona, diferentes das fibras ópticas convencionais, foram propostas fibras ópticas microestruturadas com perfil tipo D atuando, especificamente, em duas aplicações distintas: fibras compensadoras de dispersão ou fibras altamente birrefringentes.

Para o estudo teórico das fibras ópticas microestruturadas foram utilizados dois métodos numéricos: o método da Sobre-Relaxação Sucessiva (SOR) e o método de Arnoldi Implicitamente Reiniciado (IRAM). Foi necessário implementar o método IRAM para determinar os modos de mais alta ordem presentes em guias de onda multimodos, uma vez que o método SOR fornece apenas a solução para o modo fundamental.

Neste contexto, as fibras ópticas microestruturadas com perfil D, propostas e investigadas neste trabalho, demonstraram ser extremamente promissoras para atuar na compensação da dispersão cromática ou no aumento do efeito da birrefringência. Foram projetadas fibras capazes de compensar a dispersão em banda larga, cobrindo as bandas de telecomunicações S, C e L, ou, ainda, fibras com um alto coeficiente de dispersão negativo em torno do comprimento de onda de $1550 \mathrm{~nm}$. Adicionalmente, verificou-se também que com as novas configurações propostas foi possível projetar fibras com elevado grau de birrefringência, sendo atrativas no projeto de fibras mantedoras do estado de polarização.

Palavras-chave: birrefringência, compensação de dispersão, fibra de cristal fotônico, fibra óptica microestruturada. 


\begin{abstract}
SPADOTI, D.H., "Proposal and Study of Microstructured Optical Fiber D-Type: Dispersion Management and High Birefringence", 2008. Thesis (doctoral) - Escola de Engenharia de São Carlos, Universidade de São Paulo, 2008.

This work proposed to investigate new geometric configurations for the silica microstructured optical fibers. Based on their design flexibility, not usually found in conventional silica fibers, D-shape microstructured optical fibers were designed, specifically, for two different applications: dispersion compensation or high birefringence.

For the theoretical analysis two numerical methods were used: the finite difference Successive Over Relaxation (SOR) method, and the Implicitly Restarted Arnoldi Method (IRAM). It was necessary to develop the IRAM method to determine the higher order modes inside the multimodo optical waveguide, since the SOR method is able to yield only the fundamental mode.

In this framework, the D-shape microstructured optical fibers, which have been proposed and investigated in this work, proved to be extremely efficient for chromatic dispersion compensation and increasing the birefringent effect. Fibers have been designed in order to compensate the wideband dispersion, covering three entire telecommunication bands, namely: S-, C- and L- bands, simultaneously. Additionally, with these new proposed configurations it is possible to design high birefringent fibers, which are very attractive in polarization maintaining applications.
\end{abstract}

Keywords: birefringence, dispersion compensation, microstructured optical fiber, photonic crystal fiber. 


\section{Introdução}

\subsection{Fibras ópticas microestruturadas}

O interesse nas fibras ópticas microestruturadas (MOFs - microstructured optical fibers) foi fundamentado, no começo da década de 80, pelo desenvolvimento dos cristais fotônicos [1]. Estes são estruturas formadas a partir de materiais com diferentes índices de refração, ordenados de forma periódica, na escala do comprimento de onda da luz.

Nas fibras ópticas microestruturadas, um cristal fotônico bidimensional é formado por uma distribuição periódica de capilares, os quais percorrem o eixo longitudinal da fibra. É possível criar um defeito na rede cristalina de forma a permitir níveis de propagação dentro da banda proibida do cristal. Nesta estrutura, um defeito pode ser criado através da eliminação de um dos capilares ou através da retirada de sílica de uma determinada região, violando, assim, a periodicidade da estrutura. No caso particular das fibras ópticas microestruturadas, este defeito será capaz de guiar a luz, constituindo-se como o núcleo da fibra.

Durante a década de noventa, alguns grupos de pesquisadores trabalharam para estender este conceito de cristais fotônicos na região do infravermelho (IR) e comprimentos de onda no visível, alterando, para isso, as dimensões do cristal ou o tipo de material a ser empregado na fabricação dos dispositivos.

Assim, no ano de 1996, pesquisadores da Universidade de Bath, na Inglaterra, liderados por P.St.J. Russell [2], fabricaram a primeira fibra óptica microestruturada, apresentada na Figura 1. Conforme observado nesta figura, a região da casca é composta por uma estrutura complexa, formada pela presença de capilares ordenados de forma periódica, os quais percorrem todo o eixo longitudinal da fibra. Na região central, denominada núcleo, ocorre a quebra da periodicidade desse cristal, ou seja, ocorre a substituição de um capilar por um bastão sólido de sílica. Logo, a fibra apresenta núcleo sólido, com a luz sendo guiada na região de sílica. Esta nova classe de fibras ópticas é comumente denominada de fibra óptica microestruturada (MOF - microstructured optical fiber), fibra perfurada (HF - holey fiber) ou, ainda, fibra de cristal fotônico (PCF - photonic crystal fiber). 


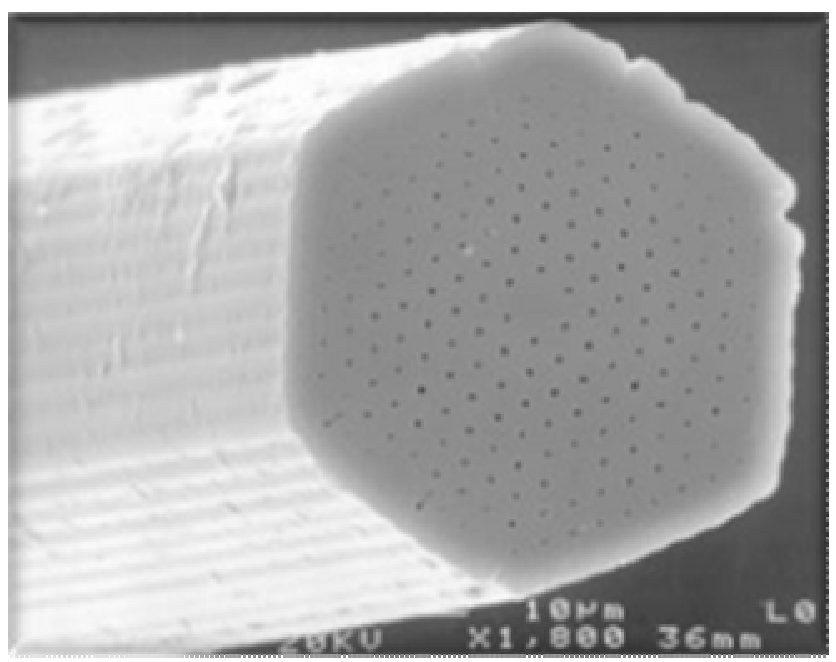

Figura 1. Seção transversal de uma fibra óptica microestruturada com núcleo sólido [2].

Em seguida, no ano de 1999, R.F. Cregan e colaboradores [3], também pertencentes ao grupo de P.St.J. Russell, fabricaram uma outra forma possível para as fibras de cristal fotônico (fibras microestruturadas), a qual, conforme visualizado na Figura 2, apresenta o núcleo de ar. Neste caso, a periodicidade do cristal é quebrada pela exclusão de sete tubos centrais, criando um defeito, o qual forma o núcleo central da fibra ao longo do qual a luz será guiada. Estas foram as duas primeiras demonstrações práticas das fibras de cristal fotônico. É valido mencionar que o desenvolvimento das fibras ópticas microestruturadas permitiu obter efeitos ópticos (como guiamento por banda fotônica proibida) que, até então, não eram possíveis de se alcançar com as fibras ópticas convencionais. 


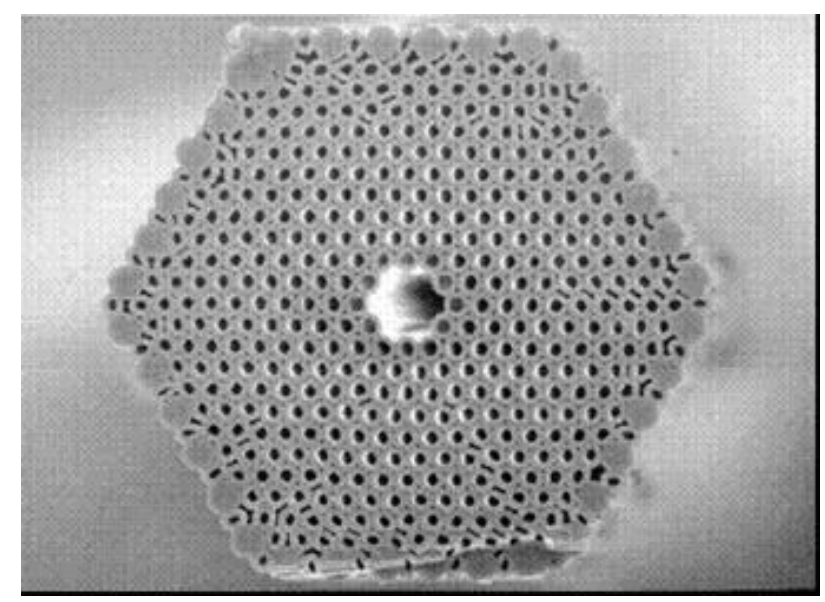

Figura 2. Fibra óptica com banda fotônica proibida e núcleo de ar (PBG) [3].

Para caracterizar as fibras ópticas microestruturadas faz-se necessário definir os seus parâmetros físicos e geométricos. Conforme apresentado na Figura 3, os parâmetros geométricos são: o diâmetro dos capilares, $d$, e o espaçamento entre os centros dos capilares, $\Lambda$, comumente chamado de pitch. Vale observar que na literatura encontram-se algumas outras denominações para descrever o termo capilar. Alguns autores, por exemplo, preferem denominá-lo como furo de ar, buraco de ar, etc. Neste trabalho será adotada a nomenclatura capilar. Os parâmetros físicos atribuídos à fibra são: o índice de refração do núcleo, $n_{c o}$, e o índice médio da casca, $n_{c l}$. Outro parâmetro muito utilizado é a relação entre o diâmetro dos capilares, $d$, e o espaçamento, $\Lambda$, definida como $f=d / \Lambda$, a qual fornece a proporção entre ar e sílica presentes na estrutura.

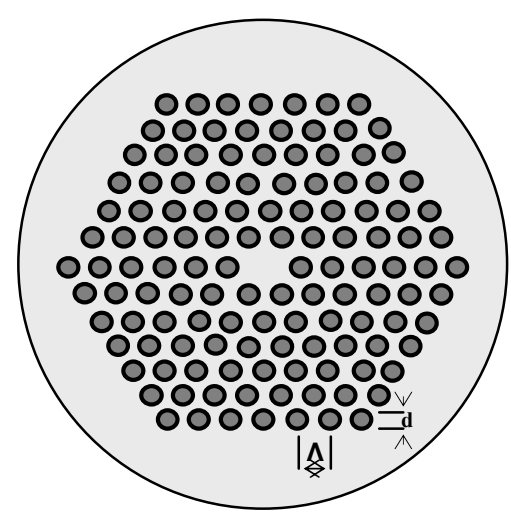

Figura 3. Esquemático de uma fibra óptica microestruturada. 
As fibras ópticas microestruturadas são divididas, basicamente, em duas categorias relacionadas ao mecanismo de guiamento de luz. Na primeira, encontram-se as fibras com núcleo sólido, Figuras 1 e 4a, denominadas fibras com guiamento por índice (IG - indexguiding) [4]. O guiamento da luz é obtido com base na diferença de índices de refração entre casca e núcleo, ou seja, o índice de refração da área central (núcleo) é maior do que o índice de refração médio do conjunto ao redor do núcleo (casca). Pode-se explicar esse guiamento por reflexão interna total, semelhante ao que ocorre nas fibras ópticas convencionais [5].

$\mathrm{Na}$ segunda categoria, encontram-se as fibras que apresentam uma estrutura geométrica periódica, Figuras 2 e 4b, capazes de exibir uma banda fotônica proibida. Pode-se, então, criar um defeito nesta estrutura de forma a quebrar essa periodicidade. Este defeito tem a propriedade de criar níveis permitidos de propagação dentro da banda proibida do cristal. Devido à existência da banda fotônica proibida, a luz permanece confinada dentro do defeito, mantendo o confinamento mesmo na presença de curvaturas. Assim, neste defeito, será possível guiar a luz, constituindo-se, portanto, como o núcleo da fibra. Por esse motivo são denominadas de fibras com banda fotônica proibida (do inglês, PBG - photonic band gap) [6]. Estas fibras possuem características únicas devido ao mecanismo de guiamento não-usual, e a perspectiva de guiar luz na região de ar é interessante, pois serão minimizados efeitos como dispersão cromática, efeitos não-lineares e absorção óptica [5], [6].

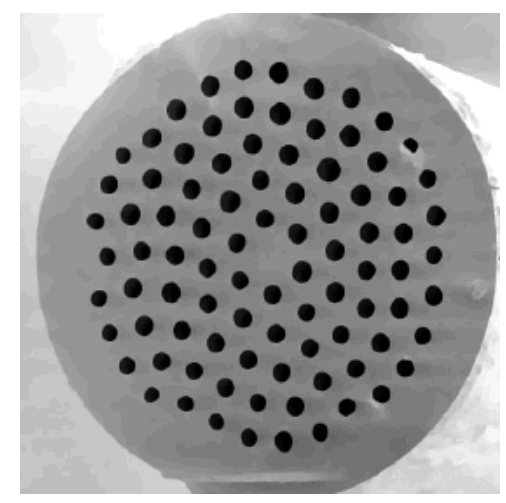

a)

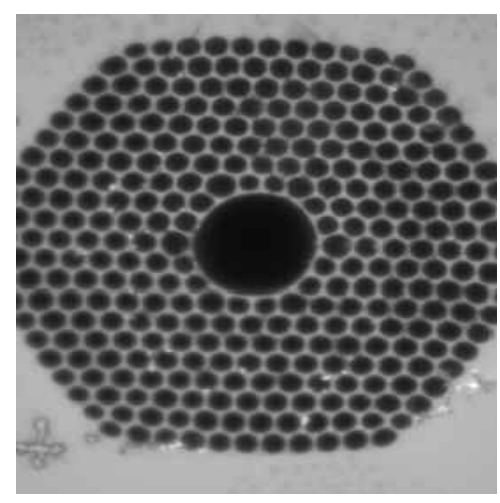

b)

Figura 4. a) Fibra óptica microestruturada IG, b) Fibra óptica microestruturada PBG. 
Essas duas categorias de fibras ópticas microestruturadas vêm chamando a atenção dos pesquisadores nos últimos anos, principalmente pela liberdade que proporcionam na manipulação dos seus parâmetros físicos e geométricos.

Dessa forma, as MOFs podem ser trabalhadas de maneira a permitirem:

- manejo das curvas de dispersão [4]-[6],

- operação monomodo em uma larga faixa de comprimentos de onda [7], [8]

- possibilidade de ajuste da área efetiva [9],

- controle dos efeitos ópticos não-lineares [10]-[12],

- controle da birrefringência [13], entre outros.

A primeira característica explorada nas MOFs foi sua propriedade em apresentar um guiamento monomodo em uma larga faixa de comprimentos de onda, possibilitando, assim, variar a freqüência de operação e manter o seu comportamento monomodo. Uma fibra óptica é efetivamente monomodo quando o parâmetro $\mathrm{V}$ é mantido abaixo de 2,405 [7], [8]. Nas MOFs, este efeito pode ser explicado fisicamente devido ao fato do índice de refração médio do conjunto da casca ser função do comprimento de onda [2]. Para comprimentos de onda curtos, a luz tende a permanecer mais confinada no núcleo da fibra, penetrando menos na região dos capilares. Essa menor interação entre o campo eletromagnético e a região de ar (menor índice de refração) aumenta o índice efetivo da região da casca, diminuindo, assim, a diferença entre os índices da casca e do núcleo. De maneira inversa, para comprimentos de onda mais longos, o confinamento da luz na região do núcleo diminui. Neste caso, a luz tem uma maior interação com a região de ar, o que tende a diminuir o índice efetivo da casca, aumentando, assim, a diferença entre os índices da casca e do núcleo. Desta forma, conseguese projetar fibras com arranjos periódicos capazes de conservar o valor $\mathrm{V}$ praticamente constante e abaixo de 2,405, possibilitando manter o guiamento monomodo em uma extensa faixa espectral [2], [8].

Outra propriedade muito estudada nesse tipo de fibra é o manejo da área efetiva, $\mathrm{A}_{\mathrm{eff}}$, dada por [9], [10]:

$$
A_{\text {eff }}=\frac{\left(\iint_{s}\left|H_{t}\right|^{2} d x d y\right)^{2}}{\iint_{s}\left|H_{t}\right|^{4} d x d y}
$$


onde $\mathrm{H}_{\mathrm{t}}$ corresponde à distribuição de campo magnético na seção transversal da fibra. A determinação da área efetiva é fundamental no controle dos efeitos não-lineares, uma vez que o coeficiente não-linear da fibra, $\gamma$, é inversamente proporcional à área efetiva, conforme observado na expressão: $\gamma=\left(2 \pi n_{2}\right) /\left(\lambda A_{\text {eff }}\right)\left[\mathrm{W}^{-1} \mathrm{~m}^{-1}\right]$, sendo $n_{2}$ o coeficiente de índice nãolinear do material (para a sílica $n_{2} \approx 2.66 \times 10^{-20}\left[\mathrm{~m}^{2} / \mathrm{W}\right]$ ) [7], [10]. Logo, as MOFs possibilitam duas situações distintas. A primeira, é o caso de uma fibra com elevada área do núcleo, podendo guiar alta intensidade de potência óptica, sem excitar efeitos não-lineares [9]. Estas fibras podem apresentar baixas perdas de confinamento modal ou por curvaturas. A segunda, oposta à primeira, diz respeito às fibras com reduzida área efetiva guiando alta densidade de potência óptica, excitando os efeitos não-lineares. Devido ao alto contraste entre os índices de refração da sílica e do ar, as fibras ópticas microestruturadas oferecem a possibilidade de forte confinamento modal para uma longa faixa de comprimento de onda [7][9]. Este efeito pode ser explorado com sucesso, por exemplo, na geração de luz supercontínua [11], na propagação de sólitons [11], em amplificadores Raman [12], entre outros.

Outras duas características extremamente exploradas nas fibras ópticas microestruturadas são: o controle da dispersão cromática e o efeito da birrefringência. Por serem os dois efeitos investigados nas aplicações das MOFs sugeridas nesta tese de doutoramento, faz-se necessário uma descrição mais detalhada, a qual é feita no Capítulo 2. 


\subsection{Proposta}

Desde que foram desenvolvidas, as fibras ópticas convencionais à base de sílica representaram uma revolução no sistema de telecomunicações, possibilitando transmissão de altas taxas de dados com segurança e mínimas perdas. Entretanto, existem alguns fatores que limitam a sua utilização na transmissão de sinais a longas distâncias. Entre os fatores penalizantes encontram-se: a atenuação, a excitação de efeitos não-lineares, a dispersão por polarização modal, a dispersão cromática, entre outros [10]-[13].

Para viabilizar a aplicação das fibras ópticas como meio de transmissão em enlaces de longas distâncias, é necessário recorrer a dispositivos capazes de recuperar o nível e a forma do sinal óptico degradado ao longo do seu caminho. Como exemplos de dispositivos, podemse citar os módulos amplificadores e os módulos compensadores de dispersão cromática.

Neste ponto, aproveitando-se da flexibilidade proporcionada pela forma estrutural das fibras ópticas microestruturadas, surgem as motivações deste trabalho, que são: propor e investigar novos arranjos geométricos para as fibras MOFs visando sua utilização como dispositivo capaz de compensar o efeito da dispersão cromática. Adicionalmente, esses novos arranjos geométricos das MOFs são otimizados para apresentar alta birrefringência e, assim, podem ser utilizadas em aplicações onde é necessário manter o estado de polarização modal. Entre as geometrias propostas neste trabalho, destacam-se as fibras ópticas microestruturadas com seção transversal tipo $\mathrm{D}$, sendo projetadas e investigadas para atuar ou como fibras compensadoras de dispersão ou como fibras altamente birrefringentes. Adicionalmente, com esses novos arranjos geométricos abrem-se perspectivas futuras de se empregar as fibras em outras funções, como por exemplo, amplificação Raman, conversores de comprimento de onda, sensores, entre outras. 


\subsection{Descrição do trabalho}

No capítulo 2, a seguir, primeiramente é discutido o efeito da dispersão cromática, seguido de uma criteriosa revisão bibliográfica, respectivamente, sobre as fibras ópticas projetadas para atuar na compensação da dispersão cromática e sobre as fibras ópticas desenvolvidas para apresentar alta birrefringência. Por fim, a fibra óptica microestruturada com seção transversal tipo D é apresentada.

No capitulo 3, são detalhados o desenvolvimento, o equacionamento e a aferição dos métodos numéricos SOR e IRAM utilizados nas simulações descritas no capítulo seguinte.

No capítulo 4, são apresentados os resultados obtidos com as novas propostas de fibras ópticas microestruturadas. Primeiro, é feita uma discussão sobre as MOFs projetadas com estrutura geométrica uniforme, isto é, com um núcleo central. Em seguida, é feito um estudo sobre as MOFs de dois núcleos.

No capítulo 5, são expostos os resultados obtidos com as fibras ópticas microestruturadas tipo D, atuando, especificamente, em duas aplicações distintas, ou como fibras compensadoras de dispersão ou como fibras altamente birrefringentes.

As conclusões, contribuições e propostas para continuação deste trabalho são descritas no capítulo 6 . 


\section{Fibras ópticas microestruturadas: compensação de dispersão e alta birrefringência}

Este capítulo inicia-se com uma discussão sobre o conceito da dispersão cromática em fibras ópticas. Em seguida, na seção 2.2, são apresentadas as fibras ópticas compensadoras de dispersão (DCF - dispersion compensating fiber), descrevendo desde os primeiros projetos de fibras compensadoras até o presente estado da arte. Na seção 2.3, é feita uma revisão da literatura sobre as fibras ópticas microestruturadas projetadas para apresentarem alta birrefringência. Por fim, na seção 2.4, é proposta e apresentada a fibra óptica microestruturada com perfil tipo D.

\subsection{Dispersão cromática: conceitos fundamentais}

A dispersão cromática é um dos principais fatores limitantes nos atuais sistemas de transmissão de dados em fibras ópticas. Este efeito torna-se ainda mais crítico à medida que a taxa de transmissão atinge valores a partir de 10Gbits/s [14]. Por isso, é de fundamental importância a aplicação de técnicas capazes de compensar esse efeito indesejado.

Em fibras ópticas monomodo convencionais à base de sílica a dispersão cromática é nula na segunda janela espectral, ou seja, em torno do comprimento de onda de 1300nm [15], [16]. Entretanto, essas fibras monomodo convencionais apresentam a atenuação espectral mínima na terceira janela, em torno do comprimento de onda de $1550 \mathrm{~nm}$. A migração da segunda para a terceira janela em transmissões a longas distâncias foi efetivamente possível no inicio da década de 90, com o surgimento dos amplificadores ópticos a fibra dopada com Érbio [15], [16]. Nessa faixa especifica de 1550nm, consegue-se, portanto, uma combinação entre atenuação espectral mínima, da ordem de $0,2 \mathrm{~dB} / \mathrm{km}$ [16], com a possibilidade da amplificação do sinal em banda larga e em regime totalmente óptico. Vale mencionar que a faixa espectral de comunicações ópticas foi dividida em bandas. A segunda janela espectral 
corresponde à banda $\mathrm{O}(1260-1360 \mathrm{~nm})$ e a terceira janela espectral foi subdividida nas bandas S (1460-1530nm), C (1530-1560nm) e L (1560-1630nm).

As fibras ópticas convencionais operando na região espectral da terceira janela exibem penalidade devido ao efeito da dispersão cromática, a qual, em 1550nm, é de aproximadamente $+17 \mathrm{ps} /(\mathrm{nm} \mathrm{km})$ [17], [18]. Portanto, foi necessário desenvolver técnicas capazes de minimizar o efeito da dispersão cromática acumulada ao longo de um enlace óptico.

A origem do fenômeno dispersivo está relacionada com as características materiais e estruturais das fibras ópticas. As componentes espectrais que formam um pulso óptico, ao serem lançadas na fibra óptica, viajam com diferentes velocidades. Após uma determinada distância de propagação, estas componentes estarão atrasadas entre si e o pulso estará temporalmente alargado [14], [19], [20]. Este efeito pode ser explicado examinando-se as características da velocidade de grupo dos modos guiados, onde a velocidade de grupo é a velocidade com que a energia de um pulso viaja pela fibra [19]. As diferentes velocidades de propagação das componentes espectrais resultam na 'dispersão da velocidade de grupo' (grup velocity dispersion, GVD), ou simplesmente 'dispersão cromática' (chromatic dispersion, $C D)$, que é a medida do alargamento temporal do pulso, em uma faixa espectral, após sua propagação por um determinado comprimento de fibra [19], [20].

Em fibras ópticas monomodo a dispersão cromática é resultado da superposição de dois efeitos: dispersão de material e dispersão de guia de onda. A dispersão do material está relacionada à variação do índice de refração em relação ao comprimento de onda. A dispersão de guia de onda, por sua vez, é dependente da estrutura geométrica da fibra óptica e pode ser ajustada, por exemplo, pelas dimensões do raio do núcleo, ou pela diferença entre os índices de refração núcleo-casca [20]. A dispersão cromática total pode ser calculada pela expressão [19], [20]:

$$
D_{t}=-\frac{\lambda}{c} \frac{d^{2} n_{e f f}(\lambda)}{d \lambda^{2}} \quad[\mathrm{ps} /(\mathrm{nm} \mathrm{Km})]
$$

onde $c$ é velocidade da luz no vácuo e $n_{\text {eff }}$ é o índice efetivo, em função do comprimento de onda $\lambda$. Este cálculo da dispersão permite obter o valor da dispersão cromática em comprimentos de onda específicos. 
Outra questão que deve ser abordada concerne à inclinação da dispersão, $S$, (dispersion slope, $S)$, dada por [15]:

$$
S=\frac{d D_{t}}{d \lambda} \quad\left[\mathrm{ps} /\left(\mathrm{nm}^{2} \mathrm{Km}\right)\right]
$$

O conhecimento dos parâmetros $D$ e $S$ é fundamental na execução do projeto visando à compensação da dispersão cromática em banda larga. Conhecendo-se o valor da dispersão cromática e da sua inclinação é possível estimar a faixa de compensação óptica da fibra. Esta caracterização é importante, principalmente, nos atuais sistemas de transmissão WDM, onde vários comprimentos de onda são transmitidos simultaneamente.

Para que a compensação da dispersão ocorra em uma faixa de comprimentos de onda, as fibras ópticas projetadas para compensação da dispersão precisam, obrigatoriamente, apresentar um valor negativo de $D$ e um valor específico da inclinação $S$. A compensação da dispersão acumulada ao longo de um enlace óptico é obtida inserindo-se neste enlace um determinado comprimento da fibra ótica compensadora e, assim, gradativamente o efeito da dispersão cromática é reduzido.

Para se obter a compensação da dispersão em banda larga a seguinte relação entre inclinação e dispersão na fibra deve ser satisfeita [15]:

$$
R D S=\frac{S_{d c}}{D_{d c}}=\frac{S_{s}}{D_{s}} \quad[1 / \mathrm{nm}]
$$

onde $D_{d c}$ e $S_{d c}$ são os respectivos valores da dispersão e da inclinação da dispersão na fibra compensadora, e $D_{s}$ e $S_{S}$ são os respectivos valores da dispersão e da inclinação da dispersão na fibra utilizada no enlace óptico, que se deseja compensar. A relação entre a inclinação da dispersão e a dispersão é denominada de 'inclinação relativa da dispersão' (relative dispersion slope, $R D S$ ) [15]. Portanto, no projeto das fibras compensadoras de dispersão é possível distinguir entre as fibras compensadoras em banda estreita e as fibras projetadas para compensação em banda larga.

Logo, com a constante busca por uma maior taxa de transmissão de dados a longas distâncias, torna-se fundamental o desenvolvimento de dispositivos capazes de compensar o efeito da dispersão cromática em um enlace óptico. Ao longo dos anos, fibras ópticas 
projetadas para atuar como fibras compensadoras da dispersão têm-se mostrado extremamente eficientes e, por isso, têm sido amplamente investigadas [15]-[30].

Na subseção a seguir, serão descritas as diferentes configurações utilizadas no projeto de fibras compensadoras de dispersão.

\subsection{Fibras ópticas projetadas para compensação de dispersão}

Inicialmente, uma das técnicas sugeridas para solucionar o problema da dispersão cromática foi a substituição das fibras ópticas convencionais instaladas por fibras com dispersão nula deslocada (dispersion shifted fiber, DSF) para a região espectral de $1550 \mathrm{~nm}$, conforme Figura 5 [17], [18]. Este procedimento, aparentemente promissor, teve sua aplicação prática inviabilizada por dois motivos fundamentais. O primeiro problema encontrado foi que a combinação entre fibras com dispersão deslocada e amplificadores ópticos atuando no mesmo sistema WDM excita efeitos não-lineares, particularmente o efeito denominado mistura de quatro ondas (four-wave mixing, $F W M$ ) [20], [21], indesejáveis para aplicação em comunicações ópticas de altas taxas de dados. Para eliminar este efeito não-linear foram desenvolvidas as fibras ópticas com dispersão deslocada não-nula (non-zero shifted fiber, NZ$D S F)$. O efeito $F W M$ é profundamente reduzido em fibras que apresentam uma pequena dispersão positiva, em torno de 2 a 6 ps/(nm km), na região de 1550nm (Figura 5) [21]. Surge, então, o segundo problema que inviabiliza a utilização das NZ-DSF. A rede mundial de fibras ópticas convencionais instaladas supera os 100 milhões de quilômetros [14], e fazer a substituição das fibras convencionais, já instaladas, pelas fibras NZ-DSF torna-se economicamente inviável. 


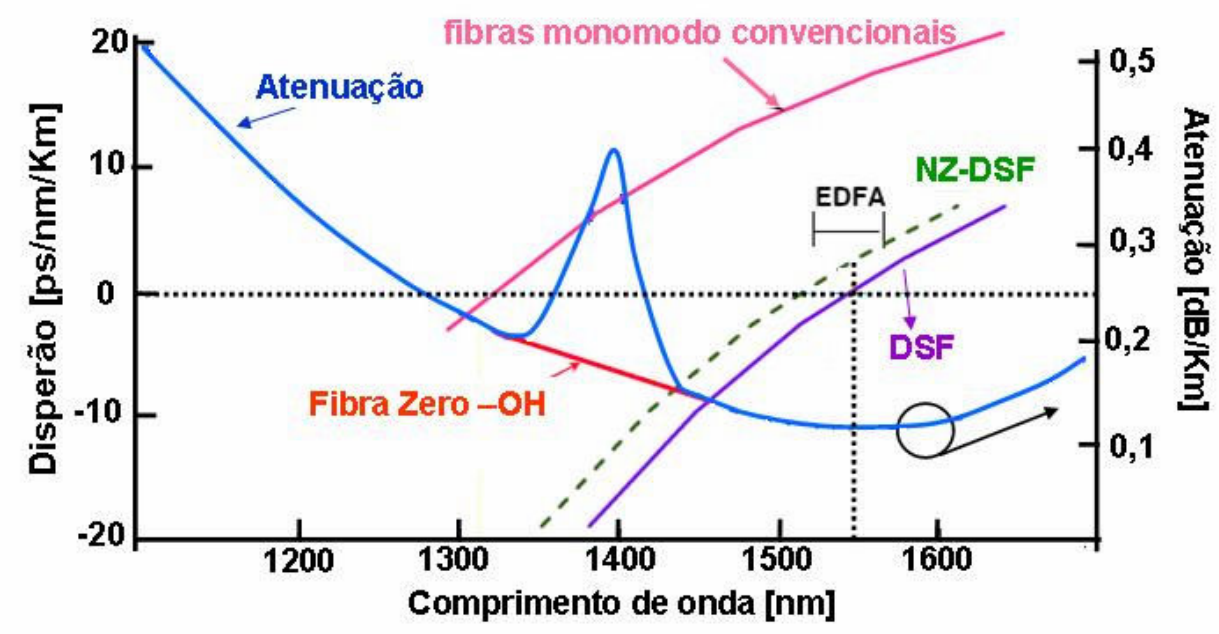

Figura 5. Coeficiente de dispersão cromática das fibras ópticas convencionais e das fibras ópticas com dispersão deslocada.

Nos subitens a seguir são descritas algumas das técnicas empregadas visando modificar a característica da dispersão das fibras e, assim, torná-las um meio capaz de compensar esse efeito.

\section{A) DCFs - fibras ópticas convencionais compensadoras de dispersão}

As fibras ópticas compensadoras de dispersão (dispersion compensating fibers - DCFs) são projetadas para apresentarem um valor negativo da dispersão $(D)$ com inclinação $(S)$ contrária ao da fibra óptica convencional. Pois, conforme comentado anteriormente, para anular o efeito da dispersão acumulada ao longo de um enlace óptico é necessária a introdução de um determinado comprimento da fibra DCF, a qual apresente valores de $D$ e $S$ contrários aos da fibra óptica convencional do enlace.

As primeiras fibras ópticas compensadoras de dispersão eram fibras similares às fibras ópticas monomodo convencionais, formadas por uma região de casca com índice de refração, $n_{c l}$, em torno do núcleo central da fibra, de índice de refração, $n_{c o}$, $\left(\mathrm{n}_{\mathrm{co}}\right.$ maior que $\left.\mathrm{n}_{\mathrm{cl}}\right)$ [22]. Entretanto, estas fibras apresentavam redução nas dimensões do núcleo e alteração nos valores do índice de refração da casca e do núcleo, de forma a modificarem o seu comportamento 
modal [22]-[25]. Com estas modificações, conforme o projeto, as fibras passavam a apresentar um valor negativo de dispersão cromática no comprimento de onda de $1550 \mathrm{~nm}$. Vale observar que outras técnicas foram desenvolvidas visando compensar o efeito da dispersão cromática. Entre elas, podem-se citar a utilização das fibras de Bragg [14] e dos regeneradores eletrônicos [16]. Nas fibras de Bragg uma perturbação periódica no índice de refração do núcleo ao longo do eixo longitudinal da fibra é feita. Esta perturbação modifica as características de transmissão da fibra, tornando-a um meio compensador de dispersão. Já, para a manipulação do sinal nos regeneradores eletrônicos é necessária a conversão do sinal do domínio óptico para o domínio elétrico.

Por outro lado, as fibras ópticas convencionais projetadas para compensação da dispersão apresentam uma técnica de compensação passiva, isto é, para a manipulação do sinal não é necessária a conversão do domínio óptico para o elétrico [18], [21]. Adicionalmente, as DCFs apresentam como vantagens o fato de serem independentes do estado de polarização (ou seja, não são birrefringentes) e, por possuírem uma técnica de fabricação já bem desenvolvida, podem ser fabricadas em grande escala com custos reduzidos.

Comercialmente, encontram-se DCFs com dispersão cromática negativa da ordem de $100 \mathrm{ps} /(\mathrm{nm} \mathrm{km})$ [22]. Como a fibra óptica monomodo convencional apresenta dispersão de $+17 \mathrm{ps} /(\mathrm{nm} \mathrm{km})$ em $1550 \mathrm{~nm}$, para compensar a dispersão imposta em um enlace de $100 \mathrm{~km}$ seriam necessários $17 \mathrm{~km}$ dessa fibra compensadora de dispersão. Portanto, quanto maior esse valor negativo da dispersão, menor o comprimento da fibra compensadora a ser inserido no enlace.

C. Lin e co-autores [23], no ano de 1980, foram os primeiros a apresentarem teoricamente uma fibra compensadora de dispersão, DCF, sendo que a primeira comprovação prática foi efetivamente obtida em 1982, por J. M. Dugan e co-autores [24] que transmitiram $10 \mathrm{~Gb} / \mathrm{s}$ em $1550 \mathrm{~nm}$ ao longo de $150 \mathrm{~km}$ de uma fibra convencional com dispersão nula em 1330nm. Desde então, consideráveis avanços vêm sendo conseguidos nos projetos de DCFs. Em 1995 os pesquisadores B. Jopson e A. Gnauck, do AT\&T Bell Laboratories [25] desenvolveram um protótipo comercial de uma DCF. Esta fibra era formada por um núcleo central envolto por uma região de casca e foi otimizada para compensação da dispersão em $1550 \mathrm{~nm}$, com um valor de dispersão negativo em torno de -100 ps/(nm km). 
Todavia, as DCFs convencionais possuem uma pequena maleabilidade de projeto, reduzida área efetiva do núcleo e, basicamente, compensam a dispersão somente em banda estreita [26]. Devido a estas dificuldades, uma modificação na geometria das fibras ópticas convencionais foi proposta, originando as fibras compensadoras de dispersão de dois núcleos (dual-core dispersion compensating fibers, $D C-D C F$ ). Por apresentarem o perfil de índice de refração tipo $\mathrm{W}$, são também conhecidas por fibras tipo $\mathrm{W}$ ou, ainda, fibras multicamadas [18]-[27]. Neste trabalho, será utilizada a denominação "fibra óptica de dois núcleos".

A Figura 6 apresenta algumas das possíveis variações de índice de refração investigadas ao longo dos anos, com $\mathrm{n}_{\mathrm{in}}, \mathrm{n}_{\mathrm{ex}}, \mathrm{n}_{\mathrm{cl}}$ sendo, respectivamente, os índices de refração do núcleo central, do núcleo externo e da casca.

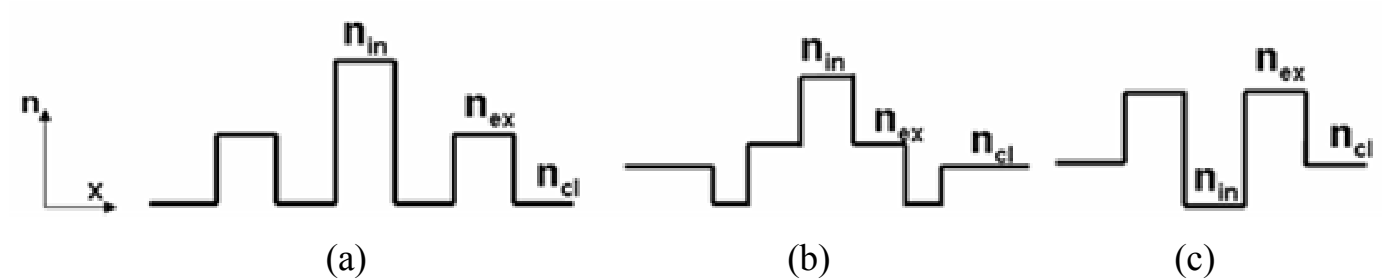

Figura 6. Diferentes perfis de índice de refração projetados para as fibras DC-DCF, [21], [22] e $[26]$.

As fibras compensadoras de dispersão de dois núcleos apresentam, como grande vantagem, um alto valor negativo de dispersão em banda larga [28]. K. Thyagarajan e coautores, em 1996, [29] propuseram um novo projeto para fibras ópticas compensadoras de dispersão atuando em sistemas WDM. Esta fibra é formada por dois núcleos concêntricos, cujos raios dos núcleos interno e externo são, respectivamente, $r_{i n}=1,0 \mu \mathrm{m}$ e $r_{e x}=3,4 \mu \mathrm{m}$, e a diferença entre os índices de refração do núcleo interno para o núcleo externo é de 1,7\%. Com essa configuração, foi possível obter um valor teórico de dispersão $D=-5100 \mathrm{ps} /(\mathrm{nm} \mathrm{km})$. Nesta fibra, no denominado comprimento de onda de casamento, $\lambda_{c}$, ocorre uma mudança na inclinação da curva do índice efetivo do modo fundamental em função do comprimento de onda. Esta mudança é devida ao acoplamento que ocorre entre os modos do núcleo interno para o núcleo externo, resultando em um alto valor negativo da dispersão [29]. Utilizando a configuração proposta em [29], em 2000, J.-L Auguste e co-autores [30] demonstraram 
experimentalmente que essa fibra de dois núcleos possui um coeficiente de dispersão negativo, em 1550nm, de $\mathrm{D}=-1800 \mathrm{ps} /(\mathrm{nm} \mathrm{km})$.

Com relação às fibras ópticas projetadas para compensação da dispersão cromática, podem-se verificar duas situações distintas. As fibras ópticas monomodo convencionais projetadas para compensação da dispersão (DCFs) apresentam compensação em banda estreita, possuem pequena área efetiva do núcleo, forte confinamento modal e pequenas perdas por curvaturas, mas exibem forte não-linearidade [27]. Por outro lado, as fibras ópticas de dois núcleos (DC-DCFs) podem compensar dispersão em banda larga mas, por possuírem uma grande área efetiva e um fraco guiamento modal, podem apresentar grandes perdas por curvaturas [29].

Com o surgimento das fibras ópticas microestruturadas e devido às suas características inovadoras e grande versatilidade, pesquisadores começaram a investigar a aplicação deste tipo de fibra na compensação da dispersão cromática, a qual é descrita a seguir.

\section{B) MOFs - fibras ópticas microestruturadas compensadoras de dispersão}

Entre as possibilidades empregadas para a compensação da dispersão cromática, as fibras ópticas microestruturadas destacam-se pela sua alta maleabilidade no projeto das curvas de dispersão. Manipulando-se adequadamente parâmetros geométricos como diâmetro dos capilares, $d$, e a periodicidade da rede, $\Lambda$, podem-se alterar, conforme a aplicação, os valores da dispersão cromática nas MOFs. Outra possibilidade para se modificar as características da dispersão é alterar o índice de refração do núcleo. Isto é possível por meio de dopagens específicas (por exemplo: com germânio), com a penalidade de se aumentar as perdas e o grau de dificuldade na fabricação das MOFs.

As primeiras fibras MOFs atuando como fibras compensadoras de dispersão foram projetadas com distribuição uniforme da rede cristalina, ou seja, com um único núcleo central [31]-[38]. Nestes casos, pequenos valores do fator ' $f$ ' conduzem as curvas de dispersão a valores próximos à curva de dispersão material da sílica pura (dispersão nula para comprimento de onda próximo de $1300 \mathrm{~nm}$ ). Aumentando-se o diâmetro dos capilares para o mesmo espaçamento $\Lambda$, a tendência é valorizar o efeito da dispersão de guia de onda. Como as fibras ópticas microestruturadas permitem uma grande variedade na escolha dos parâmetros 
físicos $\left(\mathrm{n}_{\mathrm{co}}, \mathrm{n}_{\mathrm{cl}}\right)$ e geométricos $(d, \Lambda, f)$, pode-se projetar fibras ópticas com a dispersão cromática extremamente negativa na faixa espectral usual em sistemas de telecomunicações. Esta é a grande vantagem das fibras ópticas microestruturadas atuando como compensadoras de dispersão.

O potencial de aplicação das fibras MOFs, atuando como fibras compensadoras de dispersão foi explorado teoricamente por T.A. Birks e co-autores [31] em 1999, tendo sido estimado um coeficiente de dispersão negativo, $D$, de $-2000 \mathrm{ps} /(\mathrm{nm} \mathrm{km})$. Desde então, modificações na estrutura geométrica dessas fibras vêm sendo investigadas, sendo que, algumas configurações das fibras ópticas microestruturadas apresentaram-se extremamente promissoras para atuar na compensação da dispersão cromática.

Ademais, dependendo da sua geometria, as fibras ópticas microestruturadas podem, alternativamente, apresentar dispersão plana e nula em determinadas faixas espectrais [32], [33]. Em 1999, T. Monro e colaboradores [34] discutiram teoricamente a possibilidade de uma fibra microestruturada apresentar dispersão plana, em torno de $+10 \mathrm{ps} /(\mathrm{nm} \mathrm{km})$, em uma larga faixa do comprimento de onda, variando de 1300 a 1600nm. Posteriormente, A. Ferrando e coautores [35], investigaram teoricamente uma MOF com dispersão plana e nula em uma larga faixa do comprimento de onda.

Por outro lado, na busca por um coeficiente de dispersão negativo, J. Broeng e coautores [6] propuseram uma fibra microestruturada com $\Lambda=1,7 \mu \mathrm{m}$ e $\mathrm{d} / \Lambda=0,4$ capaz de fornecer uma dispersão negativa de aproximadamente $-100 \mathrm{ps} /(\mathrm{nm} \mathrm{km})$ cobrindo as bandas $\mathrm{S}$, C e L. Um outra fibra microestruturada, com as dimensões ainda mais reduzidas, cujo espaçamento (pitch) era de $0,6 \mu \mathrm{m}$ foi apresentada teoricamente por F. Poli e colaboradores [12]. Essa fibra apresentou um pico de dispersão negativo da ordem de $-1700 \mathrm{ps} /(\mathrm{nm} \mathrm{km})$. Em 2003, L.P. Chen e co-autores [28] propuseram uma fibra microestruturada otimizada para compensação de dispersão em banda larga com $\mathrm{D}=-475 \mathrm{ps} /(\mathrm{nm} \mathrm{km})$ em uma faixa de aproximadamente $236 \mathrm{~nm}$, com uma área efetiva ainda pequena, $\mathrm{A}_{\mathrm{eff}}=1.6 \mu \mathrm{m}^{2}$.

Como se pode observar, as fibras ópticas microestruturadas com estrutura uniforme da rede cristalina, ou seja, com arranjo uniforme dos capilares ao longo do núcleo central, otimizadas para compensar dispersão, apresentam como característica principal uma pequena área efetiva. Sabe-se que uma pequena área efetiva pode propiciar a excitação de efeitos nãolineares. Logo, alguns autores [36], [37] estão propondo aproveitar esse efeito não-linear das 
MOFs, que a priori seria indesejável, visando sua utilização, simultaneamente, na compensação de dispersão e na amplificação Raman. Tendo isto em vista, em 2004, C.A. De Francisco [38] investigou este mesmo arranjo estrutural da fibra microestruturada proposto por Chen [28] e observou que a MOF com esta configuração, devido à reduzida área efetiva do núcleo, pode atuar simultaneamente na compensação de dispersão e ainda proporcionar amplificação óptica por efeito Raman. Esta fibra foi projetada com $\Lambda=0,93 \mu \mathrm{m}$ e $f=0,9$, obtendo-se a previsão de um coeficiente negativo de dispersão de $-473 \mathrm{ps} /(\mathrm{nmkm})$ cobrindo toda a banda $\mathrm{C}$, com ganho Raman $\gamma \approx 19 \mathrm{~W}^{-1} \cdot \mathrm{km}^{-1}$, o que garante a aplicação dessa MOF atuando simultaneamente na compensação da dispersão cromática e na amplificação óptica do sinal.

No entanto, as MOFs projetadas para compensação da dispersão possuem a área efetiva extremamente reduzida, o que, além de excitar os efeitos não-lineares, também pode gerar dificuldades no acoplamento óptico com fibras convencionais. Como possível alternativa no projeto das fibras ópticas microestruturadas para compensação de dispersão, pesquisadores estão propondo como solução, inspirados nos trabalhos com DCFs convencionais, a utilização das fibras ópticas microestruturadas de dois núcleos.

\section{C) DC-MOFs - fibras ópticas microestruturadas de dois núcleos}

As fibras ópticas microestruturadas de dois núcleos (dual-core microstructured optical fibers, $D C-M O F s$ ), isto é, fibras microestruturadas com perfil de índice de refração tipo W, estão sendo empregadas visando minimizar os efeitos decorrentes da pequena área efetiva, e, ainda assim, manter um alto coeficiente negativo da dispersão cromática [39]-[48].

Conforme pode ser visualizado na Figura 7, este tipo de fibra óptica apresenta dois núcleos concêntricos isolados por capilares arranjados periodicamente em forma de anéis. $\mathrm{O}$ núcleo interno é formado pela ausência do capilar na posição central da estrutura. O núcleo externo pode ser formado de duas maneiras. Uma possibilidade é a ausência dos capilares em um determinado anel, conforme esquematizado na Figura (7a). Neste caso, o núcleo externo apresenta o mesmo índice de refração da sílica. A outra forma possível consiste na redução do diâmetro dos capilares de um dos anéis, conforme Figura (7b). Aqui, o índice de refração do segundo núcleo torna-se ligeiramente inferior ao índice da sílica, Figura (7c). 


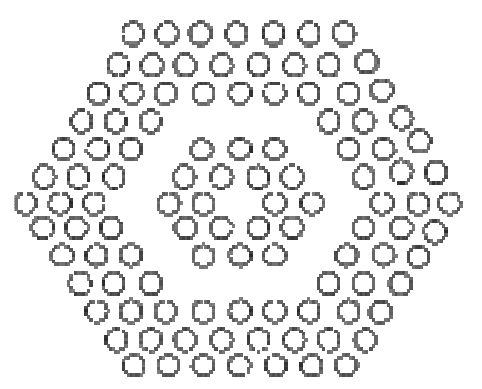

(a)

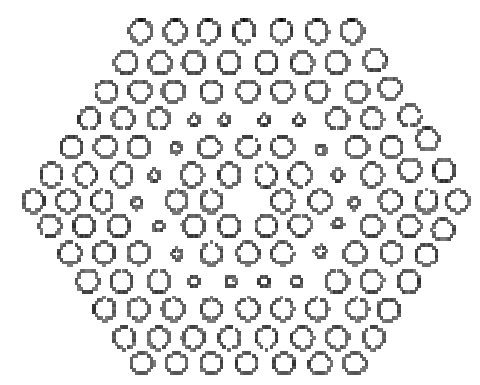

(b)

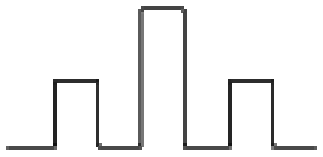

(c)

Figura 7. Esquemático da fibra óptica microestruturada de dois núcleos; a) ausência dos capilares; b) redução do diâmetro dos capilaeres; c) perfil de índice de refração médio da estrutura b.

Em 2004, tendo essas modificações em vista, Yi Ni e co-autores [39], sugeriram a primeira fibra óptica microestruturada de dois núcleos. Esse novo projeto destacou-se, pois a fibra apresentou um pico negativo de dispersão em torno do comprimento de onda de $1550 \mathrm{~nm}$ muito elevado, com o valor estimado de $\mathrm{D}=-18000 \mathrm{ps} /(\mathrm{nm} \mathrm{km})$. Entretanto, essa fibra apresentava compensação em banda estreita e um reduzido diâmetro dos capilares $\left(\mathrm{d}_{\mathrm{s}}=\right.$ $0,86 \mu \mathrm{m})$, o que causa dificuldade na fabricação.

Existia, então, motivação para outras pesquisas na busca por aumentar ainda mais esse pico negativo e ampliar a largura de banda da dispersão [40]-[43]. Ainda no ano de 2004, um grupo de pesquisadores coordenados por P.St.J. Russell [41] fabricou a primeira fibra óptica microestruturada compensadora de dispersão de núcleo duplo, a qual apresentou, para o comprimento de onda de $1550 \mathrm{~nm}$, um valor teórico $\mathrm{D}=-1800 \mathrm{ps} /(\mathrm{nm} \mathrm{km})$ e um valor experimental $\mathrm{D}=-1211 \mathrm{ps} /(\mathrm{nm} \mathrm{km})$.

Recentemente, no começo do ano de 2005, A. Huttunem e P. Törmä [44] investigaram teoricamente uma fibra óptica microestruturada de dois núcleos, com o núcleo interno dopado, cujo pico de dispersão negativo é $\mathrm{D}=-59000 \mathrm{ps} /(\mathrm{nm} \mathrm{km})$. Porém, este projeto apresenta algumas desvantagens, pois, para se obter este elevado pico de dispersão negativa, é necessário utilizar uma alta dopagem no núcleo, causando a variação do índice de refração de 1,5 a 2,8. Aumentar o índice de refração de núcleo pode excitar os modos de mais alta ordem [22], além de aumentar as dificuldades no processo de fabricação [45]. 
Para superar esses problemas, T. Fujisawa e co-autores [46], no começo do ano de 2006, utilizaram a técnica do algoritmo genético para analisar uma fibra óptica microestruturada de dois núcleos otimizada para compensação de dispersão na banda S. Esta fibra apresentou o coeficiente de dispersão negativo em torno de $-500 \mathrm{ps} /(\mathrm{nm} \mathrm{km})$, com a desvantagem de possuir 14 anéis em sua geometria e uma dispersão não tão negativa quanto à proposta por Huttunem. Em abril de 2006 [45], um grupo de pesquisadores chineses fabricou uma fibra óptica microestruturada de dois núcleos que, até o presente momento, possui a maior área efetiva demonstrada experimentalmente, cujo valor é de $40,7 \mu \mathrm{m}^{2}$, com um coeficiente negativo de dispersão de, aproximadamente, -662 ps/(nm $\mathrm{km})$. Ainda no ano de 2006, na $32^{\circ}$ ECOC - European Conference on Optical Communication, F. Gérôme e coautores [47] apresentaram uma fibra óptica microestruturada de núcleo sólido exibindo uma grande área efetiva do núcleo e com elevado coeficiente de dispersão negativo. O núcleo da fibra apresenta um diâmetro de $34 \mu \mathrm{m}$. A região da casca é formada por camadas concêntricas de materiais de diferentes índices de refração, circundando a região central do núcleo de menor índice de refração, sendo as camadas de maior índice de refração dopadas com germânio. O coeficiente de dispersão observado varia aproximadamente de $-1480 \mathrm{ps} /(\mathrm{nm} . \mathrm{km})$ a $-20300 \mathrm{ps} /(\mathrm{nm} . \mathrm{km})$, com a largura de banda a meia potência reduzindo-se, respectivamente, de $30 \mathrm{~nm}$ para $3 \mathrm{~nm}$.

Em março de 2007, T. Matsui e co-autores [48] propuseram um arranjo geométrico das fibras MOFs de dois núcleos capaz de compensar a dispersão em toda a banda de telecomunicações, cobrindo desde a banda $\mathrm{O}$ até a banda L, ou seja, de $1260 \mathrm{~nm}$ a $1625 \mathrm{~nm}$. Esta fibra, além de apresentar um pequeno valor negativo de dispersão em torno de -100 ps/(nm km), requer uma complexa distribuição geométrica dos capilares que formam a região da casca. O diâmetro dos capilares dos anéis internos é extremamente pequeno, igual a $0,75 \mu \mathrm{m}$, o que dificulta a sua fabricação [45].

A análise teórica destas fibras DC-MOFs indica que estas estruturas compostas de dois núcleos concêntricos propagam dois supermodos. Para comprimentos de onda curtos, o modo fundamental está fortemente confinado no núcleo interno. Em um determinado comprimento de onda, denominado comprimento de onda de casamento, $\lambda_{c}$, ocorre o acoplamento entre os modos do núcleo interno para o núcleo externo. Para comprimentos de onda acima de $\lambda_{\mathrm{c}}, \mathrm{o}$ modo fundamental passa a ser guiado apenas no núcleo externo [39],[42]. 
Entretanto, em comprimentos de onda curtos, menores que $\lambda_{\mathrm{c}}$, existe uma parcela de energia sendo guiada no núcleo externo, assim como, acima do $\lambda_{c}$, existe uma parcela de energia sendo guiada no núcleo interno. O cálculo da energia remanescente nos núcleos das fibras ópticas microestruturadas ainda não foi abordado na literatura. Pode-se quantificar essa energia através da teoria dos modos acoplados, a qual será objeto de estudo no item 2 do capítulo 4.

Feita a contextualização histórica das fibras ópticas projetadas para compensação da dispersão, a próxima subseção tratará do efeito da birrefringência, o qual também será explorado nas aplicações das MOFs sugeridas nessa tese de doutorado.

\subsection{Fibras Birrefringentes}

Nos últimos anos, graças à flexibilidade imposta por sua estrutura geométrica, diferentes configurações das fibras ópticas microestruturadas estão sendo propostas com o objetivo de torná-las um meio altamente birrefringente.

A birrefringência pode ser obtida calculando-se o comprimento de batimento, $\mathrm{L}_{\pi}$, entre os estados ortogonais de polarização. A relação entre o comprimento de batimento e a birrefringência modal, B, é dada por [20]:

$$
L_{\pi}=\frac{2 \pi}{\left|\beta_{x}-\beta_{y}\right|}=\frac{\lambda}{\left|n_{x}-n_{y}\right|}=\frac{\lambda}{B}
$$

onde, $\beta_{x}$ e $\beta_{y}$ são as constantes de propagação dos modos polarizados $x$ e $y$, e $n_{x}$ e $n_{y}$ são os respectivos índices efetivos, e $\lambda$ o comprimento de onda.

O efeito da birrefringência em fibras ópticas pode ser obtido de duas formas [49]: pela quebra da simetria na região do núcleo ou pela indução de stress nas fibras ópticas convencionais. Ademais, as fibras ópticas podem apresentar uma pequena birrefringência acidental devido ao processo de fabricação [49]. As fibras ópticas convencionais projetadas para alta birrefringência como, por exemplo, as fibras PANDA [50] ou Bow-tie [51], são produzidas a partir da aplicação de stress na região do núcleo das fibras convencionais,

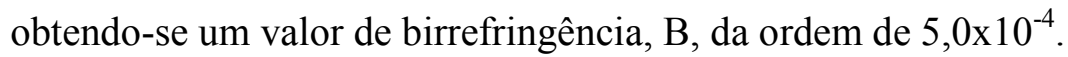


Em relação às fibras microestruturadas com núcleo sólido, A. Ortigosa-Blanch e coautores [52], em 2000, propuseram a primeira MOF com estrutura geométrica assimétrica, otimizada para apresentar alta birrefringência. A simetria da região da casca foi quebrada pela presença de dois capilares de diâmetros diferentes dispostos ao longo dos eixos ortogonais da fibra, obtendo-se um valor de birrefringência, em $1540 \mathrm{~nm}$, de $3,7 \times 10^{-3}$. No ano seguinte, M.J. Steel e R.M. Osgood Jr [53] propuseram uma fibra microestruturada com capilares em formato elíptico, alcançando birrefringência da ordem de $10^{-2}$. Neste mesmo ano, T.P Hansen e co-autores [54] investigaram uma MOF projetada com grande contraste de índice de refração entre núcleo e casca, combinados, ainda, com um núcleo assimétrico, obtendo $\mathrm{B}=7,7 \times 10^{-3}$.

Nos trabalhos desenvolvidos por S.B. Libori e co-autores [55] e K. Suzuki e co-autores [56], as MOFs investigadas apresentavam dois dos capilares centrais alargados, de forma a quebrar a simetria na região do núcleo, e, em ambos os estudos, foi alcançado a birrefringência da ordem de $10^{-3}$. De modo semelhante, K. Saitoh e M. Koshiba [57], em 2003, manipulando a posição dos dois capilares de diâmetros maiores, propuseram uma MOF monomodo, com $\mathrm{B}=3,27 \times 10^{-3}$. Por outro lado, C.-L. Zhao e colaboradores [58], investigaram uma MOF birrefringente, combinando núcleo assimétrico com intencional stress induzido na região da casca, alcançando uma birrefringência da ordem de $10^{-3}$.

A primeira fibra MOF com capilares elípticos fabricada foi apresentada por N.A. Issa e co-autores [59] em 2004. O formato elíptico foi obtido por uma técnica que permitia produzir deformações nos capilares durante o processo de puxamento. Essa fibra apresentou, para o comprimento de onda de $850 \mathrm{~nm}$, uma birrefringência de aproximadamente $1,0 \times 10^{-4}$. Uma modificação no método de empilhamento e puxamento para fabricar uma fibra MOF com o núcleo elíptico foi desenvolvida por A. Ortigosa-Blanch e colaboradores [60]. A fibra desenvolvida por Blanch apresentou a birrefringência, em torno do comprimento de onda de $1550 \mathrm{~nm}$, de aproximadamente $7 \times 10^{-3}$.

No mesmo caminho, em 2005, Y.C. Liu e Y. Lai [61] investigaram numericamente duas MOFs com capilares elípticos. No primeiro caso, os capilares eram ordenados em uma rede quadrada, e, no segundo, em uma rede retangular. Em ambas as configurações estudadas as MOFs apresentaram a birrefringência da ordem de $10^{-2}$. Por outro lado, M. Szpulake e coautores [62], em 2005, caracterizaram uma MOF com os capilares da região da casca ordenados em uma rede hexagonal, porém, projetada com triplo defeito próximo ao núcleo, 
quebrando, assim, sua simetria e obtendo um valor de B da ordem de $10^{-4}$. J. Wang e coautores [63] investigaram uma fibra MOF formada por capilares elípticos na região da casca e circular na região do núcleo, ordenados em uma rede tipo colméia (honeycomb). Esta estrutura proporcionava uma birrefringência na ordem de $10^{-3}$. Um outro arranjo estrutural no projeto de fibras altamente birrefringentes foi proposto em 2006 por Y. Yue e co-autores [64]. Neste caso os capilares foram ordenados com espaçamento constante, distribuídos em forma helicoidal, apresentando o valor de B da ordem de $10^{-4}$. Ainda em 2006, D.C. Zografopoulos e colaboradores [65] investigaram uma fibra microestruturada cujo o núcleo era preenchido por cristal líquido. Conforme o grau de dopagem do cristal (índice de refração variando entre 1,5 e 1,8) era possível alterar o índice de refração do núcleo. Dessa forma, a fibra poderia ser projetada de forma a exibir alta ou baixa birrefringência, apresentando, valores de B da ordem de $10^{-2}$.

Visando aumentar a assimetria na região do núcleo da fibra, Y. Yue e co-autores [66], em 2006, propuseram uma nova MOF, onde a região da casca era formada por capilares elípticos e a simetria da região do núcleo quebrada pela inserção de dois grandes capilares circulares. Nesse caso, a MOF apresentou a birrefringência em torno de $10^{-3}$. Já em outro estudo, no ano de 2007, Y. Yue e co-autores [67] investigaram teoricamente uma fibra MOF que, até o presente momento, apresenta o maior valor de birrefringência, com B, em $1550 \mathrm{~nm}$, igual $3,78 \times 10^{-2}$. Para obter essa alta birrefringência, a MOF proposta por Yue é formada por capilares elípticos, porém, com a grande penalidade de comprimir o arranjo hexagonal da rede a um espaçamento $\Lambda$ de $0,7 \mu \mathrm{m}$. Esse fato dificulta não só a fabricação, mas também o acoplamento óptico na fibra.

Por outro lado, Y.-S. Sun e co-autores [68] propuseram uma MOF altamente birrefringente, com B igual a $1,1294 \times 10^{-2}$, sendo que, para isso, os capilares elípticos foram ordenados em um geometria complexa, e com o raio de apenas $0,175 \mu \mathrm{m}$. Ainda em 2007, visando aumentar a birrefringência nas MOFs, D. Chen e L. Shen [69] propuseram uma arranjo estrutural para as MOFs extremamente complexo. A estrutura apresentada por Chen era formada por capilares elípticos de diferentes dimensões. Os capilares de maior diâmetro são dispostos próximos ao núcleo, com o maior eixo da elipse na direção vertical, enquanto que, os capilares de menor diâmetro têm o maior eixo da elipse orientado na direção horizontal. Com essa complexa estrutura foi possível obter uma birrefringência da ordem de 
$10^{-2}$. Por fim, neste ano de 2008, H. Ademgil e S. Haxha [70] projetaram uma MOF também com arranjo estrutural complexo, capaz de apresentar alta birrefringência, da ordem de $10^{-3}$, baixas perdas, em torno de $10^{-4} \mathrm{~dB} / \mathrm{m}$, e dispersão cromática plana de $+25 \mathrm{ps} / \mathrm{nm} / \mathrm{Km}$ na faixa do comprimento de onda de $1200 \mathrm{~nm}$ a $1700 \mathrm{~nm}$.

Logo, no Capítulo 5, além das fibras D-MOFs projetadas para apresentar alta birrefringência, será apresentada uma otimização na estrutura das D-MOFs, associando-se capilares elípticos ao perfil de índice tipo D. Este novo arranjo geométrico é definido, simplesmente, como ED-MOF (fibra óptica microestrutura tipo D com capilares elípticos), e a associação desses dois artifícios visa aumentar a assimetria da fibra na região do núcleo, e, consequentemente, o efeito da birrefringência.

\subsection{D-MOFs - Fibras ópticas microestruturadas tipo D}

Este trabalho propõe investigar a utilização das fibras ópticas microestruturas com seção transversal tipo D. Este tipo de arranjo geométrico, para as fibras microestruturadas atuando na compensação de dispersão ou como fibras altamente birrefringentes, está sendo investigado pela primeira vez. Esta estrutura poderá ser formada fazendo-se um corte longitudinal em um dos eixos transversais $(x, y)$ da fibra, tornando-a com uma face plana ao longo do seu eixo longitudinal z, conforme observado na Figura 8.
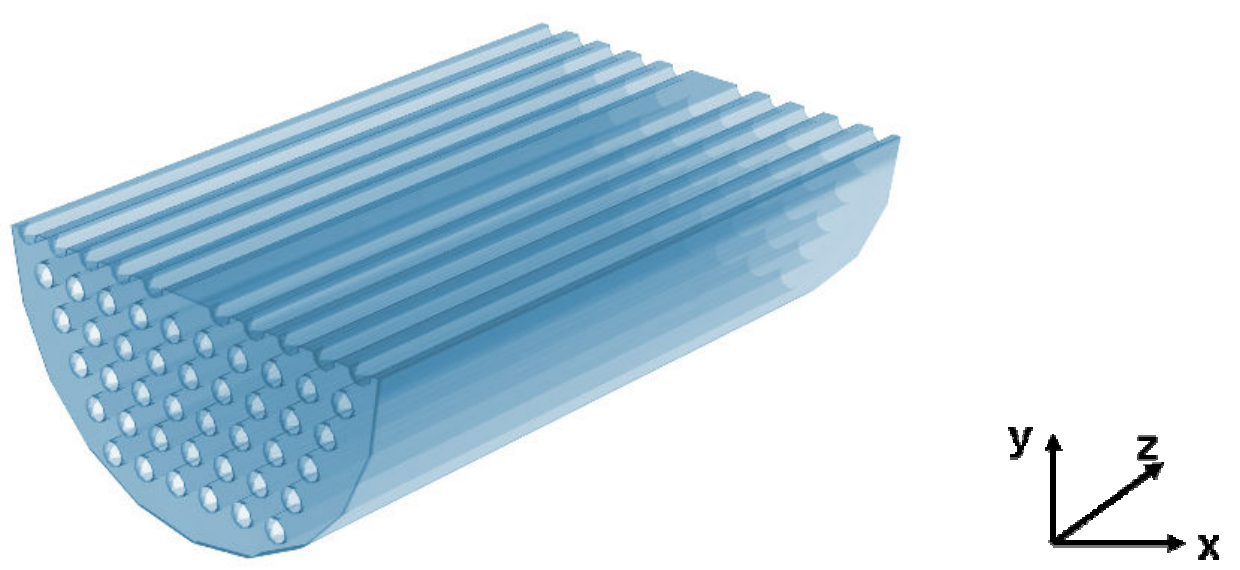

Figura 8. Esquemático da fibra óptica microestruturada tipo D. 
Esta configuração geométrica das fibras ópticas microestruturadas permite um grau maior de liberdade com relação ao projeto de fibras compensadoras de dispersão e fibras altamente birrefringentes. Além das possíveis alterações nos parâmetros físicos $\left(\mathrm{n}_{\mathrm{co}}, \mathrm{n}_{\mathrm{cl}}\right)$ e geométricos $(\Lambda, d)$, a posição do corte também pode ser deslocada, conforme apresentado na Figura 9. Neste caso, considerando-se o centro da fibra como o ponto de referência zero, podese deslocar a posição do corte no sentido vertical, conforme a necessidade de projeto, modificando-se, assim, as características da fibra.

A Figura 9 apresenta a seção transversal de duas fibras ópticas microestruturadas, uma com o corte na posição zero e a outra com o corte deslocado.

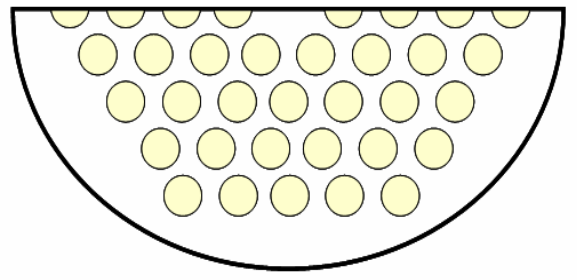

(a)

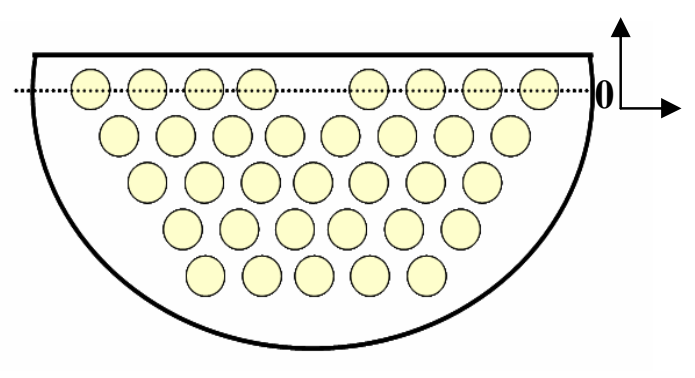

(b)

Figura 9. Fibra óptica microestruturada tipo D. (a) corte no centro, (b) corte deslocado.

As simulações que serão apresentadas no Capítulo 5 demonstram que, com as MOFs de sílica e geometria tipo $\mathrm{D}$, é possível obter um coeficiente de dispersão negativo em uma larga faixa do comprimento de onda. Assim, estas estruturas podem ser otimizadas para compensação de dispersão em banda larga.

Ademais, no Capítulo 5, também será mostrado que com essas estruturas é possível projetar fibras com alta birrefringência. Estas fibras são utilizadas em aplicações onde é necessário manter o estado de polarização, como, por exemplo, na geração de supercontínuo [71]. A geração de luz supercontínua nas MOFs tipo D é favorecida, uma vez que estas fibras podem ser projetadas de forma a exibirem uma reduzida área efetiva, alta birrefringência e dispersão nula em dois diferentes comprimentos de onda [72].

Por fim, tanto para o cálculo da birrefringência quanto para o cálculo da dispersão cromática nas MOFs e D-MOFs, é fundamental calcular o valor do índice efetivo com 
precisão. Por isso, é necessário nas simulações utilizar métodos numéricos precisos e adequados. Portanto, no capítulo seguinte, serão apresentados e discutidos, minuciosamente, os métodos numéricos utilizados nas simulações das fibras microestruturadas. 


\section{Modelagem Numérica}

A modelagem matemática das fibras ópticas microestruturadas pode ser feita por meio de diferentes técnicas. Encontram-se na literatura diversos métodos numéricos capazes de simular o comportamento do campo eletromagnético em guias de onda. Neste capítulo, são apresentados dois métodos numéricos para a modelagem das fibras ópticas microestruturadas.

O primeiro método foi desenvolvido pelo autor no seu programa de mestrado, denominado de método da Sobre-Relaxação Sucessiva - SOR, formulado em termos de diferenças finitas para a solução da equação vetorial de Helmholtz. Como resultado da simulação numérica, o método SOR é capaz de fornecer o campo eletromagnético do modo de propagação fundamental, sua constante de propagação $\beta$, e, conseqüentemente, seu índice efetivo, $n_{\text {eff, }}\left(n_{\text {eff }}=\beta / k_{0}\right)$. Entretanto, este método tem como característica convergir para a solução do modo fundamental. Caso a estrutura a ser investigada seja multimodo, o resultado fornecido pelo método SOR será apenas uma das possíveis soluções, ou seja, a solução correspondente ao modo fundamental.

O Método de Arnoldi Implicitamente Reiniciado - IRAM (Implicitly Restarted Arnoldi Method) foi o segundo método utilizado neste trabalho para a modelagem matemática das MOFs. O IRAM é um eficiente método para solução numérica de problemas de autovalor e autovetor do tipo $A x=\lambda B x$, onde ' $A$ ' e ' $B$ ' são matrizes esparsas, ' $x$ ' os autovetores e ' $\lambda$ ' os autovalores. Uma completa e detalhada descrição desse método pode ser encontrada em [73]. Neste trabalho utilizou-se a versão do IRAM definida no pacote de domínio público denominado ARPACK (Arnoldi Package) [73]. Neste pacote, encontram-se sub-rotinas do método desenvolvidas exatamente para este tipo de problema.

Este capítulo é subdividido em quatro partes específicas. Na seção 3.1, é descrita a formulação do problema a partir da equação de onda vetorial de Helmholtz e sua aproximação em diferenças finitas. Nas seções 3.2 e 3.3, são apresentadas, respectivamente, a formulação do método numérico da sobre-relaxação sucessiva e a formulação do método Arnoldi implicitamente reiniciado, disponibilizado no pacote Arpack. A seção 3.2 descreve o método SOR de uma maneira sucinta, uma vez que, um amplo desenvolvimento teórico foi apresentado no programa de mestrado [74]. Por fim, na seção 3.4, são apresentadas as respectivas validações dos métodos. 


\subsection{Formulação do problema}

Nesta subseção, é apresentada a equação vetorial de Helmholtz, a qual será expandida em diferenças finitas. A partir desta expansão será possível determinar o comportamento do campo eletromagnético em guias de onda. A dedução da equação vetorial de Helmholtz a partir das equações de Maxwell está detalhada no Apêndice I.

A equação vetorial de Helmholtz em termos do campo magnético com polarização horizontal na direção $x$ é descrita da seguinte forma [74]:

$$
\left[\frac{\partial^{2}}{\partial x^{2}}+n^{2} \frac{\partial}{\partial y}\left(\frac{1}{n^{2}} \frac{\partial}{\partial y}\right)+\kappa_{0}^{2} n^{2}-\beta^{2}\right] H_{x}=\left[n^{2} \frac{\partial}{\partial y}\left(\frac{1}{n^{2}} \frac{\partial}{\partial x}\right)-\frac{\partial^{2}}{\partial y \partial x}\right] H_{y}
$$

onde $n$ é o índice de refração, $\kappa_{0}$ é o número de onda no vácuo e $\beta$ é a constante de propagação.

Pode-se observar que o lado direito da equação 3.1 contém as derivadas cruzadas de $\mathrm{H}_{\mathrm{y}}$, as quais descrevem o acoplamento entre as componentes transversais do campo magnético nas direções x e y. O segundo termo do lado esquerdo da Equação $3.1\left(n^{2} \frac{\partial}{\partial y}\left(\frac{1}{n^{2}} \frac{\partial H_{x}}{\partial y}\right)\right.$ ) descreve os efeitos de polarização modal, uma vez que são consideradas as variações do índice de refração na direção perpendicular à componente de campo. Sendo assim, a equação 3.1 representa o formalismo vetorial completo [75]. Por outro lado, desprezando-se o acoplamento cruzado entre as componentes de campo, ou seja, supondo os modos como sendo linearmente polarizados, pode-se desprezar todo o lado direito da Equação 3.1, resultando, desta forma, conforme [76], [77], no formalismo denominado semivetorial. Assim, nesta aproximação, as componentes de campo ortogonais (direção x e y) são consideradas desacopladas. Uma simplificação ainda maior pode ser obtida desprezando-se, além das derivadas cruzadas, os efeitos relativos à polarização modal. Dessa forma, o segundo termo do lado esquerdo da Equação 3.1 torna-se uma derivada segunda discretizada de forma direta, pois os termos $\mathrm{n}^{2}$ se cancelam. Neste caso, tem-se então o tratamento escalar [77], [78]. 
Feitas estas ressalvas, o próximo passo consiste na aproximação da equação vetorial de Helmholtz em diferenças finitas de segunda ordem.

As derivadas das componentes transversais do campo no lado esquerdo da Equação 3.1 em diferenças finitas de segunda ordem tornam-se [74]:

$$
\begin{aligned}
& \frac{\partial^{2} H_{x_{(i, j)}}}{\partial x^{2}}=\frac{H_{x(i+1, j)}-2 H_{x(i, j)}+H_{x(i-1, j)}}{\Delta x^{2}} \\
& n_{i, j}^{2} \frac{\partial}{\partial y}\left(\frac{1}{n_{i, j}^{2}} \frac{\partial H_{x(i, j)}}{\partial y}\right)=\frac{a H_{x(i, j+1)}-b H_{x(i, j)}+c H_{x(i, j-1)}}{\Delta y^{2}}
\end{aligned}
$$

Os termos $a, b$ e $c$ da Equação 3.3 estão associados ao índice de refração e são definidos como:

$$
\begin{aligned}
& a=2 n_{i, j}^{2} \frac{1}{n_{i, j+1}^{2}+n_{i, j}^{2}} \\
& b=2 n_{i, j}^{2}\left(\frac{1}{n_{i, j+1}^{2}+n_{i, j}^{2}}+\frac{1}{n_{i, j-1}^{2}+n_{i, j}^{2}}\right) \Rightarrow b=a+c \\
& c=2 n_{i, j}^{2} \frac{1}{n_{i, j-1}^{2}+n_{i, j}^{2}}
\end{aligned}
$$

$\mathrm{Na}$ aproximação escalar, a derivada parcial na direção y da Equação 3.3 pode ser tratada como uma derivada de segunda ordem simples, pois os termos relativos ao índice de refração se anulam, resultando nos termos $a=c=1$.

O lado direito da Equação 3.1, que contém as derivadas cruzadas, em diferenças finitas torna-se:

$$
\begin{aligned}
& L_{D} H_{y}=\frac{H_{y_{(i+1, j+1)}}}{4 \Delta x \Delta y}\left(\frac{n_{i, j}^{2}}{n_{i, j+1}^{2}}-1\right)-\frac{H_{y_{(i-1, j+1)}}}{4 \Delta x \Delta y}\left(\frac{n_{i, j}^{2}}{n_{i, j+1}^{2}}-1\right)- \\
& -\frac{H_{y_{(i+1, j-1)}}}{4 \Delta x \Delta y}\left(\frac{n_{i, j}^{2}}{n_{i, j-1}^{2}}-1\right)+\frac{H_{y_{(i-1, j-1)}}}{4 \Delta x \Delta y}\left(\frac{n_{i, j}^{2}}{n_{i, j-1}^{2}}-1\right)
\end{aligned}
$$


Portanto, a equação vetorial de Helmholtz (3.1) discretizada em diferenças finitas resulta em :

$$
\frac{H_{x(i+1, j)}-2 H_{x(i, j)}+H_{x(i-1, j)}}{\Delta x^{2}}+\frac{a H_{x(i, j+1)}-b H_{x(i, j)}+c H_{x(i, j-1)}}{\Delta y^{2}}+\left(\kappa_{0}^{2} n_{i, j}^{2}-\beta^{2}\right) H_{x(i, j)}=L_{D} H_{y}
$$

Feita a conversão em diferenças finitas da equação vetorial de Helmholtz, a seguir, nas subseções 3.2 e 3.3 serão desenvolvidos, respectivamente, os métodos numéricos SOR e IRAM utilizados na solução da equação 3.5.

\subsection{Método da sobre-relaxação sucessiva - SOR}

O método da sobre-relaxação sucessiva (SOR) começou a ser extensivamente utilizado a partir da década de sessenta [79]. Este método é similar ao método de Jacobi e Gauss-Seidel, porém emprega uma técnica de aceleração de convergência. $\mathrm{O}$ parâmetro que determina a evolução do método é conhecido por parâmetro de relaxação, $\omega$. Encontram-se disponíveis na literatura alguns livros clássicos a respeito do método SOR, entre eles pode-se citar os elaborados por Varga [80] e Young [81].

$\mathrm{Na}$ formulação do método SOR em diferenças finitas, para a solução da equação vetorial de Helmholtz as derivadas parciais do campo eletromagnético são escritas em forma de matrizes esparsas. A equação (3.5) pode ser apresentada da seguinte forma [82]:

$$
\text { A. } x=b
$$

A matriz 'A' pode ser decomposta da seguinte forma:

$$
A=L+D+U
$$

onde: a diagonal principal D contém os termos centrados $(\mathrm{i}, \mathrm{j})$. L refere-se aos termos da matriz triangular inferior e contém os termos deslocados $(i-1, j)$ e $(i, j-1)$ dispostos na diagonal inferior, 
sendo nulos os termos fora da diagonal inferior. $U$ é a matriz triangular superior e contém somente os termos deslocados $(i+1, j)$ e $(i, j+1)$ na diagonal superior, com os demais termos iguais a zero. A equação de Helmholtz pode ser visualizada conforme a Figura 10.

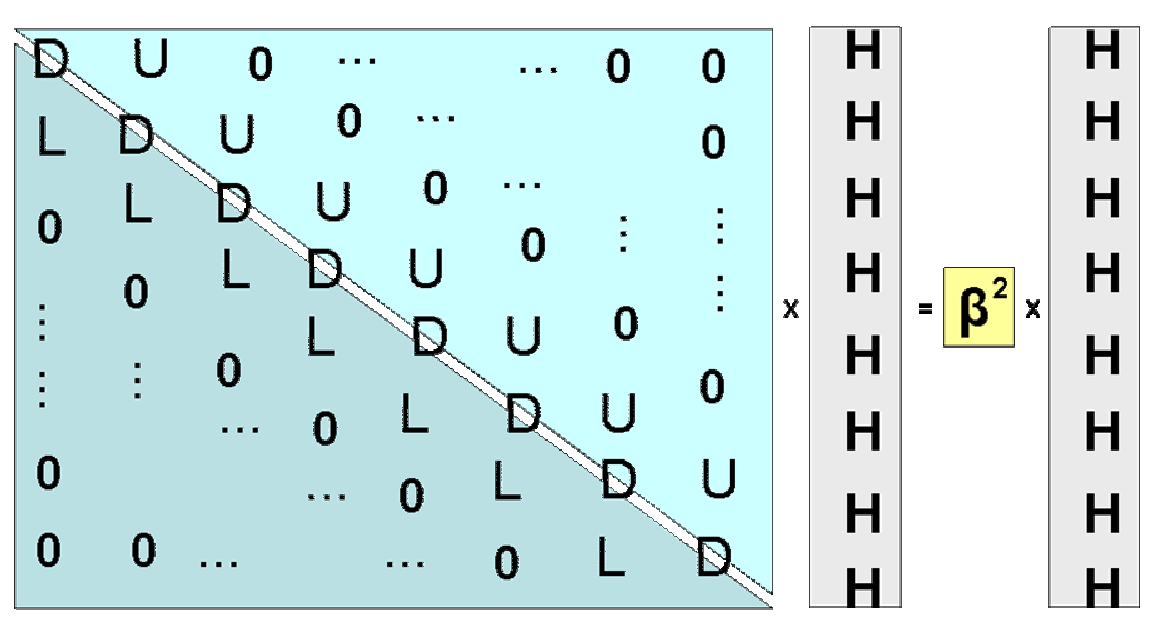

Figura 10. Visualização da equação de Helmholtz em diferenças finitas.

Para a solução da equação vetorial de onda pelo método SOR, deve-se primeiro isolar os termos da diagonal principal. Para isso, substituem-se as derivadas da equação (3.1) por seus termos discretizados em diferenças finitas, obtendo-se a equação (3.5). Da equação (3.5) a componente $H_{x(i, j)}$ pode facilmente ser isolada. Assim, isolando-se a componente $H_{x(i, j)}$ e renomeando-a como $H_{x(i, j)}^{I N T}$, tem-se:

$$
H_{x(i, j)}^{I N T}=\frac{\frac{1}{\Delta x^{2}}\left(H_{x(i+1, j)}+H_{x(i-1, j)}\right)+\frac{1}{\Delta y^{2}}\left(a H_{x(i, j+1)}+c H_{x(i, j-1)}\right)-L_{D} H_{y}}{\left(\frac{2}{\Delta x^{2}}+\frac{b}{\Delta y^{2}}-\kappa_{0}^{2} n_{i, j}^{2}+\beta^{2}\right)},
$$

Onde $H_{x(i, j)}^{I N T}$ é denominado campo intermediário.

O parâmetro $\beta$ é a constante de propagação e é calculada na aproximação vetorial completa a cada iteração por [83]: 


$$
\beta^{2}=\frac{\kappa_{0}^{2} \int n_{i, j}^{2}\left|H_{x}\right|^{2} d x d y+\int\left(\frac{\partial^{2} H_{x}}{\partial_{X}{ }^{2}}\right) H_{x}{ }^{*} d x d y+R-R_{1}+R_{2}}{\int\left|H_{x}\right|^{2} d x d y},
$$

onde, $\mathrm{H}_{\mathrm{x}}{ }^{*}$ representa o complexo conjugado do campo magnético e $\mathrm{R}, \mathrm{R}_{1}$ e $\mathrm{R}_{2}$ são calculados por:

$$
\begin{aligned}
& R=\int n_{i, j}^{2} \frac{\partial}{\partial y}\left(\frac{1}{n_{i, j}^{2}} \frac{\partial H_{x}}{\partial y}\right) H_{x}^{*} d x d y \\
& R_{1}=\int n_{i, j}^{2} \frac{\partial}{\partial y}\left(\frac{1}{n_{i, j}^{2}} \frac{\partial H_{y}}{\partial x}\right) H_{x}^{*} d x d y \\
& R_{2}=\int\left(\frac{\partial^{2} H_{y}}{\partial y \partial x}\right) H_{x}^{*} d x d y
\end{aligned}
$$

Com relação à Equação (3.7), na aproximação escalar, o termo $R$ torna-se uma segunda derivada simples de $\mathrm{H}_{\mathrm{x}}$, pois os índices de refração $n_{i, j}^{2}$ se cancelam e os termos $R_{l}$ e $R_{2}$ são iguais a zero. $\mathrm{Na}$ aproximação semivetorial considera-se o termo $R$ como descrito na Equação (3.8), sendo nulos os termos $R_{1}$ e $R_{2}$. Como comentado, no cálculo de $\beta$, a formulação vetorial completa considera todos os termos da Equação (3.7).

Após o cálculo da constante de propagação $\beta$, o termo $H_{x(i, j)}^{I N T}$ da Equação (3.6) é utilizado para o cálculo do campo subseqüente, isto é, do $H_{x} \underset{(i, j)}{\text { novo }}$, através do esquema iterativo dado pelo método SOR. A relação para a correção do campo a cada iteração é fornecida pela expressão [84]:

$$
H_{x_{i, j}}^{\text {novo }}=\omega H_{x_{i, j}}^{I N T}+(1-\omega) H_{x_{i, j}}^{\text {velho }}
$$

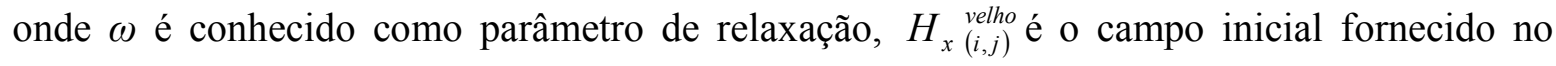
início de cada iteração, $H_{x} \underset{(i, j)}{I N T}$ é o campo intermediário definido pela Equação (3.6), e $H_{x}{ }_{x}^{\text {novo }}(i, j)$ é o campo atualizado. Sendo assim, a cada iteração o campo $H_{x}^{\text {novo }}(i, j)$ torna-se o campo $H_{x} \begin{gathered}\text { velho } \\ (i, j)\end{gathered}$ na próxima iteração. 
A escolha adequada do parâmetro de relaxação $\omega$ caracteriza a velocidade de convergência do método. Para $\omega$ igual a 1, tem-se o método de Gauss-Seidel [80]. Quando o valor de $\omega$ está entre 0 e 1, o método é conhecido como sub-relaxado e a convergência não é garantida [82], [85]. Para $\omega$ variando entre 1 e 2, o método é conhecido como sobre-relaxado, por isso a denominação SOR - sobre-relaxação sucessiva, do inglês, successive over relaxation.

É possível estabelecer um valor ótimo para o parâmetro de relaxação, denominado de $\omega_{\text {opt }}$ o qual pode ser estimado por [85]:

$$
\omega_{o p t}=\frac{2}{\sqrt{1+\left(1-\rho^{2}\right)}}
$$

onde $\rho$ é o maior autovalor da matriz de Jacobi associada e pode ser estimado iterativamente por [84]:

$$
\rho^{2} \cong \frac{\left\|e_{k}\right\|}{\left\|e_{k-1}\right\|}
$$

onde $\left\|\mathrm{e}_{\mathrm{k}}\right\|$ é a norma Euclidiana para o resíduo da iteração k, dado por:

$$
\left\|e_{k}\right\|=\sqrt{\sum_{i, j}\left|H_{x(i, j)}^{I N T}-H_{x} \begin{array}{c}
\text { velho } \\
(i, j)
\end{array}\right|^{2}}
$$

Desta forma, fica estabelecido um método iterativo capaz de gerar a distribuição de campo e o valor da constante de propagação para o modo fundamental de guias de onda genéricos.

O algoritmo pode ser resumido da seguinte forma: primeiramente, uma distribuição de campo inicial, uma gaussiana, por exemplo, é definida como o campo inicial $H^{x}$. O próximo passo é o cálculo da constante de propagação $\beta$ pelas equações (3.7). O campo intermediário $H^{x \text { int }}$ então pode ser calculado pela equação (3.6). A distribuição de campo corrigida $H_{i, j}^{x^{n e w}}$ é finalmente obtida pela equação (3.11). Este processo é repetido a cada iteração até que o critério de convergência, definido em termos da variação do índice de refração efetivo entre 
duas iterações consecutivas, seja atingido. Ao final do processo, tanto a distribuição de campo, quanto a constante de propagação são obtidas simultaneamente.

Nas implementações do método SOR desenvolvidas neste trabalho, a condição de contorno adotada foi a condição de contorno transparente (TBC - Transparent Boundary Condition) [74].

\subsection{Método IRAM via sub-rotinas Arpack}

O Método de Arnoldi Implicitamente Reiniciado - IRAM (Implicitly Restarted Arnoldi Method) [73] é uma variação do algoritmo de Arnoldi utilizado para a solução de problemas matriciais. Como já comentando, uma completa e detalhada descrição do pacote Arpack pode ser encontrada em [73].

No nosso caso particular, onde se deseja investigar o comportamento do campo eletromagnético em guias de onda deve-se, primeiro, reescrever a equação vetorial de Helmohotz em diferenças finitas (equação 3.5) de forma a transformá-la em um problema de autovetor e autovalor. Para isso, serão utilizados os passos descritos em [82], iniciando-se com transformação da matriz, originalmente com dimensões [i,j], em um vetor coluna com dimensões [d,1], conforme a relação [82]:

$$
d=j(N+1)+i
$$

com:

$$
\mathrm{j}=0,1, \ldots, \mathrm{N} \quad \text { e } \quad \mathrm{i}=0,1, \ldots, \mathrm{N}
$$

onde: 'N' é o número de elementos da matriz que descreve o campo eletromagnético discretizado inicialmente em duas dimensões $(i, j)$ e ' $d$ ' é a nova dimensão do vetor coluna. Adicionalmente, como demonstrado em [84], a análise de guias de onda pode ser feita com extrema eficiência por formulações semi-vetoriais, não sendo necessário, salvo em casos específicos [74], o emprego do formalismo vetorial completo, que acarreta em um peso computacional elevado. Portanto, neste trabalho a utilização das sub-rotinas Arpack foram construídas considerando apenas a formulação semi-vetorial. 
Reescrevendo a equação (3.5):

$$
\frac{H_{x(i-1, j)}}{\Delta x^{2}}+\frac{c H_{x(i, j-1)}}{\Delta y^{2}}+\left(\kappa_{0}^{2} n_{i, j}^{2}-\frac{2}{\Delta x^{2}}-\frac{b}{\Delta y^{2}}\right) H_{x(i, j)}+\frac{H_{x(i+1, j)}}{\Delta x^{2}}+\frac{a H_{x(i, j+1)}}{\Delta y^{2}}=\beta^{2} H_{x(i, j)}
$$

agora, utilizando a relação (3.12), a equação passa a ser apresentada da seguinte forma:

$$
\frac{H_{x(d-(N+1))}}{\Delta x^{2}}+\frac{H_{x[d-1]}}{\Delta y^{2}}+\left(\kappa_{0}^{2} n_{d}^{2}-\frac{2}{\Delta x^{2}}-\frac{2}{\Delta y^{2}}\right) H_{x(d)}+\frac{H_{x(d+(N+1))}}{\Delta x^{2}}+\frac{H_{x(d+1)}}{\Delta y^{2}}=\beta^{2} H_{x(d)}
$$

Portanto, a matriz A, que contém os termos multiplicadores dos campos magnéticos, pode ser esquematizada conforme a Figura 11.

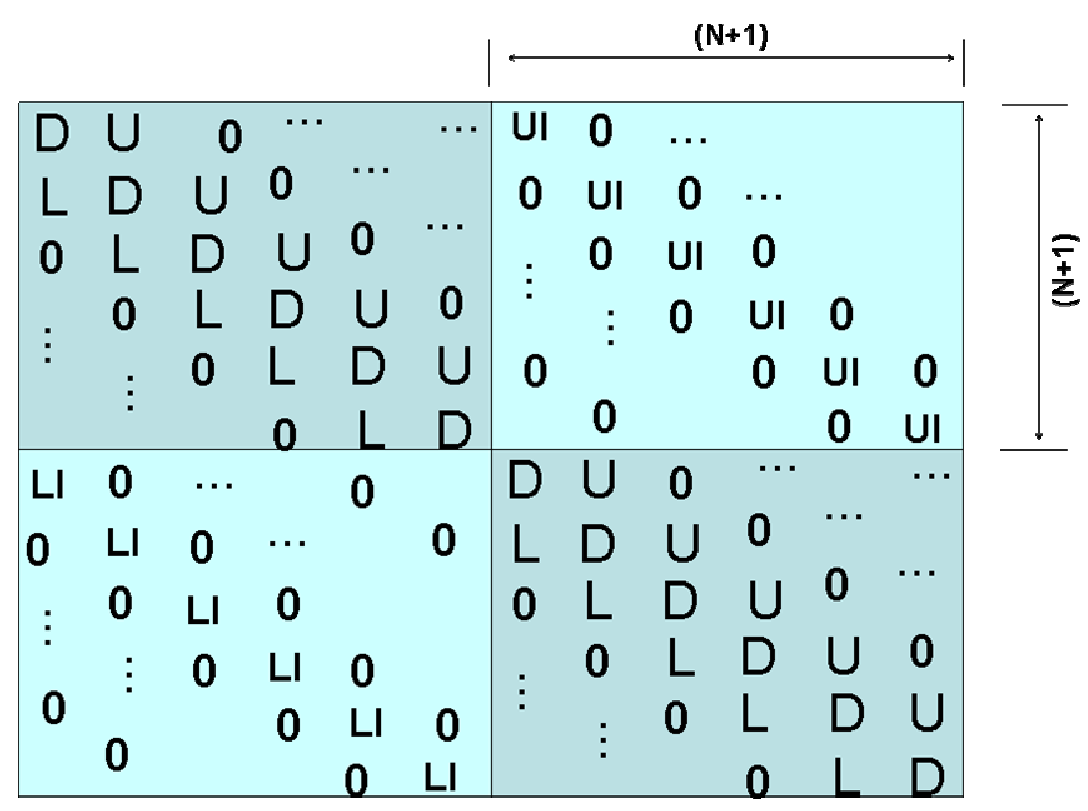

Figura 11. Estrutura da matriz A na forma penta-diagonal.

Neste caso, a matriz é denominada de penta-diagonal ou tri-diagonal com franjas. A diagonal principal ' $D$ ', novamente contém os elementos centrais $(i, j)$. Os termos discretizados em $(i, j+1)$ e $(i, j-1)$ passam a formar, respectivamente, a diagonal superior $U$ e inferior $L$. Os 
termos discretizados em (i+1,j) e (i-1,j) passam, então, a formar as 'franjas' da matriz, Ul e Ll respectivamente.

Deve-se observar que anteriormente a matriz era composta com $(n \times n)$ elementos e, nessa nova disposição, passa a ser formada com $\left(\mathrm{n}^{2} \times \mathrm{n}^{2}\right)$ elementos, o que torna computacionalmente custoso o armazenamento de todos os termos da matriz. Neste caso, uma estratégia que torna o método eficiente é armazenar apenas os termos que carregam informação. Como se trata de uma matriz esparsa, o método IRAM foi otimizado para receber apenas os dados que contêm os elementos não nulos. Portanto, a entrada de dados nas subrotinas é feita com 5 vetores de dimensão $\left(\mathrm{n}^{2} \times 1\right)$.

Neste trabalho, foram utilizadas especificamente duas sub-rotinas do pacote Arpack: “dsaupd", para solução dos autovalores, e "dseupd", para solução dos autovetores. O algoritmo para utilização das sub-rotinas Arpack pode ser resumido da seguinte forma: primeiramente, é necessário ajustar os parâmetros de entrada 'nev' e 'ncv' que especificam respectivamente o número de autovalores e autovetores a serem determinados. O próximo passo é discretizar a malha correspondente à estrutura a ser investigada e, conforme equação (3.12), transformá-la em um vetor coluna [82]. Antes de chamar as sub-rotinas no programa, é possível limitar a faixa de busca dos autovalores e obter somente os autovetores correspondentes a essa faixa específica. Outro ajuste necessário se refere à tolerância, ou seja, ao critério de parada relativo à precisão aceitável para o método. Em seguida, a primeira subrotina 'dsaupd' é chamada. Esta rotina fornecerá todos os autovalores correspondentes ao sistema em estudo, ou seja, fornecerá a constante de propagação $\beta$ e, conseqüentemente, o índice efetivo procurado. A solução é obtida quando o critério de convergência, definido em termos da variação do autovalor entre duas iterações consecutivas, é atingido. Por fim, chamase a segunda sub-rotina 'dseupd'. Esta rotina fornece todos os autovetores correspondentes aos autovalores calculados anteriormente. Logo, fornece a distribuição do campo magnético que corresponde à constante de propagação calculada. Portanto, ao final do processo, tanto a distribuição de campo quanto a constante de propagação, para todas as possíveis soluções do guia de onda, são obtidas simultaneamente.

Tendo concluído a descrição dos métodos SOR e IRAM, faz-se necessária a aferição dos métodos implementados. Para isso, serão utilizadas algumas estruturas encontradas na literatura, comumente utilizadas na validação de métodos numéricos. 


\subsection{Validação dos métodos SOR e IRAM}

Esta seção apresenta os resultados da validação dos métodos SOR e IRAM, feita por meio da comparação entre os resultados fornecidos por estes métodos com os resultados padrão encontrados na literatura para três guias de ondas diferentes.

O primeiro guia de onda utilizado na aferição é uma fibra óptica microestruturada monomodo com núcleo de sílica [4]. O segundo guia de onda é uma fibra óptica microestruturada multimodo de dois núcleos [44]. Por fim, a terceira estrutura é uma fibra óptica onde a região central é formada por ar [86]. Em todos os casos investigados, o valor do índice efetivo $n_{\text {eff }}$ foi utilizado como parâmetro comparativo.

\section{A) Fibra óptica microestruturada monomodo}

Esta primeira fibra óptica microestruturada utilizada na aferição foi investigada por Brechet e colaboradores em [4]. Os parâmetros físicos e geométricos utilizados estão listados na Tabela 1.

Tabela 1: Parâmetros físicos e geométricos da MOF

\begin{tabular}{ccccc}
\hline $\mathbf{n}_{\mathbf{c}}$ & $\mathbf{n}_{\mathbf{a r}}$ & $\boldsymbol{\Lambda}(\boldsymbol{\mu m})$ & $\mathbf{d}(\boldsymbol{\mu} \mathbf{m})$ & $\boldsymbol{\lambda}(\boldsymbol{\mu} \mathbf{m})$ \\
\hline Sílica & 1,0 & 2,3 & 1,0 & $0,5-1,8$ \\
\hline
\end{tabular}

Esta fibra investigada em [4] é uma fibra óptica microestruturada com a esturura regular dos capilares, ou seja, a região da casca é formada por capilares ordenados em uma rede hexagonal. O gráfico da Figura 12 apresenta a variação do índice efetivo em função do comprimento de onda encontrada pelos métodos SOR e IRAM semivetoriais. Nestas simulações, os passos de discretização utilizados foram $\Delta_{\mathrm{x}}=\Delta_{\mathrm{y}}=0,07 \mu \mathrm{m}$, com uma janela computacional $\mathrm{L}_{\mathrm{x}}=\mathrm{L}_{\mathrm{y}}=39 \mu \mathrm{m}$. Foi demonstrado em [84] que a utilização do formalismo semivetorial pode ser empregada nas simulações de guias de onda, uma vez que seus resultados têm adequada concordância com formulações vetoriais completas e, adicionalmente, apresentam a vantagem de apresentarem um custo computacional mais reduzido. 


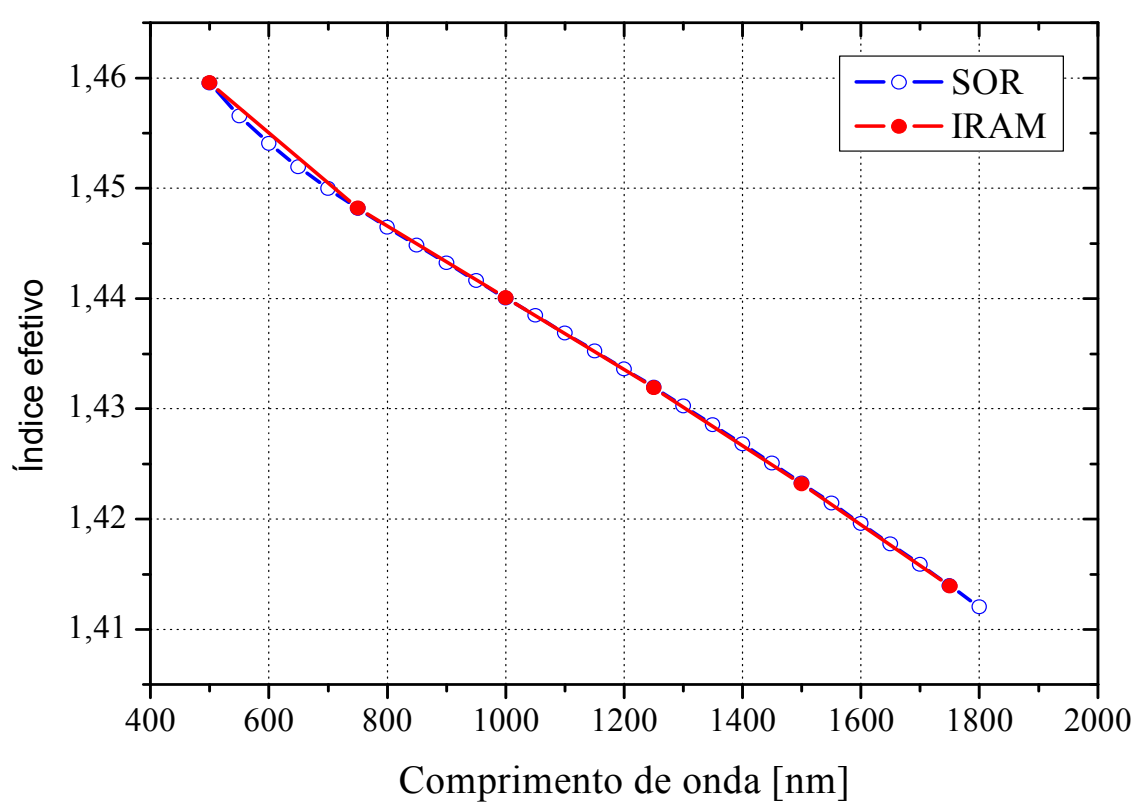

Figura 12. Comparação entre os valores do índice efetivo calculados pelo método SOR e IRAM.

Conforme observado na Figura 12, pode-se notar a proximidade entre os valores do índice efetivo obtidos pelos métodos SOR e IRAM. De posse dos valores do índice efetivo em função do comprimento de onda, é possível determinar, conforme Equação (2.1), a curva de dispersão dessa fibra. Visando validar as formulações implementadas, o gráfico da Figura 13 apresenta a comparação entre os valores de dispersão obtidos pelas presentes formulações com os valores obtidos pela formulação vetorial baseado no método dos elementos finitos (fullvector based on the FEM) [4], cujos valores foram cedidos pelo autor. 


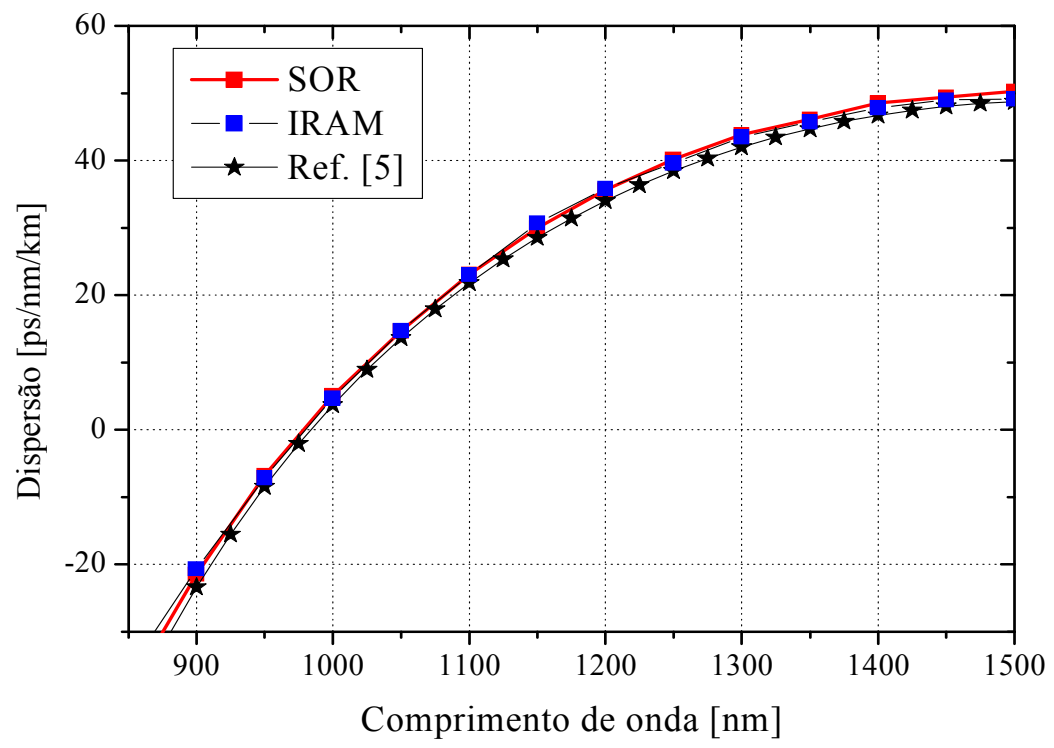

Figura 13. Dispersão cromática em função do comprimento de onda.

Por fim, pode-se visualizar graficamente na Figura 14 o comportamento da componente fundamental do campo magnético para dois diferentes comprimentos de onda, $\lambda$. Na Figura (14a) $\lambda=1.0 \mu \mathrm{m}$ e na Figura (14b) $\lambda=1.8 \mu \mathrm{m}$.

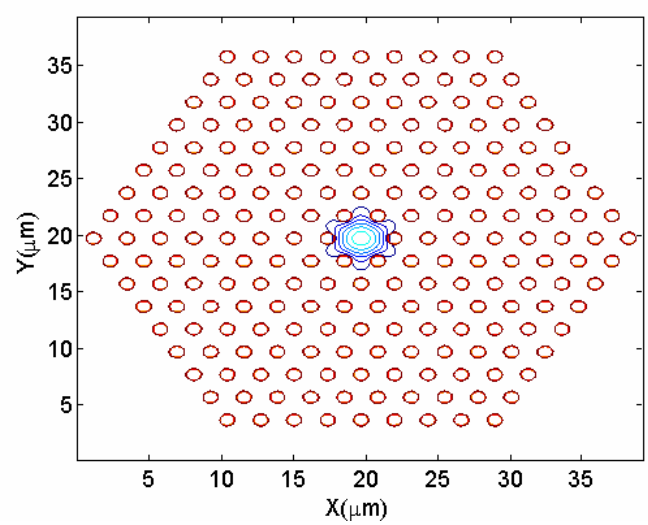

(a)

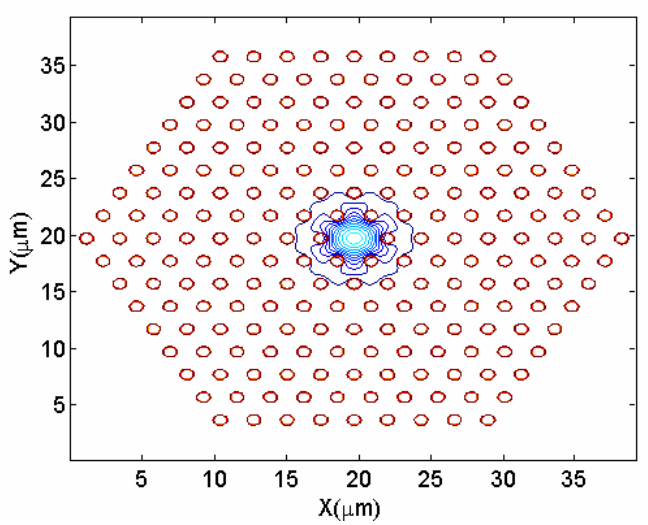

(b)

Figura 14. Perfil de campo magnético fundamental para dois comprimentos de onda diferentes.

$$
\text { (a) } \lambda=1,0 \mu \mathrm{m} \text {; (b) } \lambda=1,6 \mu \mathrm{m} \text {. }
$$

Analisando o comportamento do campo na Figura 14, nota-se claramente que, em comprimentos de onda curtos, o modo permanece confinado na região do núcleo, enquanto 
que, para comprimentos de onda mais longos, o campo tende a espalhar-se pela região da casca. Este espalhamento diminui o índice médio da casca, pois o campo tem maior interação com as regiões de ar (de menor índice de refração), o que, por sua vez, diminui o índice efetivo da fibra, conforme observado na Figura 12.

\section{B) Fibra óptica microestruturada de dois núcleos}

A segunda estrutura analisada neste trabalho para aferição dos métodos é uma fibra microestruturada composta de dois núcleos, estudada por Huttunen e Törmä em [44]. Esta fibra foi escolhida por ser uma fibra microestruturada multimodo, formada por núcleos concêntricos, isolados por 2 anéis de capilares conforme apresentado na Figura 15. Neste caso particular, a fibra possui o núcleo interno dopado, com índice de refração, $\mathrm{n}_{\mathrm{c}}=1,753 \mathrm{e}$ diâmetro $d_{c}=1,163 \mu \mathrm{m}$. O núcleo externo possui índice de refração $n_{e x}=1,444$ e é formado pela ausência dos capilares no terceiro anel. O diâmetro dos capilares e o espaçamento entre eles são, respectivamente, $\mathrm{d}=0,8838 \mu \mathrm{m}$ e $\Lambda=1,163 \mu \mathrm{m}$.
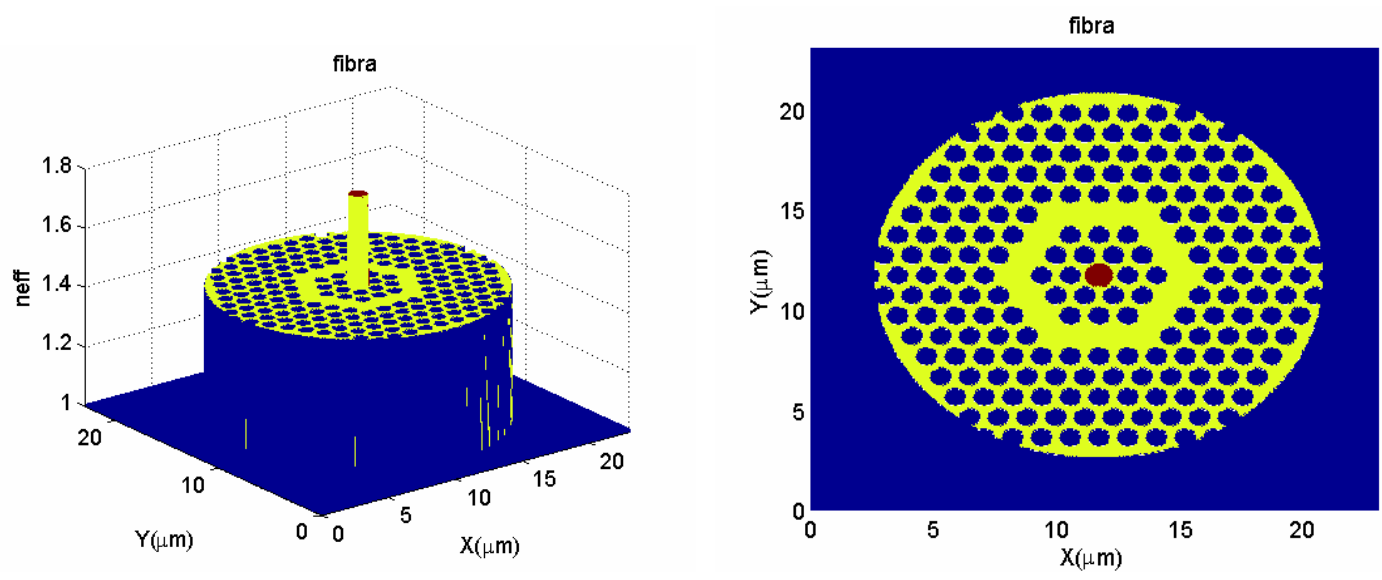

Figura 15. Esquemático da fibra óptica microestruturada de dois núcleos.

Esta fibra foi escolhida por ser uma fibra multimodo e cujo terceiro modo de mais alta ordem apresenta um valor de dispersão negativo de aproximadamente $\mathrm{D}=-8000 \mathrm{ps} /(\mathrm{nm} \mathrm{km})$. Para o estudo deste tipo de estrutura, o método SOR não é indicado, pois não é capaz de simular os modos de mais alta ordem, apenas o modo fundamental, justificando, portanto, a implementação das sub-rotinas do Arpack. 
O gráfico da Figura 16 apresenta a variação do índice efetivo em função do comprimento de onda encontrado pelo método IRAM em comparação com os valores obtidos pelo método de ondas planas vetorial completo [44]. Nestas simulações, os passos de discretização utilizados foram $\Delta_{\mathrm{x}}=\Delta_{\mathrm{y}}=0,065 \mu \mathrm{m}$, com uma janela computacional $\mathrm{L}_{\mathrm{x}}=\mathrm{L}_{\mathrm{y}}=38,3 \mu \mathrm{m}$.

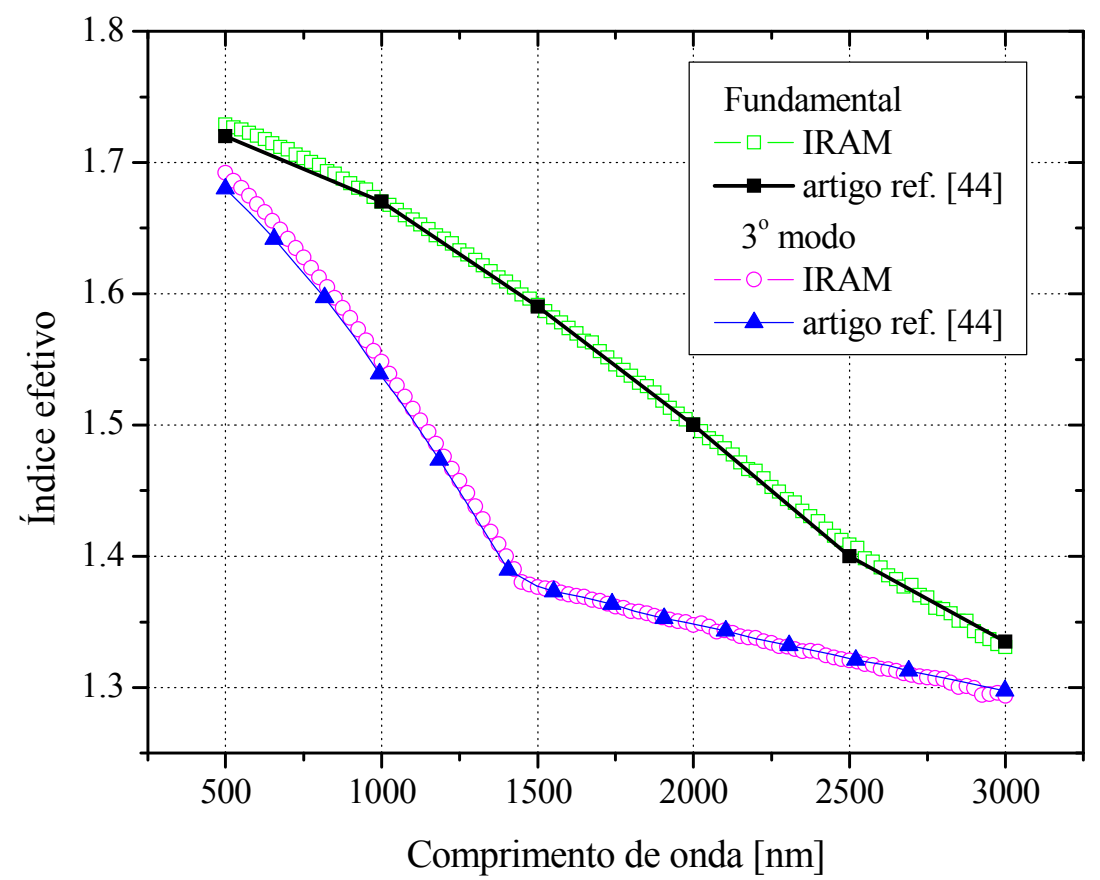

Figura 16. Variação do índice efetivo em função com comprimento de onda - modo fundamental e terceiro modo.

Como observado na Figura 16, os valores dos índices efetivos calculados pelo método IRAM estão em plena concordância com valores obtidos em [44], o que valida a utilização do método implementado. O comportamento modal desta fibra pode ser descrito da seguinte maneira: o modo fundamental, para a faixa de comprimentos de onda estudada, $0,5 \mu \mathrm{m} \leq$ $\lambda \leq 3,0 \mu \mathrm{m}$, permanece sempre confinado no núcleo interno conforme pode ser observado graficamente na Figura 16, e visualizado na Figura 17, via a componente de campo magnético $\mathrm{H}_{\mathrm{x}}$. 


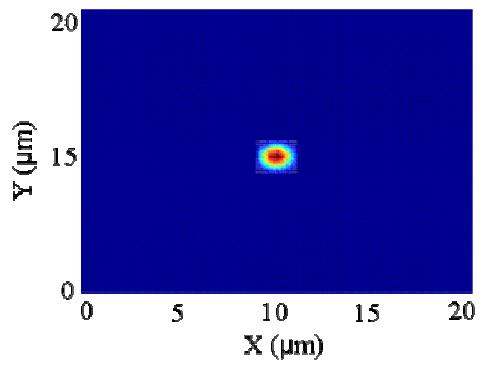

(a)

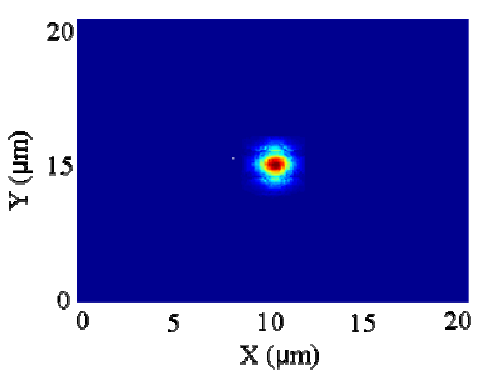

(d)

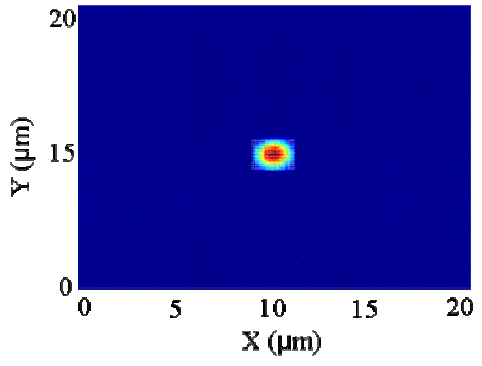

(b)

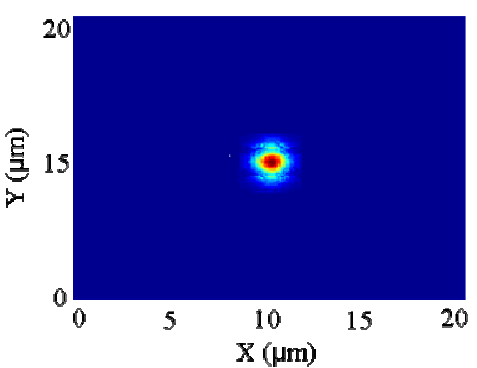

(e)

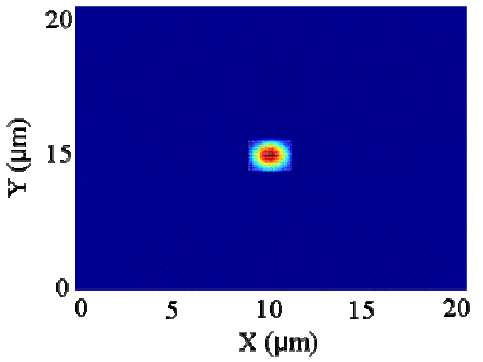

(c)

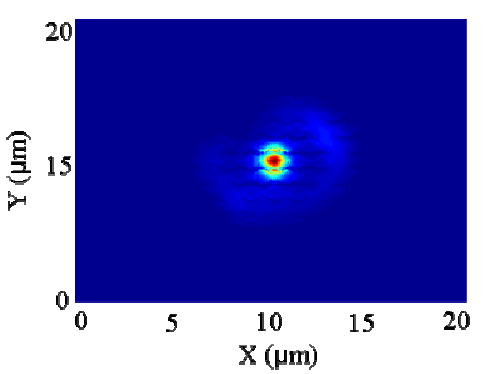

(f)

Figura 17. Componente de campo magnético $H_{x}$ do modo fundamental. a) $\lambda=0,5 \mu \mathrm{m}$, b) $\lambda=1,0 \mu \mathrm{m}$, c) $\lambda=1,5 \mu \mathrm{m}$, d) $\lambda=2,0 \mu \mathrm{m}$, e) $\lambda=2,5 \mu \mathrm{m}$, f) $\lambda=3,0 \mu \mathrm{m}$.

Assim, conforme apresentado no gráfico da Figura 16 e observado na Figura 17, o modo fundamental permanece confinado no núcleo interno, não tendo sua energia acoplada para o núcleo externo. Por outro lado, considerando os modos de mais alta ordem, verifica-se que existe um determinado comprimento de onda, denominado comprimento de onda de casamento $\lambda_{\mathrm{c}}$, onde ocorre o casamento de fase e, neste ponto, o modo que estava sendo guiado no núcleo interno da fibra passa a ser guiado o núcleo externo.

A Figura 18 (a)-(b) apresenta o comportamento da componente de campo magnético $\mathrm{H}_{\mathrm{x}}$ do terceiro modo. Neste caso, para comprimentos de onda abaixo de $1,50 \mu \mathrm{m}$, verifica-se que o modo está muito bem confinado no núcleo interno, mas para comprimentos de onda acima de $1,50 \mu \mathrm{m}$, esse modo de mais alta ordem passa a ser guiado no núcleo externo, conforme Figura 18 (c)-(f). 


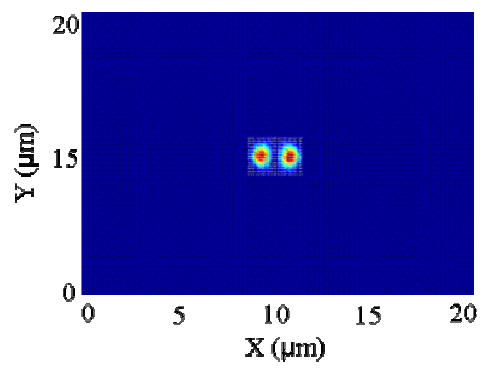

(a)

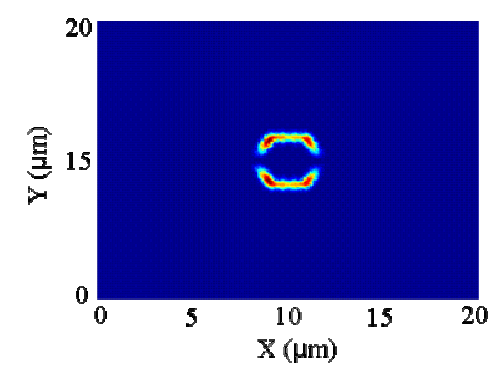

(d)

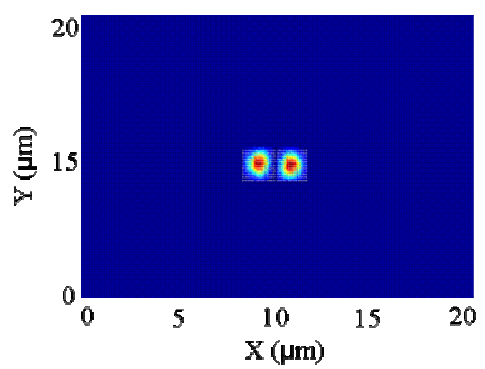

(b)

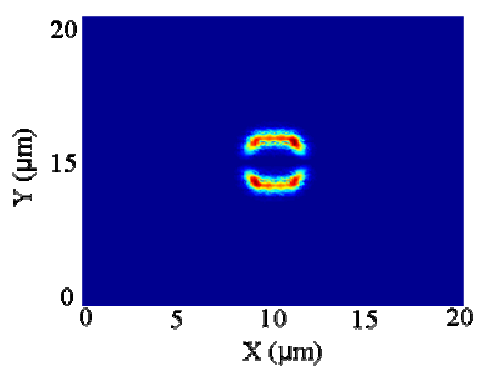

(e)

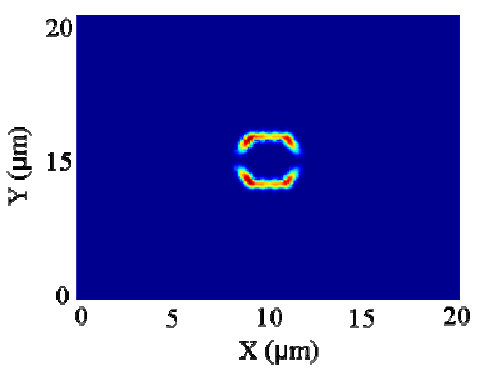

(c)

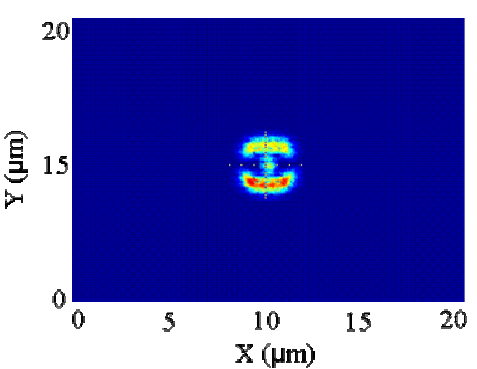

(f)

Figura 18. Componente de campo magnético $H_{x}$ do terceiro modo. a) $\lambda=0,5 \mu \mathrm{m}$, b) $\lambda=1,0 \mu \mathrm{m}$, c) $\lambda=1,5 \mu \mathrm{m}$, d) $\lambda=2,0 \mu \mathrm{m}$, e) $\lambda=2,5 \mu \mathrm{m}$, f) $\lambda=3,0 \mu \mathrm{m}$.

Pode-se observar facilmente na Figura 18 que ocorreu uma mudança no comportamento do campo magnético, ou seja, a partir do comprimento de onda de casamento, a maior parte da energia do terceiro modo passou a ser transportada no núcleo externo.

Para uma melhor visualização, as Figuras 19 e 20 apresentam o comportamento modal em dois comprimentos de onda distintos. Na Figura 19, foi considerado o caso onde $\lambda<\lambda_{\mathrm{c}} \mathrm{e}$ na Figura 20, o caso $\lambda>\lambda_{c}$. Nestas Figuras, é apresentada a visualização em três dimensões e, também, do contorno da componente de campo magnético $\mathrm{H}_{\mathrm{x}}$ tanto do modo fundamental quanto do terceiro modo. 

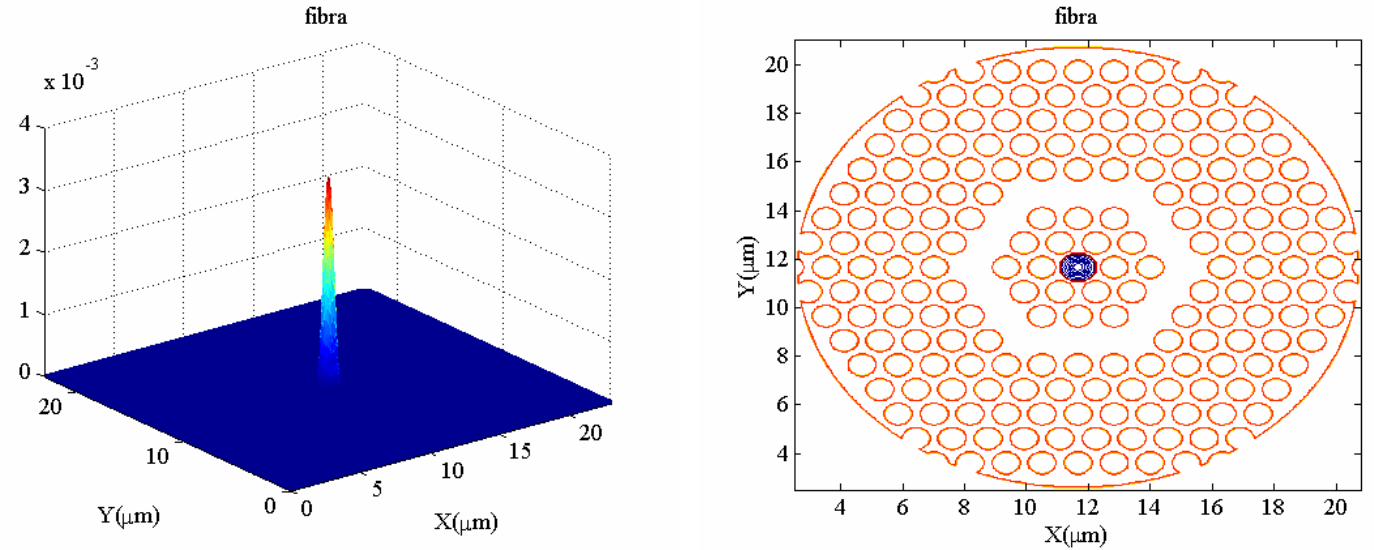

(a)
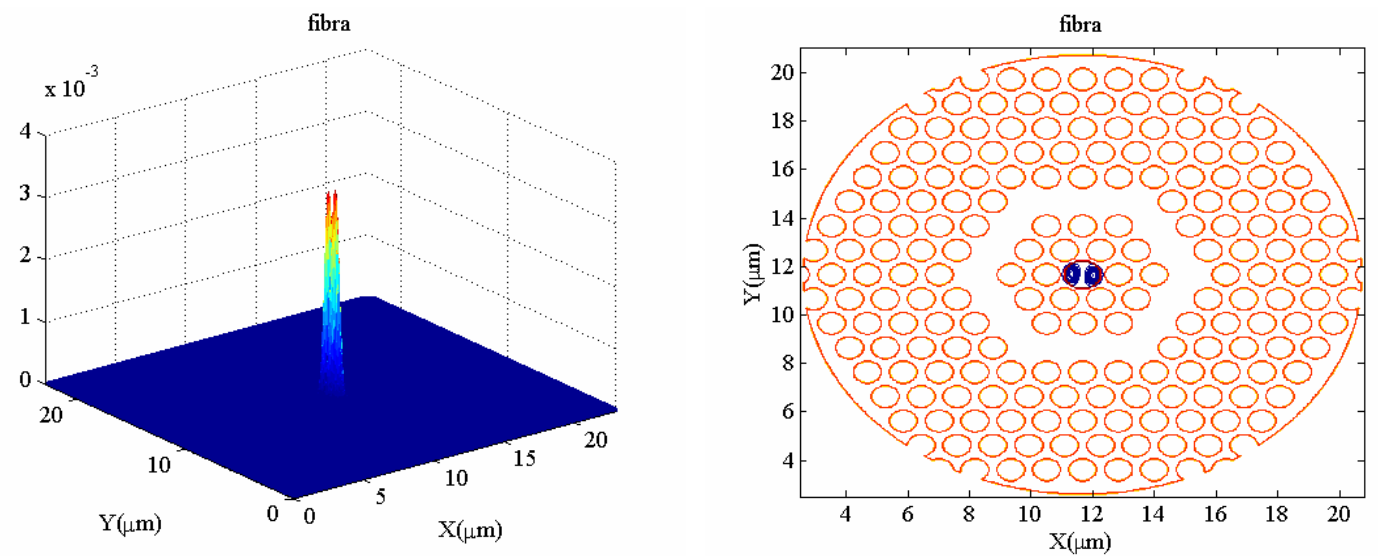

(b)

Figura 19. Comportamento da componente de campo $H_{x}$ para $\lambda<\lambda_{c}$; a) modo fundamental b) terceiro modo.

Como visualizado na Figura 19, em comprimentos de onda abaixo do comprimento de onda de casamento, a maior parte da energia da componente de campo magnético $\mathrm{H}_{\mathrm{x}}$ é propagada no núcleo interno. Este fato ocorre tanto para o modo fundamental quanto para o terceiro modo. 

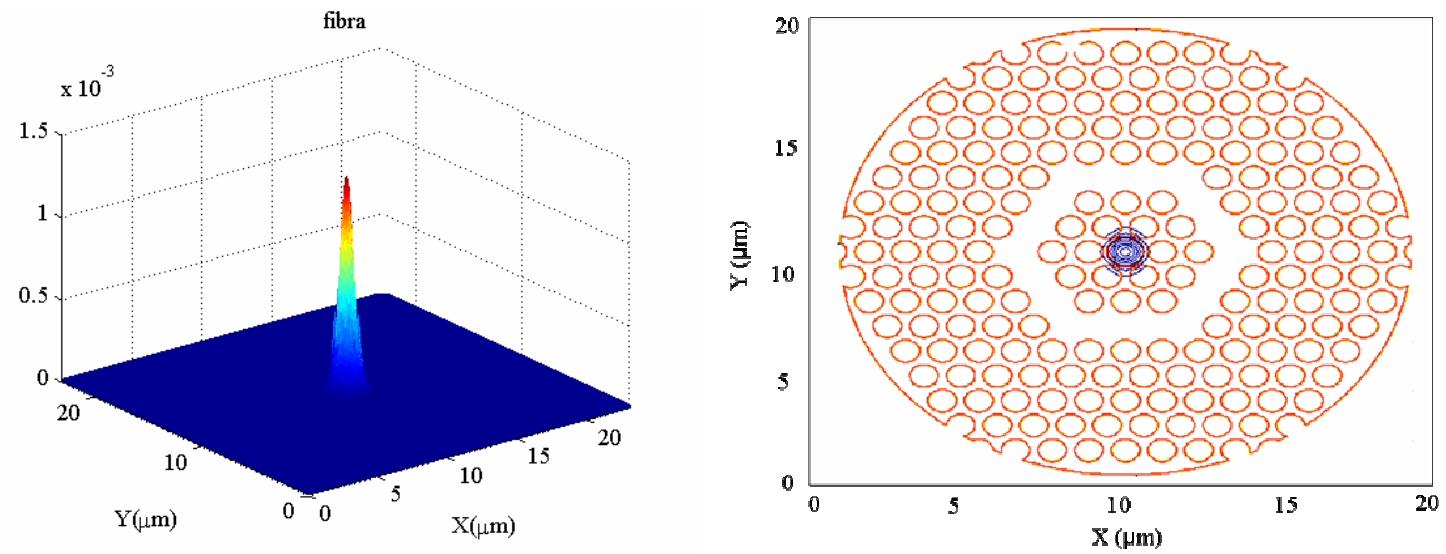

(a)
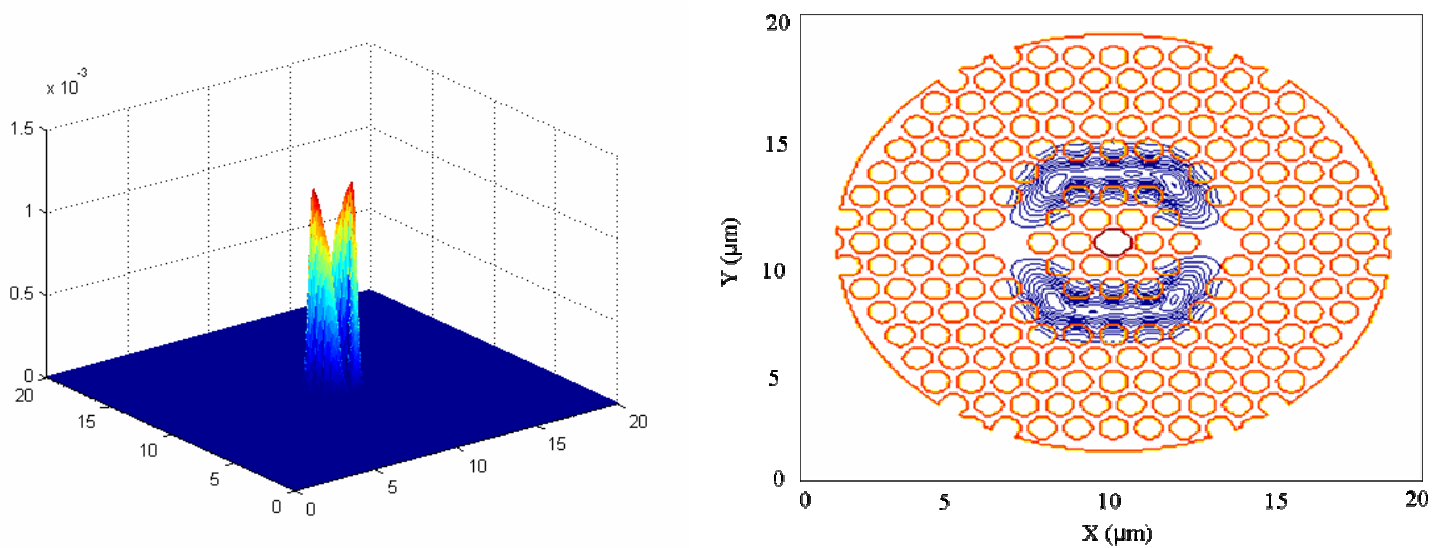

(b)

Figura 20. Comportamento da componente de campo $H_{x}$ para $\lambda>\lambda_{c}$; a) modo fundamental

b) terceiro modo.

Pode-se visualizar na Figura 20 a diferença no comportamento da componente de campo magnético $\mathrm{H}_{\mathrm{x}}$ para o modo fundamental e o terceiro modo. No caso do modo fundamental, a energia se propaga unicamente no núcleo interno. Por outro lado, a energia do terceiro modo, para comprimentos de onda abaixo de $\lambda_{\mathrm{c}}$, fica confinada no núcleo interno e, em comprimentos de onda acima de $\lambda_{c}$, passa a ser guiada no núcleo externo. Esta troca de energia acarreta uma mudança na inclinação da curva do índice efetivo em função do comprimento de onda, conforme mostrado no gráfico da Figura 16. Este efeito é fundamental no projeto das fibras ópticas microestruturadas de dois núcleos otimizadas para compensação de dispersão [44]. 


\section{C) Fibra óptica microestruturada $\mathrm{HOF}$}

Por fim, ainda para comprovar precisão do método IRAM, foi analisada uma fibra óptica formada com uma região central de ar envolta em sílica, conforme Figura 21. Esta fibra foi estudada por Chaudhuri e co-autores [86] e foi escolhida como parâmetro para aferição, pois o autor apresenta a distribuição de campo dos modos de mais alta ordem com seus respectivos valores de índice efetivo.

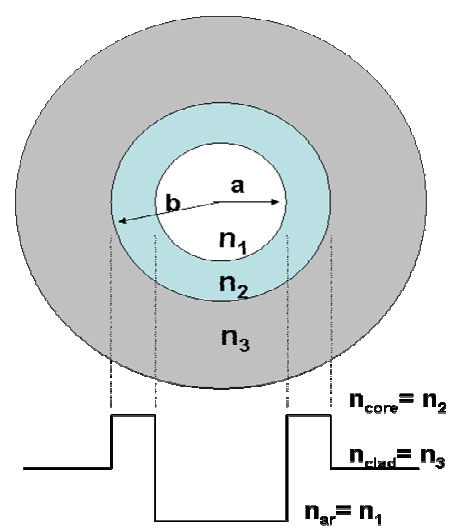

Figura 21. Esquemático da seção transversal da fibra HOF e o perfil de índice de refração.

Este tipo de fibra óptica, também chamado de fibra oca - do inglês 'hollow optical fiber $-H O F$, tem despertado a atenção dos pesquisadores devido às novas aplicações que essa configuração possibilita. Como exemplos, aplicação em projetos de fibras atuando como filtros passa-faixa [87], conversor de modo em banda larga em sistemas Gigabit Eternet [88], compensador de dispersão em modos de alta ordem [89], entre outras.

Os parâmetros utilizados nas simulações são: $\mathrm{n}_{1}=1,0, \mathrm{n}_{2}=1,452, \mathrm{n}_{3}=1,4471$, raio a $=$ $3,4 \mu \mathrm{m}$, raio $\mathrm{b}=25,0 \mu \mathrm{m}$, no comprimento de onda $\lambda=1,55 \mu \mathrm{m}$, com o passo de discretização $\Delta_{\mathrm{x}}=\Delta_{\mathrm{x}}=0,7 \mu \mathrm{m}$. Estes parâmetros resultam em uma fibra multimodo.

A Figura 22 apresenta: (a) a distribuição da componente de campo magnético do modo fundamental; (b-c) dos modos de primeira ordem $\mathrm{H}_{\mathrm{x}}$ e $\mathrm{H}_{\mathrm{y}}$; (d-e) dos modos de segunda ordem $\mathrm{H}_{\mathrm{x}}$ e $\mathrm{H}_{\mathrm{y}}$; (f) o contorno das componentes de campo magnético $\mathrm{H}_{\mathrm{x}}$. Na Tabela 2 estão listados os valores do índice efetivo encontrados pelo método IRAM, comparados com os valores analíticos apresentados em [86]. 


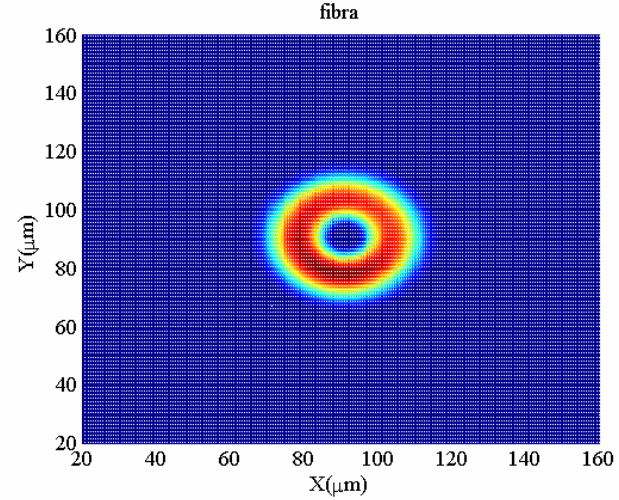

(a)

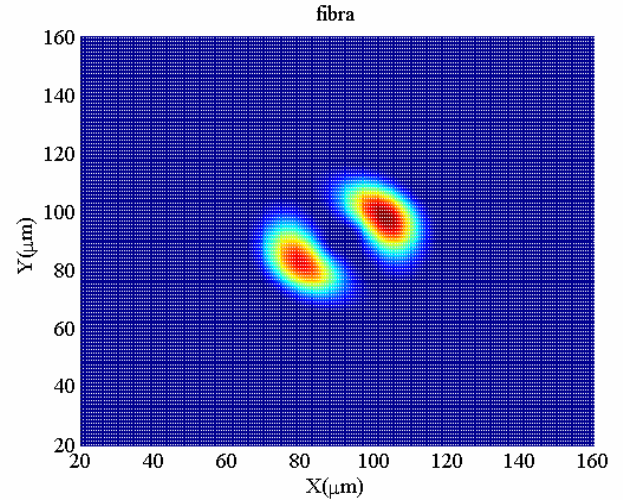

(b)

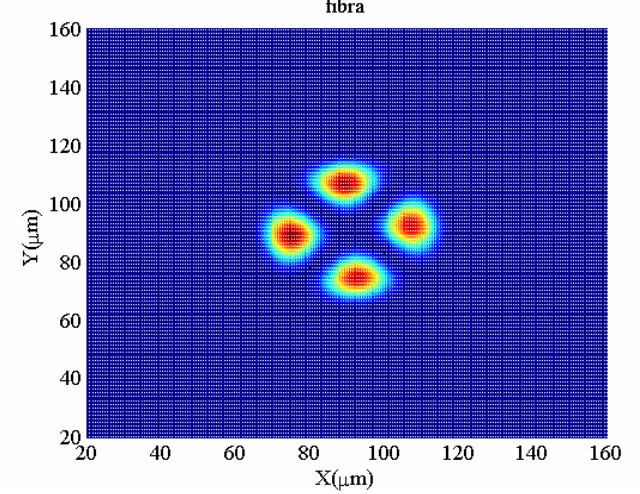

(d)

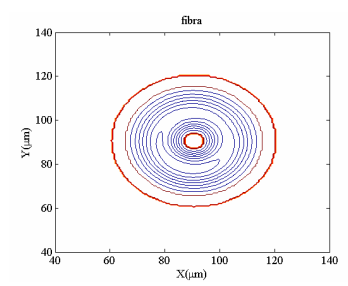

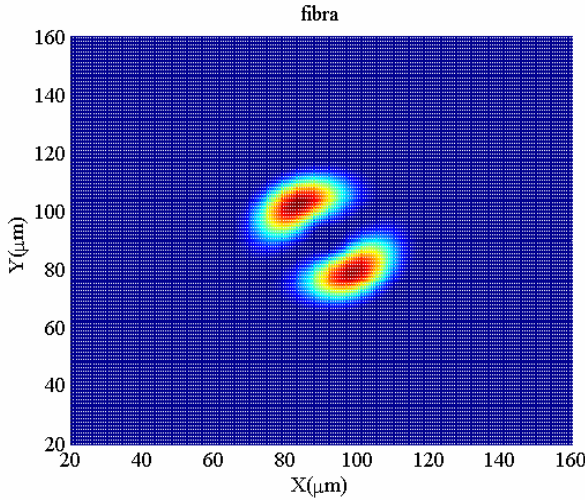

(c)

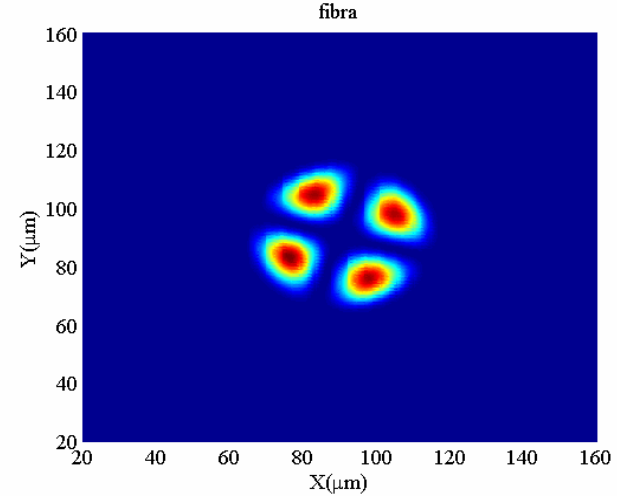

(e)

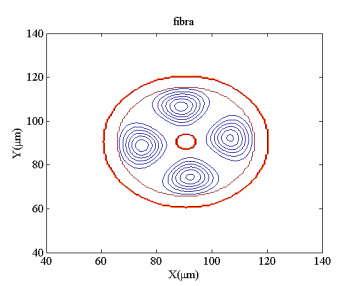

(f)

Figura 22. Componentes de campo magnético da fibra HOF. (a) modo fundamental, (b)-(c) primeiro modo $H_{x}$ e $H_{y}$, (d)-(e) segundo modo $H_{x}$ e $H_{y}$; (f) contornos da componente de campo $H_{x}$ de $a, b, d$, respectivamente. 
Como pode ser visualizado na Figura 22, e verificado na Tabela 2, os modos de mais alta ordem dessa fibra são modos degenerados, isto é, apresentam a mesma constante de propagação e a sua combinação (b-c) ou (d-e) forma um modo guiado na fibra [15].

Tabela 2: Comparação entre os valores do índice efetivo obtidos para a fibra HOF da componente de campo $H_{x}$ pelo método IRAM com os valores obtidos em [86].

\begin{tabular}{cccc}
\hline Modo & IRAM & Ref. [86] & Diferença* $^{*}$ \\
\hline fund. (a) & 1,451677 & 1,451670 & $4,82 \times 10^{-6}$ \\
\hline $1^{\circ}(\mathrm{b})$ & 1,451553 & 1,451547 & $4,13 \times 10^{-6}$ \\
\hline $1^{\circ}(\mathrm{c})$ & 1,451549 & 1.451545 & $4,20 \times 10^{-6}$ \\
\hline $2^{\circ}(\mathrm{d})$ & 1,451248 & 1,451243 & $3,44 \times 10^{-6}$ \\
\hline $2^{\circ}(\mathrm{e})$ & 1,451259 & 1,451243 & $1,10 \times 10^{-5}$ \\
\hline diferença $=\left(\mathrm{n}_{\text {eff Iram }}-\mathrm{n}_{\text {eff }[85]}\right) /\left(\mathrm{n}_{\text {eff Iram }}\right)$ &
\end{tabular}

Os resultados obtidos com o método IRAM implementado neste trabalho estão em plena concordância com os valores analíticos obtidos em [86], validando, portanto, o método implementado. Por fim, como visto nas Figuras 20 e 22 o método IRAM é capaz de fornecer a distribuição modal não só do modo fundamental, mas também de todos os modos de ordem superior. 


\section{Estudos em Fibras Ópticas Microestruturadas Convencionais}

Os capítulos anteriores apresentaram um embasamento teórico sobre as fibras ópticas microestruturadas, demonstrando algumas das características que as tornam atrativas em aplicações em comunicações ópticas. Ademais, foram detalhados e aferidos os métodos numéricos SOR e IRAM utilizados nas simulações das estruturas.

Este capítulo é subdivido em dois tópicos específicos, nos quais são descritas e investigadas as novas propostas e configurações para as fibras ópticas microestruturadas com geometria uniforme e para as fibras ópticas microestruturadas de dois núcleos.

Na primeira parte, é apresentada uma continuação do estudo desenvolvido em [38], onde foi proposta e investigada teoricamente uma fibra óptica microestruturada capaz de apresentar simultaneamente os efeitos de compensação de dispersão e amplificação Raman. Dando seqüência a este estudo, neste trabalho são apresentados os resultados experimentais obtidos para esta fibra. Este estudo tem a colaboração de dois centros de pesquisas, sendo o “Optical Fibre Technology Centre”, da Universidade de Sydney na Austrália, chefiados por J. Canning, responsável pela fabricação da fibra, e o "Centro de Pesquisa e Desenvolvimento em Telecomunicações - CPqD”, em Campinas, que cedeu os laboratórios para que fossem feitas as caracterizações experimentais desta fibra.

Em seguida, visto o grande interesse dos pesquisadores nas fibras ópticas microestruturadas de dois núcleos, é feito um estudo teórico do comportamento modal das fibras DC-MOFs. Neste estudo, a teoria dos modos acoplados foi utilizada para justificar uma nova interpretação do comportamento modal proposto para as DC-MOFs. 


\subsection{Fibra óptica microestruturada para compensação de dispersão e amplificação Raman}

Fibras ópticas compensadoras de dispersão (DCFs) são componentes fundamentais em sistemas de comunicações ópticas de alta velocidade. Com o fornecimento de um bombeio óptico adequado, torna-se possível induzir amplificação Raman e compensar as perdas da fibra compensadora de dispersão [90]. Como resultado, tem-se um módulo compensador de dispersão transparente, o qual melhora a margem e o orçamento de potência óptica do sistema. Uma desvantagem, ainda restante, resulta do fato de que a amplificação Raman convencional necessita de uma densidade de potência óptica relativamente alta e/ou um longo comprimento de interação.

Estas fibras podem fornecer valores altamente negativos para o coeficiente de dispersão, D, [91] assim como fornecer eficiente amplificação Raman em apenas algumas centenas de metros [92]. Estes resultados prometem amenizar as limitações expostas acima e têm motivado recentes investigações teóricas a respeito da associação de amplificação Raman e compensação de dispersão em MOFs [26], [93].

Como mencionado acima, o objetivo desta seção é investigar experimentalmente a MOF proposta por De Francisco [38] (no seu programa de doutorado) que estudou teoricamente a MOF atuando simultaneamente em amplificação Raman e na compensação da dispersão cromática. Embora reconhecendo a flexibilidade das fibras ópticas de dois núcleos [93], nas quais os parâmetros geométricos variam ao longo da seção radial da fibra, procurouse demonstrar que é possível obter resultados semelhantes utilizando uma fibra com geometria uniforme, reduzindo, deste modo, a complexibilidade de fabricação.

O projeto desta fibra encontra-se detalhado em [38]. A modelagem das propriedades da dispersão cromática para as fibras microestruturadas foi realizada pelo método da sobrerelaxação sucessiva (SOR) em diferenças finitas [74]. No projeto da fibra compensadora de dispersão, foram empregadas duas figuras de mérito, definidas como parâmetro $\mathrm{R}$, que quantifica a relação entre os coeficientes de dispersão da fibra compensadora com o da fibra presente no enlace óptico, e o fator $\mathrm{K}$, que mede a capacidade de compensação dos efeitos de dispersão sobre uma faixa de comprimentos de onda. Este parâmetro descreve a capacidade de 
compensação da dispersão sobre uma faixa de comprimentos de onda e deve ser o mesmo para a fibra compensadora e para a fibra do sistema. Estes fatores são descritos por [28]:

$$
R=-\frac{D_{c}\left(\lambda_{0}\right)}{D_{l}\left(\lambda_{0}\right)}
$$

onde $D_{c}$ e $D_{1}$ são, respectivamente, os coeficientes de dispersão da fibra compensadora e da fibra utilizada no enlace, enquanto:

$$
K=\frac{D_{c}\left(\lambda_{0}\right)}{S_{c}\left(\lambda_{0}\right)}=\frac{D_{l}\left(\lambda_{0}\right)}{S_{l}\left(\lambda_{0}\right)}
$$

onde $S_{c}$ e $S_{1}$ descrevem a inclinação das curvas de dispersão para a fibra compensadora e para a fibra utilizada no enlace, respectivamente.

$\mathrm{O}$ procedimento de projeto é maximizar o parâmetro $\mathrm{R}$ e adequar o parâmetro $\mathrm{K}$ ao sistema em questão [28]. Foram analisados diversos casos visando atingir os requisitos de projeto [38]. A MOF projetada apresenta os parâmetros geométricos $\Lambda=0,93 \mu \mathrm{m}$ e d=0,83 $\mu \mathrm{m}$, com a dispersão, $\mathrm{D}$, igual a $-473 \mathrm{ps} /(\mathrm{nm} \mathrm{km})$. Considerando que o coeficiente de dispersão, no comprimento de onda central da banda $\mathrm{C}$, para a fibra utilizada no enlace, é de 17,08 ps/(nm $\mathrm{km}$ ), resulta $\mathrm{um}$ valor de $\mathrm{R}$ de aproximadamente 27 . Isto significa que $3,6 \mathrm{~km}$ da fibra microestruturada projetada deve ser plenamente capaz de compensar a dispersão imposta em $100 \mathrm{~km}$ de um enlace WDM operando na banda C. As simulações também indicam que a área efetiva para essa fibra microestruturada projetada é de aproximadamente $1,65 \mu \mathrm{m}^{2}$, a qual é bastante reduzida, indicando, portanto, sua potencial aplicação em amplificação Raman.

Como os resultados teóricos mostraram-se promissores para a fibra atuando tanto na compensação da dispersão em banda larga como na amplificação Raman, vislumbrou-se a possível fabricação dessa fibra, a qual foi realizada no Optical Fibre Technology Centre, Unividade de Sydney, Austrália.

O primeiro passo para fabricação foi selecionar o número final de capilares na fibra microestruturada. Devido à pequena área efetiva dessa fibra em particular, as simulações numéricas indicam que são necessários pelo menos oito anéis para assegurar baixas perdas e manter a perda por confinamento menor do que as perdas por absorção intrínseca da sílica [94]. Entretanto, perdas aceitáveis ainda são conseguidas em configurações com seis ou sete anéis. Tendo em vista os esforços na montagem da preforma, decidiu-se realizar a fabricação 
inicial da fibra microestruturada a partir de uma preforma com seis anéis. Outra questão relevante é o controle da geometria da fibra, particularmente, tendo em vista a alta fração de ar requerida no projeto proposto. De fato, um dos maiores desafios para a fabricação das fibras MOFs é manter a uniformidade geométrica ao longo de todo o comprimento da fibra. Neste caso, a uniformidade geométrica é alcançada controlando-se a pressão durante o processo de puxamento [95]. Um resultado típico do controle na estrutura, fornecido por J. Canning, é apresentado na Figura 23 onde é mostrado o parâmetro d/ $\Lambda$ em função da pressão aplicada para duas seções transversais de uma mesma fibra tomados a 500 metros de distância um do outro.

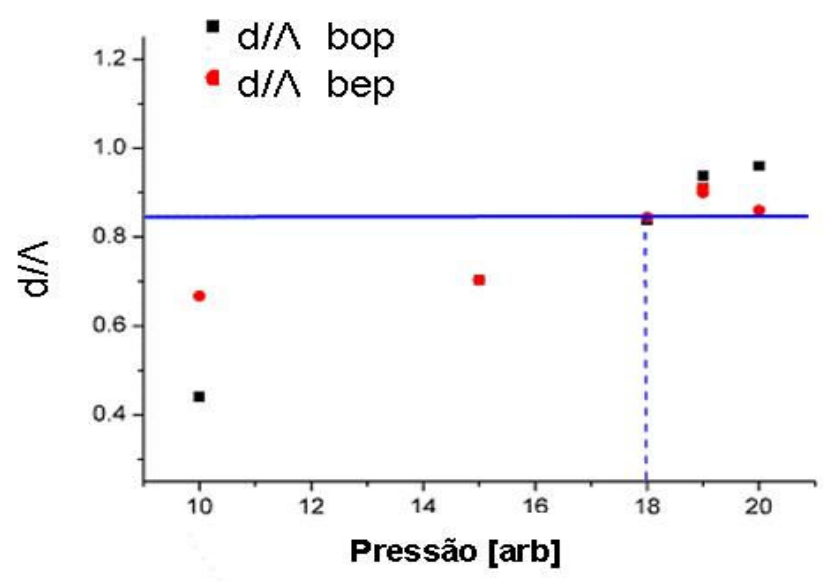

Figura 23. Parâmetro $d / \Lambda$ como função da pressão aplicada. BOP representa o corte transversal da fibra na posição de puxamento inicial, enquanto que, EOP representa o corte transversal da fibra localizado entre 100-500 metros ao longo do eixo de fibra. A linha azul representa a meta desejada.

A Figura 24 apresenta a fibra óptica microestruturada final fabricada com seis anéis capilares. 


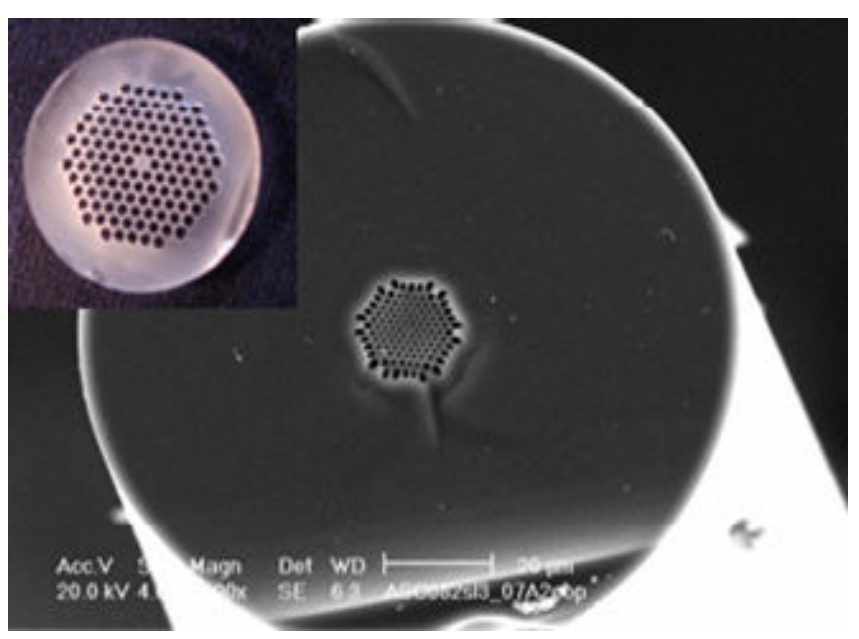

Figura 24. Imagem da seção transversal de $125 \mu \mathrm{m}$ da fibra microestruturada fabricada. No canto superior, a seção transversal da preforma à partir da qual a fibra foi puxada.

\subsection{1 - RESULTADOS EXPERIMENTAIS}

Considerando a relativa complexidade da estrutura da MOF, principalmente devido ao grande número de anéis e à alta fração de ar, a primeira geração fabricada desta fibra microestruturada, em particular, foi produzida com sílica de baixo grau de pureza. Por um lado, isso permite aperfeiçoar o processo de fabricação e manter baixos os custos envolvidos no projeto. Por outro lado, os resultados obtidos experimentalmente podem não apresentar valores tão próximos ao obtidos nas investigações numéricas.

Tendo em mente o exposto acima, a Figura 25 apresenta o espectro de potência medido na saída da fibra microestruturada quando bombeada por uma fonte em 1480nm com uma potência de 1,5Watt. A medida do espectro de potência de ruído demonstra que há uma possibilidade clara de amplificação Raman. De fato, há um pico nítido de espalhamento Raman ao redor do comprimento de onda em $1583 \mathrm{~nm}$. 


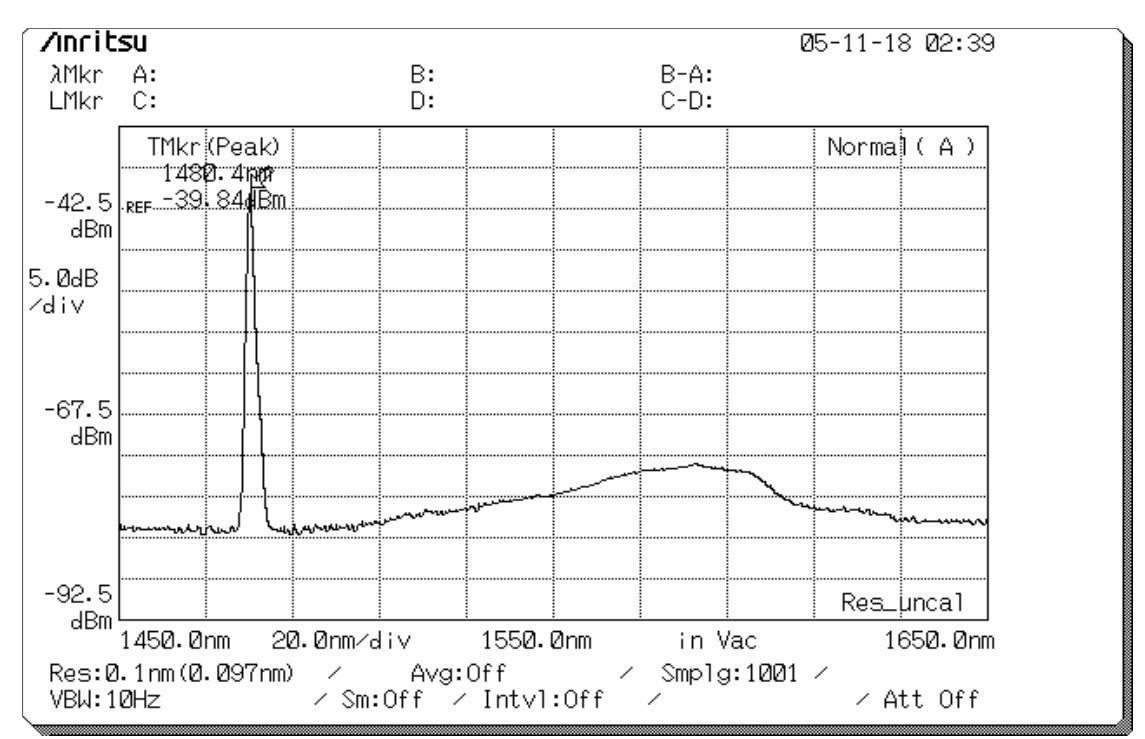

Figura 25. Espectro de potência na saída da fibra microestruturada para uma potência de bombeio (em 1480nm) de $1,5 \mathrm{~W}$.

Foi medido também o coeficiente de dispersão na MOF. Nesta verificação o coeficiente de dispersão apresentou-se negativo, conforme necessário para compensação de dispersão. Os valores medidos de D correspondem a uma variação de 70,52 ps/(nm km), para $1540 \mathrm{~nm}$, até $-124,31 \mathrm{ps} /(\mathrm{nm} \mathrm{km})$, para $1560 \mathrm{~nm}$.

Como o material (ś́lica) utilizado na fabricação deste primeiro protótipo apresentava um reduzido grau de pureza e, portanto, altas perdas, a caracterização completa do ganho Raman ficou prejudicada (o ganho "ON-OFF" se reduz a algo em torno de $1 \mathrm{~dB}$ ). No entanto, acredita-se que a presente caracterização experimental forneceu as diretrizes úteis para a validação do projeto. Portanto, este primeiro protótipo experimental da fibra microestruturada fabricada apresentou resultados experimentais consistentes em ambas as finalidades, compensação de dispersão e ganho Raman. Vale mencionar que existe planejamento para a retomada do trabalho, visando reproduzir a estrutura da Figura 24 em uma matriz de sílica com pureza adequada para uso em telecomunicações.

Todavia, devido às características de projeto, as fibras ópticas microestruturadas para compensação da dispersão apresentam uma área efetiva reduzida, no presente caso $\mathrm{A}_{\text {eff }}=1,65 \mu \mathrm{m}^{2}$. Isso facilita a excitação de efeitos não-lineares (entre eles o efeito Raman), mas também pode gerar dificuldades no acoplamento óptico com fibras convencionais. Sendo 
assim, diversos pesquisadores estão propondo como possível solução a utilização das fibras ópticas microestruturadas de dois núcleos [39]-[48], o que será objeto de estudo na seção a seguir.

\subsection{Acoplamento modal em fibras ópticas microestruturadas de dois núcleos}

Nos últimos anos, as fibras ópticas microestruturadas de dois núcleos têm sido amplamente investigadas devido às suas propriedades peculiares de propagação. Especificamente, as MOFs de dois núcleos têm sido extensamente pesquisadas para atuarem como fibras compensadoras de dispersão, pois apresentam um elevado coeficiente de dispersão negativo associado a uma área efetiva do núcleo favorável para aplicações práticas.

$\mathrm{O}$ interesse nas fibras ópticas microestruturadas de dois núcleos deve-se ao fato das MOFs com arranjo uniforme da rede cristalina, ou seja, com apenas um núcleo central, projetadas para compensação de dispersão, normalmente possuírem área efetiva pequena, conforme visto na seção anterior [45]. Buscando minimizar as perdas por acoplamento foram, então, desenvolvidas as fibras ópticas microestruturadas de dois núcleos [39]-[48]. As MOFs de dois núcleos, encontradas na literatura, além de apresentarem maior área efetiva do núcleo, também proporcionam pico de dispersão extremamente negativo.

O objetivo desta seção é investigar o comportamento do campo eletromagnético nas fibras ópticas microestruturadas de dois núcleos, principalmente na região em torno do comprimento de onda onde ocorre a transferência de energia entre o núcleo interno e o núcleo externo, uma vez que este é o fator determinante para se obter elevado pico de dispersão negativo. Para o estudo do comportamento modal das MOFs de dois núcleos utilizou-se da teoria dos modos acoplados [96]-[98].

Para isso, são consideradas três estruturas distintas, esquematizadas na Figura 26 com seus respectivos perfis de índice de refração: 
guia 1) fibra completa, composta com os dois núcleos, Figura 25(a);

guia 2) fibra formada apenas com o núcleo interno, Figura 25(b);

guia 3) fibra somente com o núcleo externo, Figura 25(c).
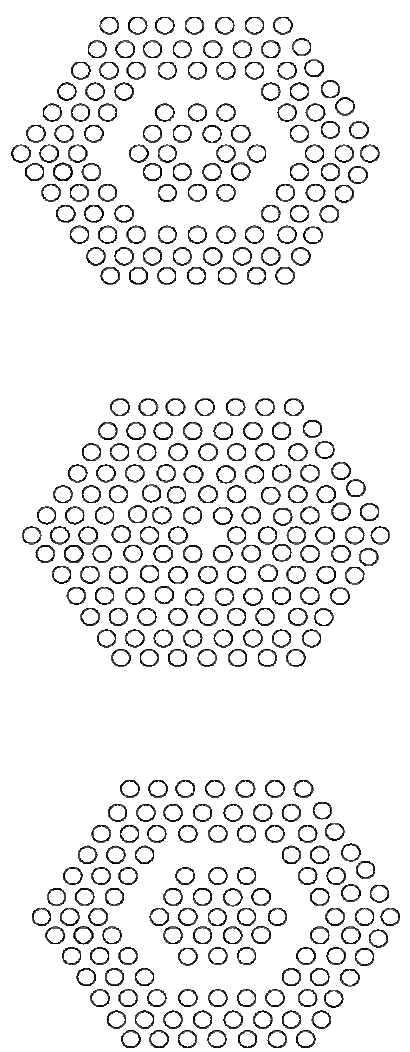

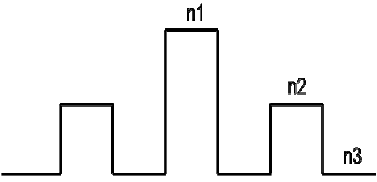

(a)

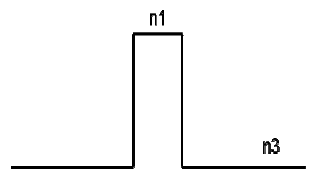

(b)

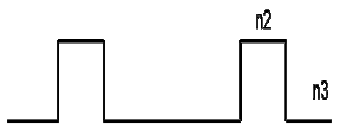

(c)

Figura 26. Esquemático das estruturas com os perfis de índice de refração médio. a) guia 1 estrutura da DC-PCF completa, b) guia 2 - núcleo interno, c) guia 3 - núcleo externo.

As MOFs de dois núcleos são estruturas compostas de dois núcleos concêntricos (conforme esquematizado na Figura 26(a)) e propagam dois supermodos. A propagação da onda nesta estrutura pode ser descrita com base nas equações de Maxwell.

Considerando o campo eletromagnético como em [96]:

$$
\Psi_{2,3}=A_{2,3} \exp ^{-j \beta_{2,3} z}
$$


onde, $A_{2,3}$ é a amplitude do campo, $\beta_{2,3}$ é a constante de propagação, e os índices 2 e 3 representam os campos eletromagnéticos guiados, respectivamente, no núcleo interno e externo, conforme Figura 26 (b) e (c).

O comportamento modal desta fibra, como função do comprimento de onda, pode ser descrito da seguinte forma: para comprimentos de ondas curtos o modo fundamental está bem confinado no núcleo interno. Em um comprimento de onda específico, denominado de comprimento de onda de casamento, $\lambda_{c}$, ocorre o casamento de fase, ou seja, $\beta_{2}=\beta_{3}$, e, nesse ponto, acontece o acoplamento entre o modo do núcleo interno para o núcleo externo. Em comprimentos de onda acima de $\lambda_{\mathrm{c}}$ o modo fundamental passa a ser guiado apenas no núcleo externo [39], [40].

Até o presente momento, as pesquisas com relação às MOFs de dois núcleos, atuando na compensação da dispersão cromática, sugerem que o pico negativo de dispersão é obtido quando ocorre essa transição abrupta do modo confinado no núcleo interno para o núcleo externo [43], [44]. Dessa forma, em comprimentos de onda menores que o comprimento de onda de casamento $\lambda_{c}$, o modo está muito bem comportado no núcleo interno. Por outro lado, em comprimentos de onda maiores que $\lambda_{\mathrm{c}} \mathrm{o}$ modo passa a existir apenas no núcleo externo.

Entretanto, analisando o comportamento modal dessas fibras nota-se que essa transição modal do campo do núcleo interno para o núcleo externo não ocorre dessa forma abrupta, mas sim de forma gradual [99]. Esta energia remanescente nos núcleos, até o presente momento, não foi abordada na literatura. Busca-se aqui, por meio da teoria dos modos acoplados [98], quantificar a energia remanescente associada a cada guia e analisar a sua contribuição no efeito da dispersão cromática. Assim, é possível demonstrar que essa transição de energia não ocorre de forma tão abrupta, em um determinado $\lambda_{c}$ específico.

Para esta análise serão consideradas três estruturas separadamente: a primeira é uma fibra de dois núcleos, com o núcleo interno e externo, conforme Figura 26(a), a segunda fibra apresenta somente o núcleo interno (Figura 26(b)) e a terceira é uma fibra contendo apenas o núcleo externo (Figura 26(c)).

Inicialmente, considera-se a estrutura completa, propagando os dois supermodos, definidos pelos índices 'e'(par) e 'o'(ímpar). Define-se, para o guia 1, o campo magnético fundamental par e ímpar conforme as equações (4.3) e (4.4) [96]: 


$$
\begin{aligned}
& H_{e}=A_{e} \exp ^{-j \beta_{e} z} \\
& H_{o}=A_{o} \exp ^{-j \beta_{o} z}
\end{aligned}
$$

onde, $A_{e, o}$ é a distribuição radial do campo e $\beta_{\mathrm{e}, \mathrm{o}}$ é a constante de propagação do modo par (e) e ímpar $(o)$.

Em seguida, define-se o campo magnético para os guias isolados 2 e 3 (Figura 26 (b) e (c)), conforme as equações (4.5) e (4.6)

$$
\begin{aligned}
& H_{1}=A_{1} \exp ^{-j \beta_{1} z} \\
& H_{2}=A_{2} \exp ^{-j \beta_{2} z}
\end{aligned}
$$

A distribuição radial do modo dos campos é obtida numericamente. Para isso, utilizouse o método IRAM para o cálculo dos autovalores e autovetores da fibra com dois núcleos, assim como o método da sobre-relaxação sucessiva SOR para o cálculo dos guias isolados.

Depois de calculada a distribuição radial, calculam-se os coeficientes modais pela solução não-ortogonal de modos acoplados, dadas pelas equações (4.7) e (4.8), conforme definido em [96]:

$$
\begin{aligned}
& b_{e 1}=-b_{o 2}=\frac{1}{\sqrt{2}} \sqrt{1-\frac{\Delta \beta}{\Delta S}} \\
& b_{e 2}=b_{o 1}=\frac{1}{\sqrt{2}} \sqrt{1+\frac{\Delta \beta}{\Delta S}}
\end{aligned}
$$

onde a variação da constante de propagação, $\Delta \beta$, é dada pela equação (4.9):

$$
\Delta \beta=\beta_{2}-\beta_{1}
$$

o coeficiente de acoplamento, $C_{k}$, para comprimento de onda $\lambda_{0}$, é definido em (4.10)

$$
C_{k}=\frac{\beta_{e}-\beta_{o}}{2}
$$

e, por fim, define-se um parâmetro auxiliar $S$, conforme equação (4.11)

$$
S=\sqrt{\left(\frac{\Delta \beta}{2}\right)^{2}+C_{k}^{2}}
$$


Com isso, é possível quantificar a fração de energia de cada modo em função do comprimento de onda.

Para a aplicação da teoria desenvolvida acima, foi escolhida uma fibra óptica microestruturada de dois núcleos similar à fibra da referência [45]. Os parâmetros utilizados são: $\Lambda=6,65 \mu \mathrm{m}$ com $\mathrm{d} / \Lambda=0,45$. O núcleo interno possui diâmetro igual a $5,018 \mu \mathrm{m}$, ligeiramente dopado com germânio, com índice de refração em $\lambda=1550 \mathrm{~nm}$ de $\mathrm{n}_{\mathrm{cl}}=1,446724$. O passo de discretização utilizado foi $\Delta_{\mathrm{x}}=\Delta_{\mathrm{y}}=0,35 \mu \mathrm{m}$.

A Figura 27 apresenta a evolução do índice efetivo dos modos em função do comprimento de onda para as três estruturas ilustradas na Figura 26. As curvas preta e verde representam, respectivamente, o supermodo par e ímpar do guia 1, as curvas azul e vermelha, por sua vez, referem-se ao modo fundamental dos guias 2 e 3, respectivamente. Os parâmetros dessa fibra foram escolhidos de forma a apresentar o comprimento de onda de casamento próximo a $1550 \mathrm{~nm}$ e, conseqüentemente, atuar como fibra compensadora de dispersão em torno deste comprimento de onda.

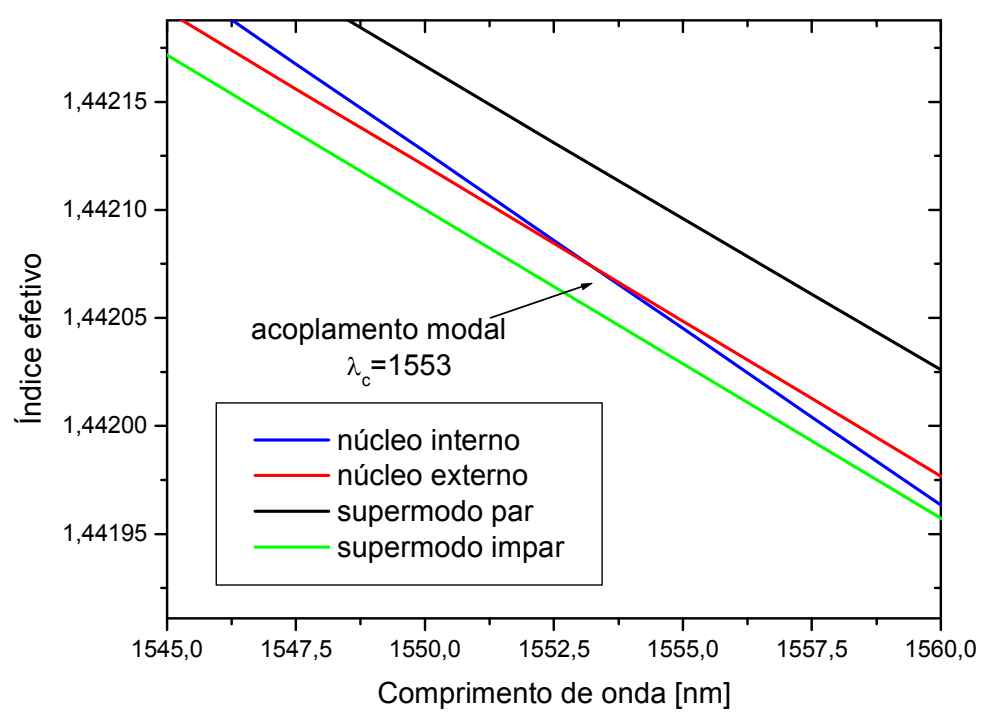

Figura 27. Variação do índice efetivo dos guias em função do comprimento de onda.

Como comentando anteriormente, o campo eletromagnético em comprimentos de onda abaixo do comprimento de onda de casamento, neste caso $\lambda_{\mathrm{c}}=1553 \mathrm{~nm}$, está confinado no núcleo interno da fibra. No entanto, em $\lambda_{\mathrm{c}}$ ocorre o acoplamento óptico entre o núcleo interno 
e o núcleo externo [39], [40]. Pode-se visualizar no gráfico da Figura 27 que o comprimento de onda $\lambda_{c}$, onde as curvas em azul e vermelho se cruzam, é o ponto exato onde ocorre o casamento de fase $\left(\beta_{2}=\beta_{3}\right)$. Assim, a escolha apropriada dos parâmetros geométricos pode deslocar o comprimento de onda de casamento e modificar a curva de dispersão.

Conforme pode ser observado na Figura 28, em comprimentos de onda menores que o comprimento de onda de casamento, $\lambda_{\mathrm{c}}$, existe uma parcela de energia sendo guiada no núcleo externo (curva em vermelho), e de forma análoga, após o acoplamento, resta uma parcela de energia sendo guiada no núcleo interno (curva em preto).

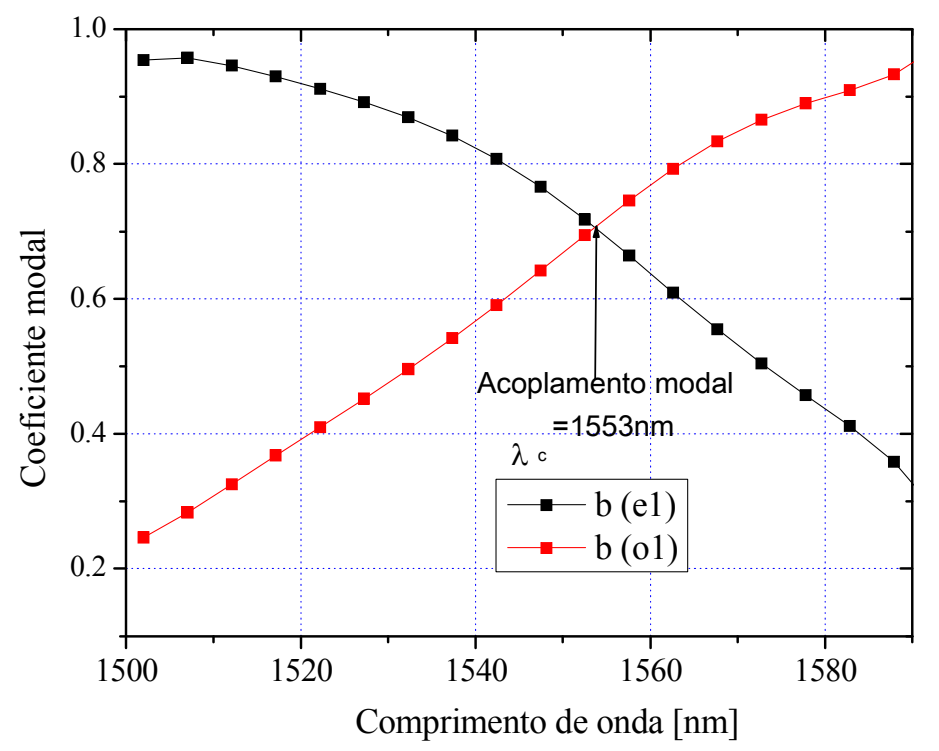

Figura 28. Coeficiente modal em função do comprimento de onda.

Analisando a Figura 28, verifica-se que o modo estritamente confinado no núcleo interno ou no núcleo externo não existe. O que realmente ocorre é a existência do modo com parcelas de energia distribuídas simultaneamente, em diferentes quantidades, entre os dois núcleos. $\mathrm{O}$ acoplamento modal ocorre quando a energia do modo presente no núcleo interno reduz-se a aproximadamente $70 \%$ do seu valor inicial. Nesse ponto então, o campo eletromagnético passa a ser guiado no núcleo externo, porém, ainda com parte da energia sendo guiada no núcleo interno. Consequentemente, os dois supermodos nas vizinhanças de $\lambda_{c}$ não podem ser estudados independentemente, pois a energia dos modos está distribuída nos dois núcleos. Logo, a energia do modo presente em um núcleo irá transferir-se gradualmente para o outro núcleo. 
Como a intenção ao se trabalhar com as MOFs de dois núcleos é projetar uma fibra compensadora de dispersão e, ainda assim, manter uma grande área efetiva do núcleo, torna-se fundamental ajustar $\lambda_{\mathrm{c}}$ para o comprimento de onda no qual se deseja compensar a dispersão. Um dos parâmetros que influenciam a posição do $\lambda_{c}$ é a relação entre o diâmetro dos capilares, $d$, e o espaçamento, $\Lambda,(f=d / \Lambda)$. A Figura 29 apresenta as curvas dos coeficientes modais, $b_{e l}$ e $b_{e 2}$, para duas fibras microestruturadas de dois núcleos com fatores distintos, $f=0,85$ e $f=$ 0,45 .

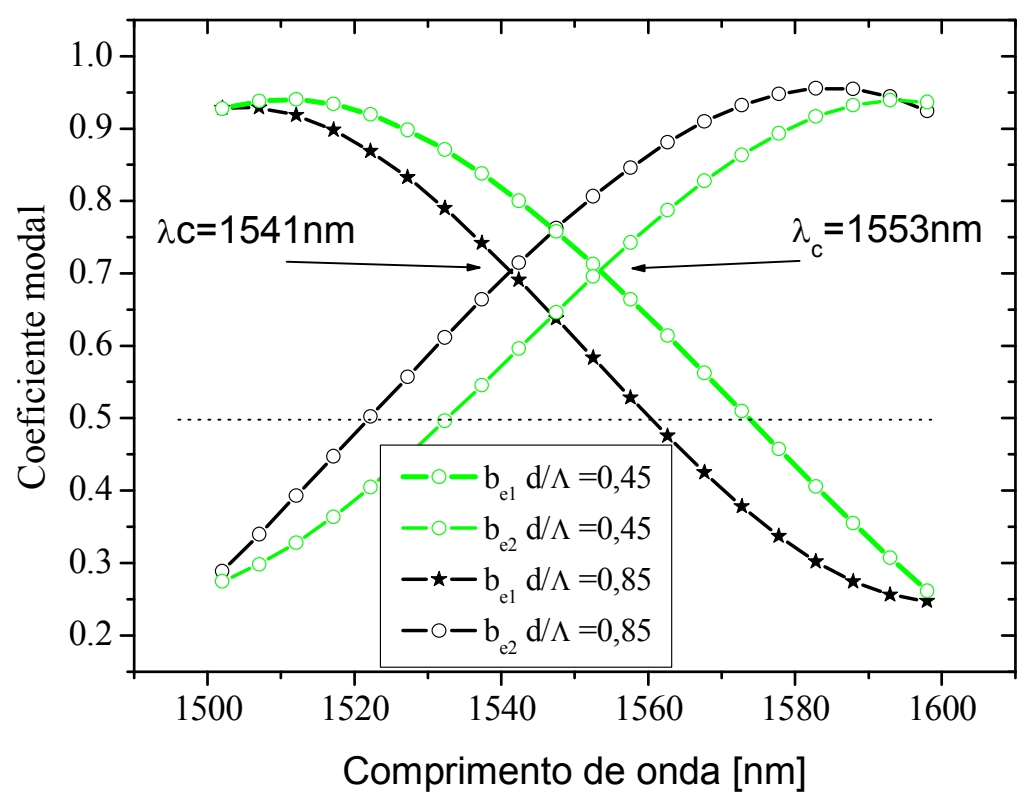

Figura 29. Evolução do coeficiente modal em função do comprimento de onda para diferentes $f$.

Símbolos cheio $\mathrm{f}=\mathbf{0 , 4 5}$, símbolos vazados $\mathrm{f}=\mathbf{0 , 8 5}$.

Analisando a Figura 29, verifica-se que a escolha adequada do fator ' $f$ ' é fundamental para o ajuste do $\lambda_{\mathrm{c}} \mathrm{e}$, consequentemente, para a sintonia do pico negativo de dispersão. Aumentar ' $f$ 'significa aumentar o confinamento modal, o que, por sua vez, desloca o acoplamento modal para comprimentos de ondas mais curtos.

Por fim, exemplificando a discussão acima, as Figura 30 e 31 apresentam, respectivamente, o comportamento da componente de campo magnético $\mathrm{H}_{\mathrm{x}}$ dos supermodos par e ímpar, em três diferentes comprimentos de onda: (a) $1500 \mathrm{~nm}$, (b) $1550 \mathrm{~nm}$ e (c) $1600 \mathrm{~nm}$. 

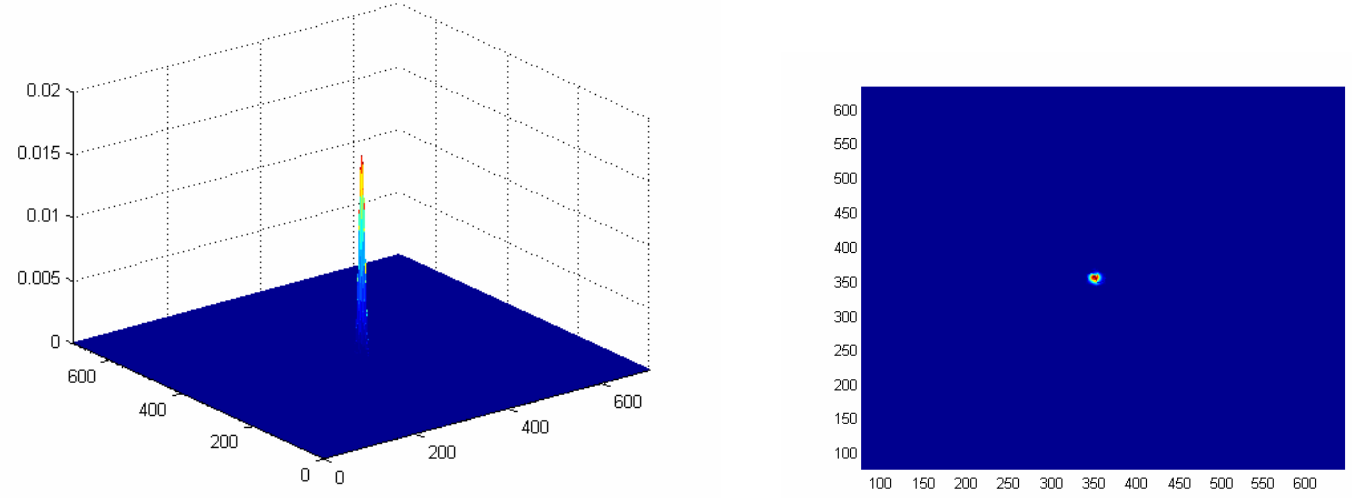

(a)
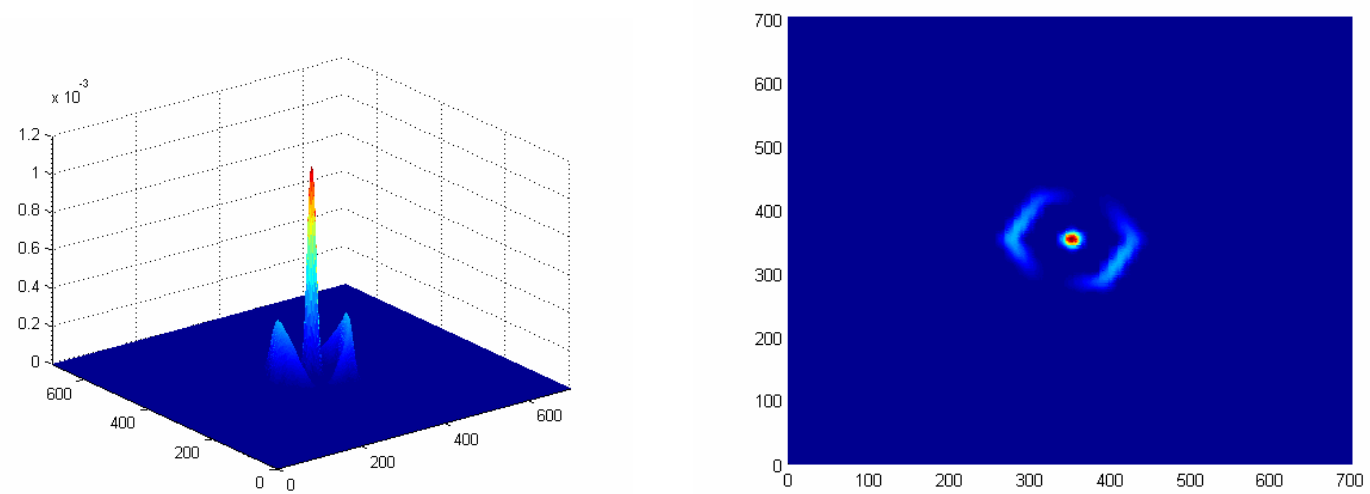

(b)
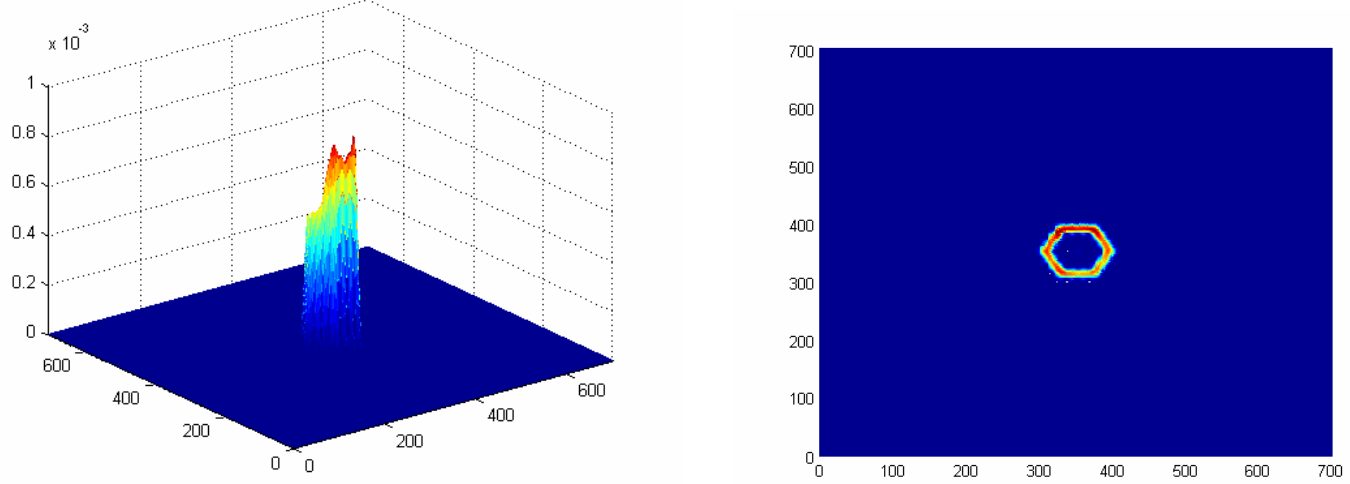

(c)

Figura 30. Componente de campo $H_{x}$ do supermodo par. (a) $\lambda=1500 \mathrm{~nm}$, (b) $\lambda=1550 \mathrm{~nm}$ e (c) $\lambda=1600 \mathrm{~nm}$. 

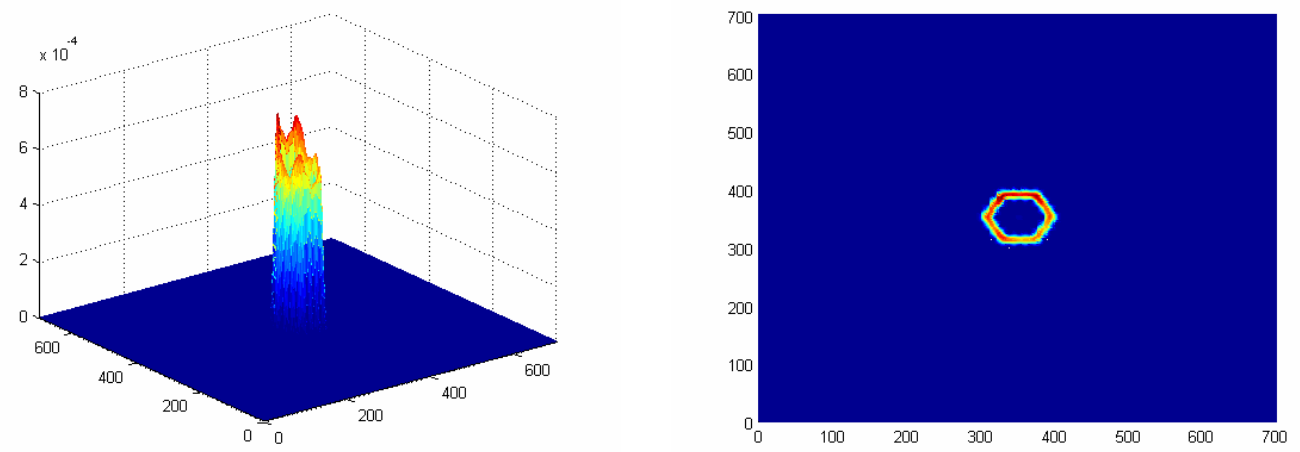

(a)
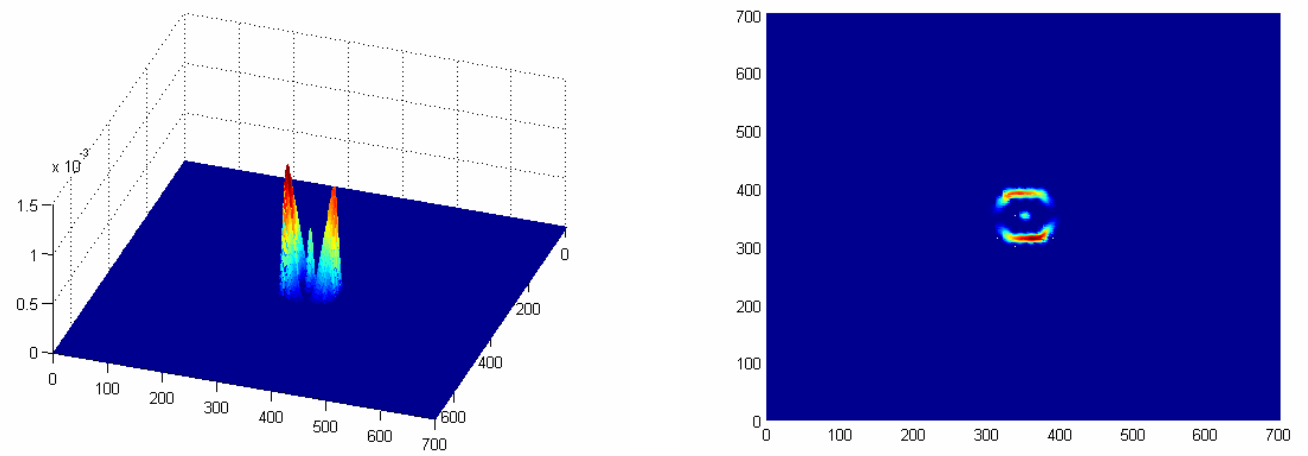

(b)
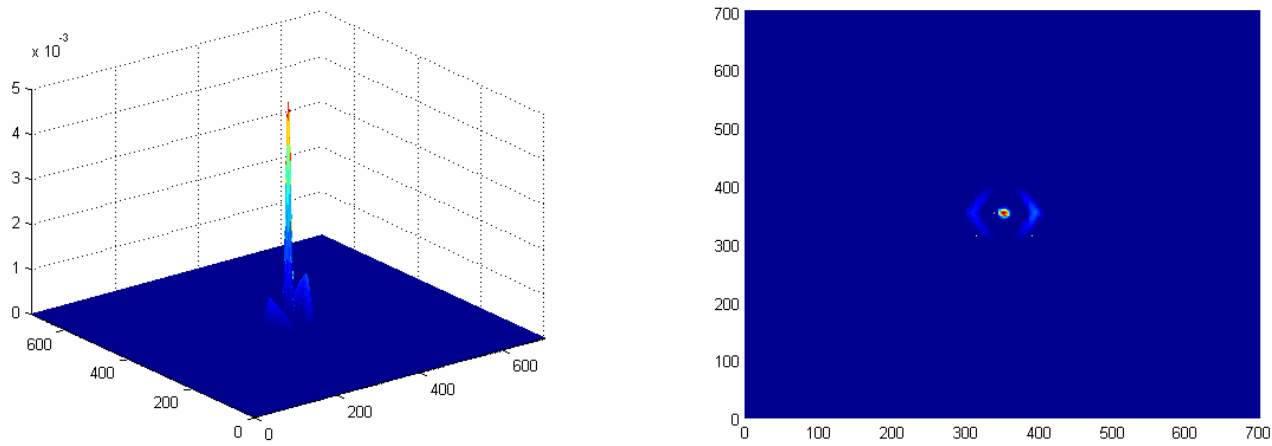

(c)

Figura 31. Componente de campo $H_{x}$ do supermodo ímpar. (a) $\lambda=1500 \mathrm{~nm}$, (b) $\lambda=1550 \mathrm{~nm}$ e (c) $\lambda=1600 \mathrm{~nm}$. 
Na Figura 30(a), $\lambda=1500 \mathrm{~nm}$, o campo está com a maior parcela de energia no núcleo interno. Na Figura 30(b), $\lambda=1550 \mathrm{~nm}$, ocorre uma redistribuição da energia do campo entre os núcleos interno e externo. Já na Figura $30(\mathrm{c}), \lambda=1600 \mathrm{~nm}$, verifica-se que o campo está com a maior parte de sua energia distribuída no núcleo externo. De maneira análoga, a Figura 31 apresenta o comportamento do supermodo ímpar. Neste caso, ocorre uma inversão na distribuição de energia. O campo em 1500nm está com a maior parte da energia distribuída no núcleo externo (Figura 31(a)). Em1550nm ocorre uma distribuição parcial da energia entre os núcleos interno e o externo (Figura 31(b)). E, por fim, em 1600nm, a maior parte da energia do campo está confinada no núcleo interno. 


\section{Proposição e análise de fibras ópticas microestruturadas tipo D}

Neste capítulo são investigadas as fibras ópticas microestruturadas com geometria tipo D, definidas, simplesmente, como D-MOFs. Inicialmente, as geometrias tipo D foram utilizadas nas fibras ópticas convencionais, particularmente em aplicações como sensores [100], onde manter o controle do estado de polarização é importante. Apenas recentemente, em meados de 2005, foram produzidas MOFs com perfil D, projetadas para atuar como filtros sintonizáveis em banda larga [101], [102], ou como acopladores direcionais ajustáveis [103]. Porém, é a primeira vez que se investigam as MOFs tipo D atuando ou como fibras compensadoras de dispersão ou como fibras altamente birrefringentes.

As primeiras D-MOFs foram fabricadas pela técnica do polimento lateral [101]-[103]. Esta técnica é incapaz de produzir fibras com longos comprimentos (e com qualidade desejada na compensação da dispersão), pois, como resultado do processo de fabricação, rugosidades são introduzidas na região do polimento, acarretando perdas por espalhamento [103]. Sugerese, portanto, que as fibras MOFs com perfil tipo $\mathrm{D}$, aqui propostas, sejam produzidas utilizando a já conhecida técnica de empilhamento e puxamento "stacking and drawing" [104]. Esta técnica consiste no empilhamento dos capilares dentro da jaqueta, de forma que o perfil D possa ser obtido, como desejado, durante a montagem da preforma. A metade superior dentro da jaqueta não é ocupada pelos capilares, por isso, um grande túnel de ar será criado nessa região, com a jaqueta sendo preservada ao longo de todo o comprimento, conforme exemplificado na Figura 32. Durante o processo de puxamento, faz-se necessário manter um cuidadoso controle da pressão exercida no interior do túnel e dos capilares, de modo a impedilos de colapsar (sobretudo o túnel) [104]-[106]. Esta técnica de empilhamento e puxamento, utilizada na fabricação das MOFs, evoluiu consideravelmente nos últimos anos, possibilitando a vários grupos de pesquisa obter, com sucesso, fibras MOFs com geometrias extremamente complexas [60]-[62], [68], [106], [107]. 


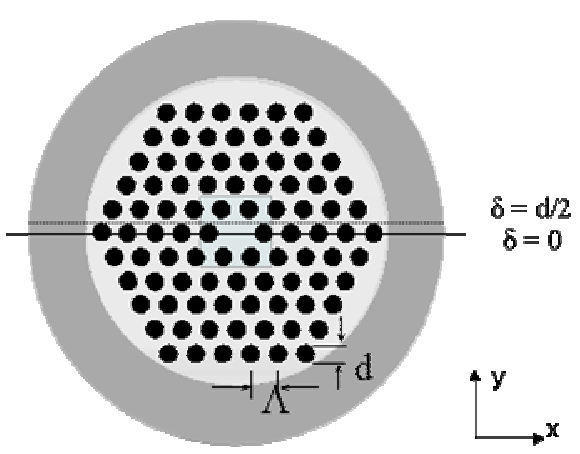

(a)

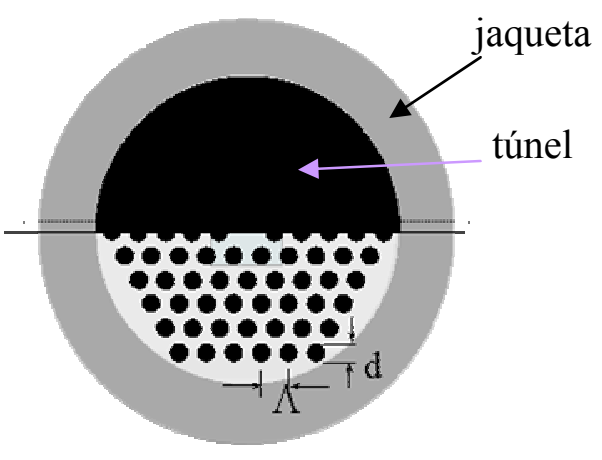

(b)

Figura 32. Fibra óptica microestruturada. (a) MOF convencional; (b) D-MOF.

Como pode ser observado na Figura 32(b), neste tipo de estrutura forma-se um túnel de ar entre a região guiada e a casca. Uma das possibilidades vislumbradas para essa estrutura é a sua utilização em aplicações como sensores, pois pode-se preencher a região de ar com amostras de líquidos ou gases e analisar o comportamento dessa amostra via campo evanescente.

Uma das vantagens já discutidas no projeto das MOFs é a possibilidade de modificar sua geometria alterando a razão entre o diâmetro dos capilares, $d$, e o espaçamento entre eles, $\Lambda,(f=d / \Lambda)$. Esta característica das MOFs fornece um enorme grau de liberdade no projeto de novos dispositivos, incluindo o manejo da dispersão cromática e o controle da birrefringência. Particularmente, as MOFs vêm se mostrando uma estrutura apropriada na investigação de efeitos não-lineares, particularmente na geração de supercontínuo [71], [107].

Como se sabe, as fibras MOFs podem ser caracterizadas pelos parâmetros físicos $\left(\mathrm{n}_{\mathrm{c}}\right.$, $\mathrm{n}_{\mathrm{cl}}$ ) e geométricos $(\mathrm{d}, \Lambda)$. Já, as fibras microestruturadas com perfil $\mathrm{D}, \mathrm{D}-\mathrm{MOFs}$, permitem um grau de liberdade adicional ao projeto, pois a posição do corte, $\delta$, também pode ser deslocada, conforme ilustrado na Figura 33. Neste trabalho, o espaçamento, $\Lambda$, e a relação, $d / \Lambda$, foram escolhidos considerando as dimensões práticas de fabricação das MOFs encontradas na literatura. O corte, $\delta$, foi investigado variando de $\delta=0$, Figura 33(a), onde o núcleo da fibra é reduzido pela metade, até um corte onde a região do núcleo é preservada completamente, $\delta>\Lambda$, Figura 33(b). 


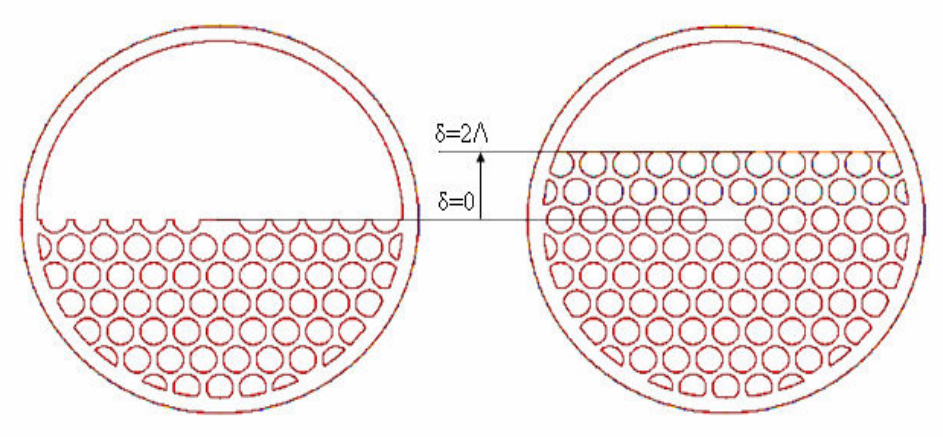

(a)

(b)

Figura 33. Seção transversal da D-MOF (a) $\delta=0$ (b) $\delta=2 \Lambda$

Em todos os casos investigados o índice de refração da sílica foi obtido via equação de Sellmeier [20]:

$$
n_{S I L}(\lambda)=\left[1+\sum_{i=1}^{3} \frac{B_{i} \omega_{i}^{2}}{\omega_{i}^{2}-\omega_{\lambda}^{2}}\right]^{1 / 2}
$$

onde: $\omega_{i}$ é a freqüência de ressonância, $B_{i}$ é a intensidade da i-ésima ressonância, $\mathrm{B}_{1}=0,6961663, \quad \mathrm{~B}_{2}=0,4079426, \quad \mathrm{~B}_{3}=0,8974794, \quad \mathrm{~L}_{1}=0,0684043 \times 10^{-6}, \quad \mathrm{~L}_{2}=0,1162414 \times 10^{-6}$, $\mathrm{L}_{3}=9,896161 \times 10^{-6}$, com $\omega_{\mathrm{i}}=2 \pi \mathrm{c} / \mathrm{L}_{\mathrm{i}}, \omega_{\lambda}=2 \pi \mathrm{c} / \lambda$, e c é a velocidade da luz no vácuo.

Neste capítulo, primeiramente, são apresentados os resultados obtidos com as D-MOFs projetadas para compensação da dispersão, seguidos de um estudo das D-MOFs altamente birrefringentes, finalizando com as D-MOF projetadas para apresentar dispersão plana e alta birrefringência. Particularmente, neste último estudo, as fibras ópticas microestruturadas tipo $\mathrm{D}$ foram preenchidas com diferentes materiais.

\subsection{D-MOF compensadora de dispersão}

Uma das principais questões em sistemas de comunicações ópticas de alta velocidade é o alargamento temporal do pulso óptico causado pela dispersão cromática. Este problema torna-se ainda mais relevante com o aumento do número de canais WDM. Faz-se necessário, portanto, recorrer a dispositivos capazes de compensar a dispersão em banda larga. 
Para se projetar corretamente fibras compensadoras de dispersão em banda larga, é fundamental o ajuste dos parâmetros R e K, definidos nas equações (4.1) e (4.2), respectivamente.

As D-MOFs foram simuladas pelo método em diferenças finitas da sobre-relaxação sucessiva - SOR, na formulação vetorial completa de campo H [74]. A análise modal foi feita em termos das polarizações horizontal $\left(\mathrm{H}_{\mathrm{x}}\right)$ e vertical $\left(\mathrm{H}_{\mathrm{y}}\right)$. Com base neste algoritmo, foram calculadas as constantes de propagação $\beta_{\mathrm{x}}$ e $\beta_{\mathrm{y}}$, para os modos com polarização horizontal e vertical, seus respectivos índices efetivos, assim como suas distribuições de campo.

A dispersão cromática, por sua vez, pode ser calculada numericamente por [44]:

$$
D_{c}=-\frac{\lambda}{c} \frac{\partial^{2} n_{e f f}(\lambda)}{\partial \lambda^{2}} \text {, }
$$

onde, $c$ é a velocidade da luz no vácuo e $\mathrm{n}_{\mathrm{eff}}=\beta / \mathrm{k}_{0}$. A dependência do índice de refração em função do comprimento de onda também foi considerada nesse formalismo.

A D-MOF investigada é composta por cinco anéis, com os capilares ordenados em rede hexagonal, conforme a Figura 33(a). A distância entre os centros dos capilares, $\Lambda$, igual a $1,6 \mu \mathrm{m}$ com a relação $\mathrm{d} / \Lambda$ variando de 0,65 a 0,90 . Estes parâmetros foram os que se mostraram mais adequados no projeto em estudo. Já, com relação à distância do corte, foram simuladas duas situações. Na primeira posição, o corte é mantido no eixo central, $\delta=0$, e na segunda, o corte é deslocado de $0,2 \mu \mathrm{m}$. No caso de $\delta$ deslocado, não foram obtidos resultados relevantes, isto é, a fibra não apresentou valores de dispersão adequados ao projeto de fibras compensadoras de dispersão, pois com $\delta>0,2 \mu \mathrm{m}$ o efeito da assimetria do núcleo não altera significantemente os valores do índice efetivo. Por isso, no decorrer desta seção serão comentados somente os resultados $\operatorname{com} \delta=0$.

Nos casos investigados, as D-MOFs possuem a relação $d / \Lambda$, respectivamente, iguais a: $0,875,0,75$ e 0,6875 , com o passo de discretização mantido abaixo de $0,05 \mu \mathrm{m}$. Sabe-se que quanto menor a relação $\mathrm{d} / \Lambda$, menor é o confinamento do campo. Como a D-MOF proposta apresenta metade do núcleo de uma MOF regular, o efeito dessa redução na geometria da área efetiva modal é extremamente significante. A Figura 34 apresenta a área efetiva modal em função do comprimento de onda para três casos investigados. As linhas pontilhadas com símbolos vazados representam a fibra MOF sem o corte $\delta$, ou seja, como se fosse um MOF 
convencional, as linhas sólidas com símbolos cheios representando a D-MOF com o corte na posição $\delta=0$.

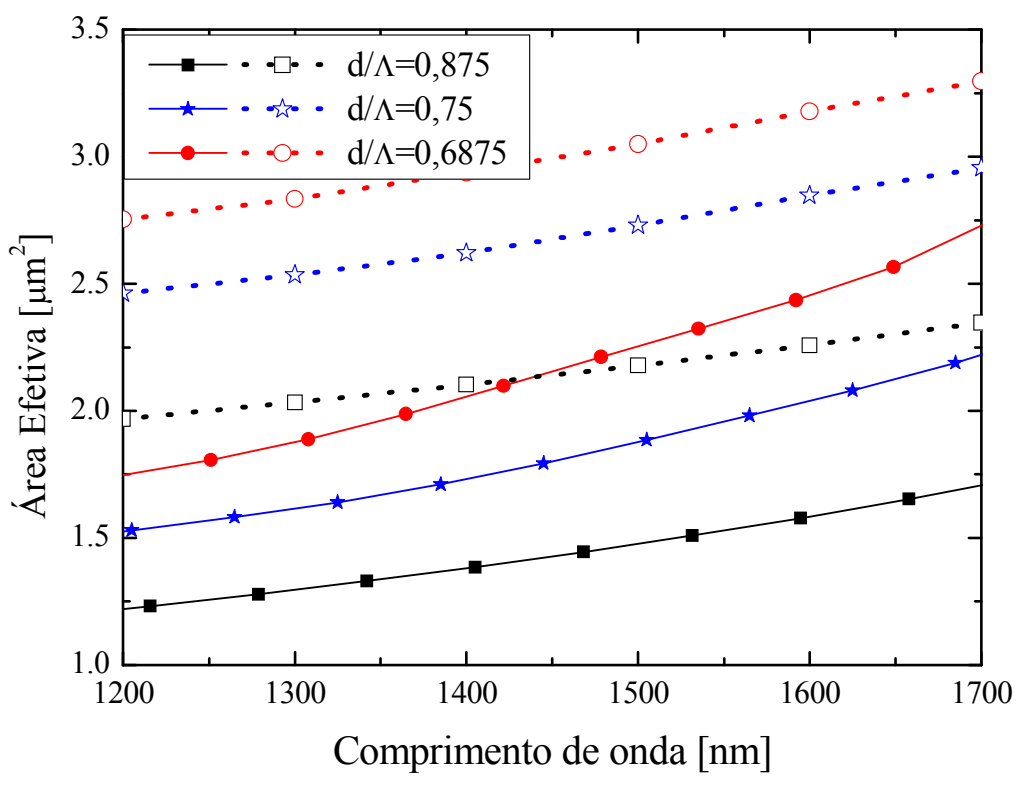

Figura 34. Área efetiva em função do comprimento de onda. Fibra MOF convencional linhas pontilhadas e símbolos vazados, D-MOF linhas sólidas com símbolos cheios.

Os valores obtidos para a área efetiva das D-MOFs são certamente menores do que aqueles obtidos com as MOFs de dois núcleos [44]. Entretanto, comparando com as MOFs de geometria convencional projetadas para compensação de dispersão, como, por exemplo, a MOF proposta por Chen [28], as D-MOFs aqui investigadas possuem praticamente a mesma área efetiva, ou seja, em $1550 \mathrm{~nm}, \mathrm{~A}_{\mathrm{eff}} \approx 1,5 \mu \mathrm{m}^{2}$.

No projeto de fibras ópticas compensadoras de dispersão em banda larga é necessário determinar os parâmetros $\mathrm{R}$ e K, conforme discutido anteriormente na seção 4.1. O objetivo é maximizar o parâmetro $\mathrm{R}$ e ajustar o fator $\mathrm{K}$, de modo que seu valor esteja tão próximo quanto possível do valor da fibra cuja dispersão necessita ser compensada, isto é, a fibra do enlace óptico. A fibra óptica adotada neste sistema é suposta como a SMF-28 [28], considerada aqui como sendo a fibra do enlace óptico. A fibra SMF-28, no comprimento de onda de $1550 \mathrm{~nm}$, possui: $\mathrm{K}=301,8 \mathrm{~nm}, \mathrm{D}_{\mathrm{s}}=+17,08 \mathrm{ps} /(\mathrm{nm} \mathrm{km})$, e $\mathrm{S}_{\mathrm{s}}=+0,056 \mathrm{ps} /\left(\mathrm{nm}^{2} \mathrm{~km}\right)$ [28]. Os parâmetros calculados de $\mathrm{R}$ e de $\mathrm{K}$ da D-MOF, obtidos para ambos os estados de polarização e para as três geometrias $(\mathrm{d} / \Lambda=0,875,0,75$ e 0,6875$)$ estão listados na Tabela 3 . 
Tabela 3: Projeto para compensação em banda larga. Bandas C e L (1530 - 1610nm).

\begin{tabular}{ccccc}
\hline \multirow{2}{*}{ Polarização } & \multirow{\Lambda}{*}{$\boldsymbol{\mu \mathbf { m } ]}$} & $\mathbf{d} / \boldsymbol{\Lambda}$ & $\begin{array}{c}\text { Parâmetro } \\
\mathbf{K}\end{array}$ & $\begin{array}{c}\text { Parâmetro } \\
\mathbf{R}\end{array}$ \\
\hline \hline $\mathbf{y}$ & 1,6 & 0,875 & 95 & 3,2 \\
\hline $\mathbf{y}$ & 1,6 & 0,750 & 153 & 4,7 \\
\hline $\mathbf{y}$ & 1,6 & 0,6875 & 205 & 8,0 \\
\hline $\mathbf{x}$ & 1,6 & 0,875 & 170 & 13.8 \\
\hline $\mathbf{x}$ & 1,6 & 0,750 & 208 & 16,1 \\
\hline $\boldsymbol{x}$ & 1,6 & 0,6875 & 288 & 32,2 \\
\hline
\end{tabular}

Analisando os resultados da Tabela 3 verifica-se que a estrutura que possui os valores que mais se aproximam dos parâmetros da fibra óptica do sistema é a D-MOF com polarização $\mathrm{x}, \Lambda=1,6 \mu \mathrm{m}$ e $\mathrm{d} / \Lambda=0,6875$. A D-MOF com esta geometria possui um coeficiente de dispersão cromática $\mathrm{D}=-550 \mathrm{ps} /(\mathrm{nm} \mathrm{km}) \mathrm{em} \lambda=1550 \mathrm{~nm}$. Foi verificado que esta estrutura pode ser utilizada como uma fibra compensadora de dispersão, atuando, simultaneamente, nas bandas $\mathrm{C}$ e L. Analisando o valor de $\mathrm{R}(\mathrm{R}=32,2)$ verifica-se que, aproximadamente $3,1 \mathrm{~km}$ da D-MOF seriam necessários para compensar a dispersão cromática imposta em um enlace de $100 \mathrm{~km}$ da fibra SMF-28.

No entanto, analisando os resultados apresentados acima, verifica-se que é possível aumentar o pico negativo de dispersão diminuindo o confinamento modal. K. Saitoh e M. Koshiba [110] propuseram uma MOF com um pequeno capilar inserido na região central da fibra, de forma a reduzir o confinamento de campo na região do núcleo. Saitoh investigou uma MOF com dispersão ultra-plana e com baixas perdas por confinamento.

Assim, foram investigadas diferentes configurações para as D-MOFs com a presença de um pequeno capilar central de raio $r_{c}$. A Figura 35 apresenta os valores da dispersão calculados para as fibras D-MOFs com polarização horizontal, $\Lambda=1,6 \mu \mathrm{m}$ e $d / \Lambda=0,6875$, respectivamente: sem o capilar central (linha preta), com o capilar central de raio $r_{c}=0,10 \mathrm{r}$ (linha azul) e $\mathrm{r}_{\mathrm{c}}=0,25 \mathrm{r}$ (linha vermelha), onde $r$ é o raio dos capilares da casca. Adicionalmente, verificou-se o comportamento de uma fibra D-MOF, com $\Lambda=1,3 \mu \mathrm{m}$, $\mathrm{d} / \Lambda=0,875$ e com capilar central de raio $\mathrm{r}_{\mathrm{c}}=0,25 \mathrm{r}$ (linha verde). 


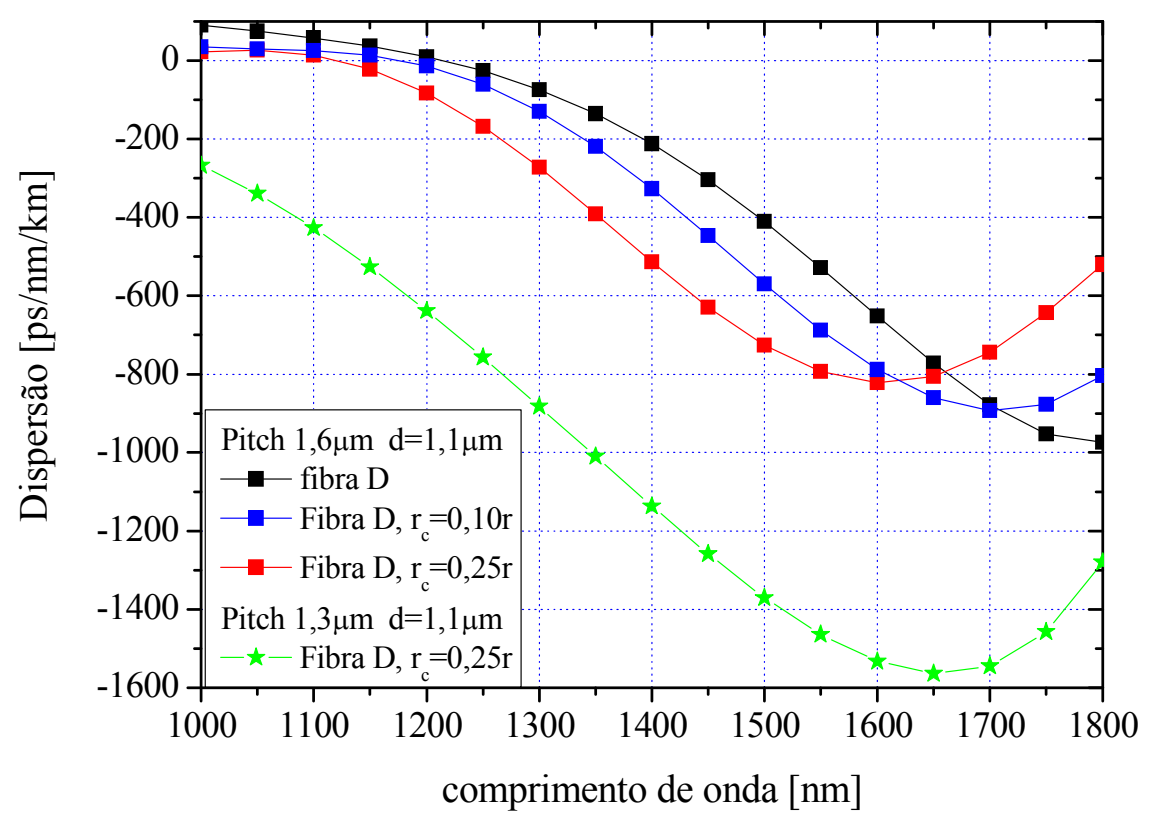

Figura 35. Dispersão em função do comprimento de onda para polarização-x. D-MOF com $\Lambda=1,6 \mu \mathrm{m}, \mathrm{d} / \Lambda=0,6875$ e sem o capilar central (linha em preto). D-MOF $\operatorname{com} \Lambda=1,6 \mu \mathrm{m}$, $d / \Lambda=0,6875$ e $r_{c}=0,10 r$ (linha em azul). D-MOF com $\Lambda=1,6 \mu \mathrm{m}, d / \Lambda=0,6875$ e $r_{c}=0,25 r$ (linha em vermelho). $D-M O F$ com $\Lambda=1,3 \mu \mathrm{m}, \mathrm{d} / \Lambda=0,846$ e $r_{c}=0,25 \mathrm{r}$ (linha em verde).

Analisando o gráfico da Figura 35, verifica-se que, modificando a geometria da fibra ou o diâmetro do capilar central, é possível ajustar a inclinação da curva de dispersão conforme necessidade de projeto. A Tabela 4 lista os valores dos parâmetros $\mathrm{R}$ e K encontrados para as quatro configurações descritas na Figura 36.

Tabela 4: Projeto de uma D-MOF com capilar central.

\begin{tabular}{ccc}
\hline Linha & Fator $\mathbf{K}$ & Fator $\mathbf{R}$ \\
\hline \hline preta & $\mathbf{2 4 0}$ & $\mathbf{3 1 , 0}$ \\
\hline azul & 300 & 40,4 \\
\hline vermelha & $\mathbf{5 4 6}$ & 46,6 \\
\hline verde & 739 & $\mathbf{8 6 , 1}$ \\
\hline \hline
\end{tabular}


Considerando os resultados apresentados nas Tabelas 3 e 4, verifica-se que a fibra óptica D-MOF com os parâmetros $\Lambda=1,6 \mu \mathrm{m}, \mathrm{d} / \Lambda=0,6875$ e com o capilar central de raio $r_{c}=0,10 \mathrm{r}$ (linha azul) apresenta os valores mais adequados no projeto de fibras ópticas compensadoras de dispersão em banda larga, pois possui o fator K próximo ao da fibra SMF$28(\mathrm{~K}=301,8 \mathrm{~nm})$. Apesar das configurações das D-MOFs representadas pelas linhas vermelha e verde apresentarem um valor mais negativo de dispersão em $\lambda=1550 \mathrm{~nm}$, o melhor casamento entre a inclinação da curva de dispersão da fibra convencional SMF-28 e da fibra compensadora, isto é, o fator $\mathrm{K}$, ocorreu para a fibra representada pela linha azul.

Com isso, a fibra D-MOF com $\Lambda=1,6 \mu \mathrm{m}, \mathrm{d} / \Lambda=0,6875, \mathrm{r}_{\mathrm{c}}=0,10 \mathrm{r}$, proposta neste trabalho, tem a grande vantagem de ser capaz de compensar o efeito da dispersão cromática simultaneamente nas três bandas: S (1460-1530nm), C (1530-1565nm) e L (1565-1625nm) com a dispersão residual abaixo de 1,0ps/(nm km). Conforme [108], manter a dispersão residual abaixo de 1,0ps/(nm km) garante sua aplicação em sistemas WDM de 10Gbps. Nas demais faixas do espectro óptico verificou-se que a dispersão residual permanece acima de 1,0ps/(nmkm). Para demonstrar a eficiência da D-MOF com o capilar central, a Figura 36 apresenta os valores da dispersão para o SMF-28 convencional (linha azul), para a D-MOF otimizada (linha verde) e o cancelamento resultante da compensação de dispersão (linha preta) em um enlace de $40 \mathrm{~km}$.

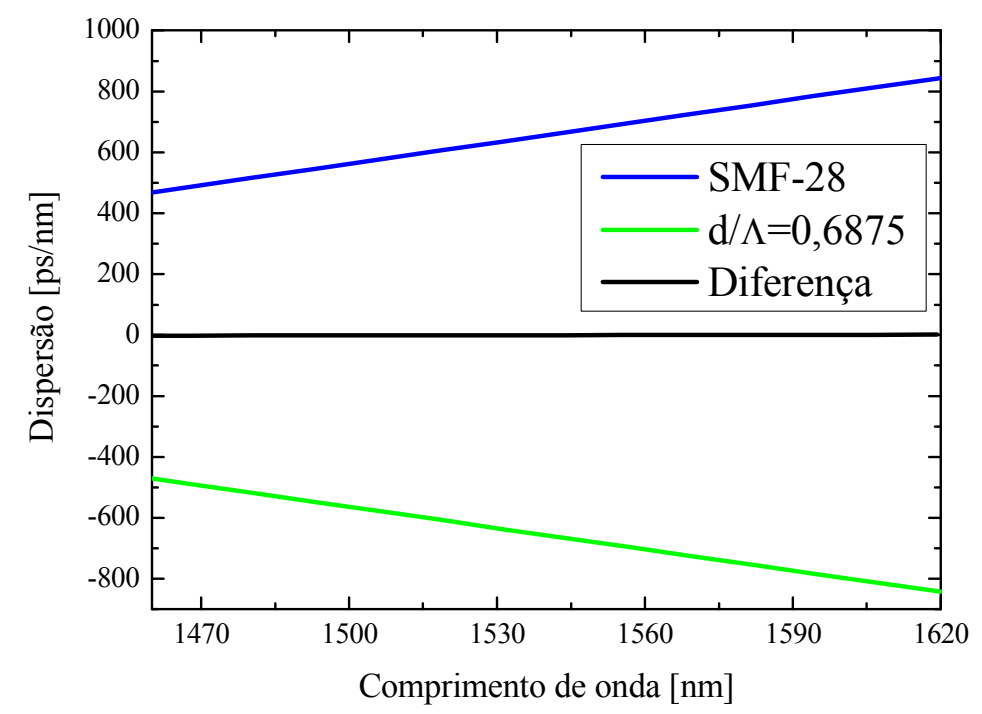

Figura 36. Compensação da dispersão acumulada nas bandas S, C e L. Linha azul - fibra convencional SMF-28; linha verde - D-MOF otimizada; linha preta - cancelamento resultante da compensação de dispersão em um enlace de 40km. Dispersão residual abaixo de 1,0ps/(nm km). 
A fibra óptica microestruturada tipo D otimizada para compensação de dispersão em banda larga projetada neste trabalho apresenta um valor de dispersão negativo de aproximadamente $-690 \mathrm{ps} /(\mathrm{nm} \mathrm{km})$ em $1550 \mathrm{~nm}$. Considerando as três bandas, a dispersão residual permanece abaixo de 1,0ps/(nm $\mathrm{km})$, demonstrando, portanto, a eficiência da fibra DMOF projetada para compensação da dispersão nas bandas S, C e L. Assim, aproximadamente $2,5 \mathrm{~km}$ dessa fibra D-MOF com o parâmetro $\mathrm{R}=40,4$, é capaz de compensar a dispersão imposta em um enlace de $100 \mathrm{~km}$ da fibra SMF-28.

As análises apresentadas anteriormente foram feitas considerando a fibra com polarização horizontal. Entretanto, como a estrutura geométrica das D-MOFs apresentam uma grande assimetria, torna-se importante calcular, para as diferentes geometrias propostas, a dependência da dispersão cromática em função do estado de polarização. Esta dependência é apresentada na Figura 37 para ondas polarizadas na direção ' $\mathrm{x}$ ' (linhas pretas com símbolos cheios) e 'y' (linhas azuis com símbolos vazados). Os casos investigados novamente são: $\mathrm{f}=$ 0,875 (quadrados), $\mathrm{f}=0,75$ (estrelas) e f =0,6875 (círculos).

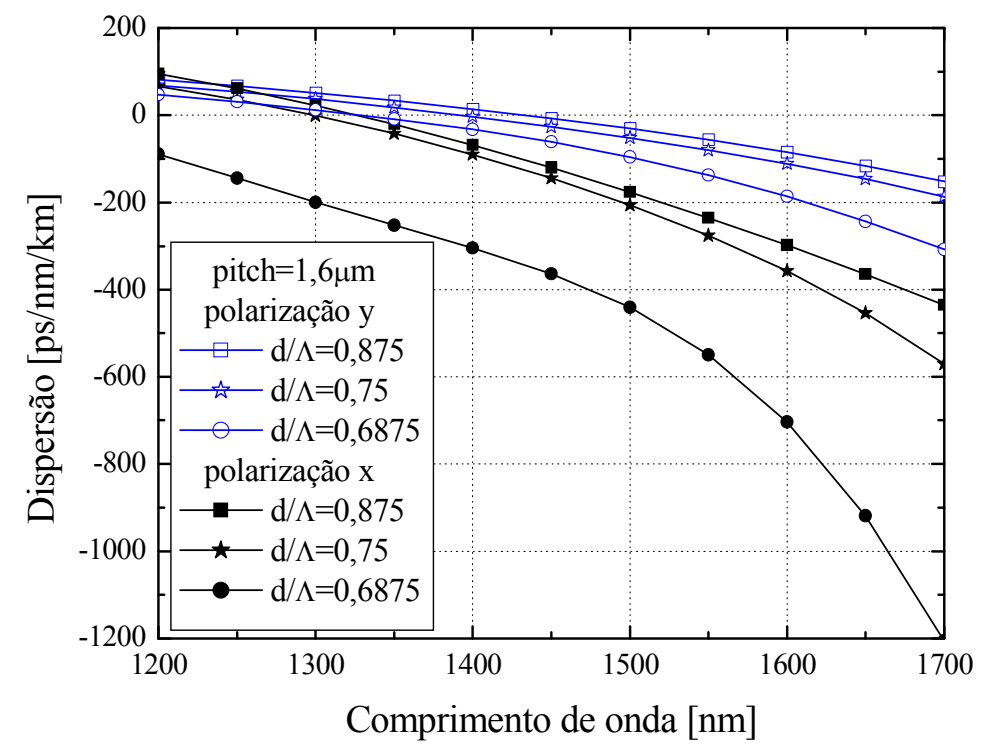

Figura 37. Dispersão cromática em função do comprimento de onda. Polarização na direção $x$ linhas em preto com símbolos cheios e polarização na direção y linhas em azul com símbolos vazados; $f=0,875$ (quadrados) $f=0,75$ (estrelas) e $f=0,6875$ (círculos). 
Como pode ser observado claramente na Figura 37, os modos com polarização x (linhas pretas) possuem valores de dispersão mais negativos do que os modos com polarização y (linhas azuis). Isto decorre possivelmente do fato das fibras com perfil D apresentarem na direção do eixo y uma maior assimetria, com um elevado grau de diferença no índice de refração $\left(\mathrm{n}_{\text {sílica }} \approx 1,44\right.$ para $\left.\mathrm{n}_{\mathrm{ar}} \approx 1,0\right)$. Portanto, na direção $\mathrm{y}$, o campo permanece mais confinado na região no núcleo, enquanto que no eixo x o modo tende a se espalhar para a região da casca. Diminuindo a fração de ar, $f$, o confinamento modal tende a diminuir, e, quanto menor a fração de $\operatorname{ar} f$, mais negativo tende a ser o valor da dispersão cromática. Logo, os resultados sugerem que há um compromisso entre a dispersão cromática e o confinamento modal.

Todavia, a extrema assimetria das D-MOFs resulta em um aumento considerável no efeito da birrefringência. Em conseqüência, as fibras ópticas microestruturadas com perfil D, além da sua utilização como fibras compensadoras de dispersão, podem ser utilizadas em aplicações em que haja necessidade de preservar o estado de polarização. Esta outra possibilidade de utilização motivou a investigação da característica birrefringente das DMOFs, cujos resultados são descritos na subseção seguinte.

\subsection{D-MOF altamente birrefringente}

As fibras ópticas altamente birrefringentes têm como objetivo reduzir o acoplamento entre os estados ortogonais do modo fundamental [52]. Fibras ópticas convencionais, com simetria circular, não mantêm o estado de polarização do modo guiado ao longo do seu comprimento. Dessa forma, as fibras com alta birrefringência são utilizadas em aplicações onde é necessário manter o estado de polarização, como, por exemplo, na geração de supercontínuo [107], em sensoriamento óptico [111] e em sistemas de telecomunicações [112].

Como apresentado na seção 2.3, equação 2.4, a birrefringência pode ser obtida calculando-se o comprimento de batimento, $\mathrm{L}_{\pi}$, entre os dois modos com polarizações ortogonais [20]. A relação entre o comprimento de batimento e a birrefringência modal, B, é dada por [20]: 


$$
L_{\pi}=\frac{2 \pi}{\left|\beta_{x}-\beta_{y}\right|}=\frac{\lambda}{\left|n_{x}-n_{y}\right|}=\frac{\lambda}{B},
$$

onde, $\beta_{x}$ e $\beta_{y}$ são as constantes de propagação dos modos com polarização x e y, $n_{x}$ e $n_{y}$ são os índices efetivos para cada modo polarizado e $\lambda$ é comprimento de onda da luz.

A primeira análise realizada busca verificar a influência da posição do corte, $\delta$, e do espaçamento, $\Lambda$, no cálculo da birrefringência nas fibras D-MOFs. Na Figura 38, são apresentados os resultados para as D-MOFs com a mesma relação $d / \Lambda=0,875$ e com o espaçamento, respectivamente, igual a: $\Lambda=1,0 \mu \mathrm{m}$ (quadrado), $\Lambda=1,2 \mu \mathrm{m}$ (triangulo), $\Lambda=1,6 \mu \mathrm{m}$ (estrela) e $\Lambda=2,3 \mu \mathrm{m}$ (diamante). As linhas em preto com símbolos cheios representam o cálculo da birrefringência para a posição do corte no centro da fibra, $\delta=0$, e as linhas em azul com símbolos vazados para o corte situado acima do centro da fibra. No caso particular, adotou-se $\delta=\mathrm{d} / 2$ micrometros.

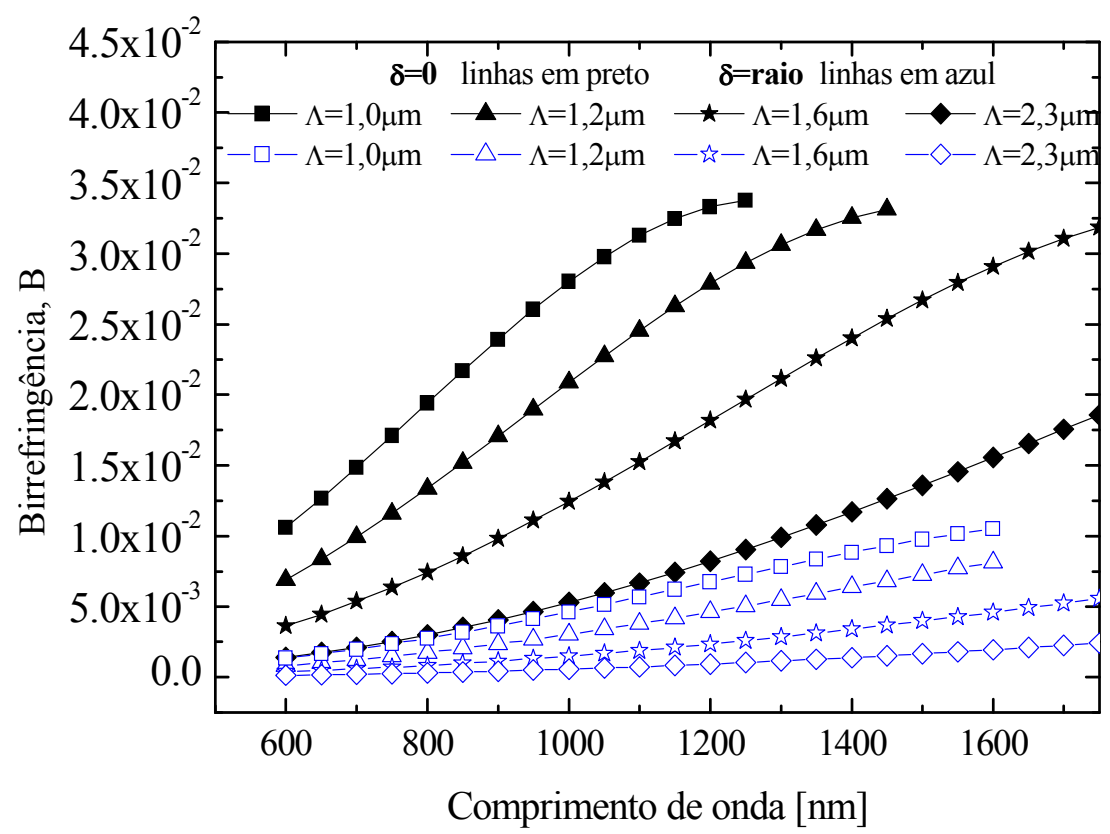

Figura 38. Cálculo da birrefringência para $D-M O F \operatorname{com} d / \Lambda=0,875$ e a posição do corte em $\delta=0$ (linhas em preto e símbolos cheios ) e $\delta=$ raio (linhas em azul e símbolos vazados), respectivamente, para: $\Lambda=1,0 \mu \mathrm{m}$ (quadrado), $\Lambda=1,2 \mu \mathrm{m}$ (triângulo), $\Lambda=1,6 \mu \mathrm{m}$ (estrela) e $\Lambda=2,3 \mu \mathrm{m}$ (diamante). 
Analisando o gráfico da Figura 38, verifica-se que a posição do corte e as dimensões das fibras são fundamentais no projeto de fibras altamente birrefringentes. Estruturas semelhantes com os mesmos parâmetros físicos e geométricos, apenas com o corte em posição diferente, apresentam diferentes valores de B. Mantendo o corte $\delta=0$ é possível obter, para uma larga faixa de comprimentos de onda, o valor de B da ordem de $10^{-2}$. Este valor é da mesma ordem de magnitude das fibras microestruturadas projetadas para apresentarem alta birrefringência [66]-[70], com a vantagem de ser obtido sem a necessidade de dopagem da região do núcleo e com uma estrutura relativamente simples.

Justifica-se uma fibra D-MOF, com o corte posicionado em $\delta=0$, apresentar uma maior birrefringência quando comparada com a mesma fibra com o corte deslocado, pois, com o corte mantido em $\delta=0$, o efeito da assimetria da estrutura é acentuado e o confinamento de campo aumenta. Além disso, verifica-se que estruturas com dimensões menores também apresentam uma maior birrefringência para o mesmo comprimento de onda. Portanto, conforme discutido em [60], o aumento do valor de B é diretamente proporcional ao confinamento de campo e à quebra da simetria na região do núcleo.

Com base nos resultados discutidos acima, o gráfico da figura 39 traz uma análise da fibra D-MOF com o corte na posição $\delta=0$, com a relação $d / \Lambda=0,90$ (símbolos cheios) e $\mathrm{d} / \Lambda=0,95$ (símbolos vazados) para $\Lambda=1,3 \mu \mathrm{m}, \Lambda=1,2 \mu \mathrm{m}$ e $\Lambda=1,0 \mu \mathrm{m}$, respectivamente, linhas em preto, verde e azul. Estes valores foram utilizados visando aumentar o confinamento de campo, e, assim, obter uma maior birrefringência. 


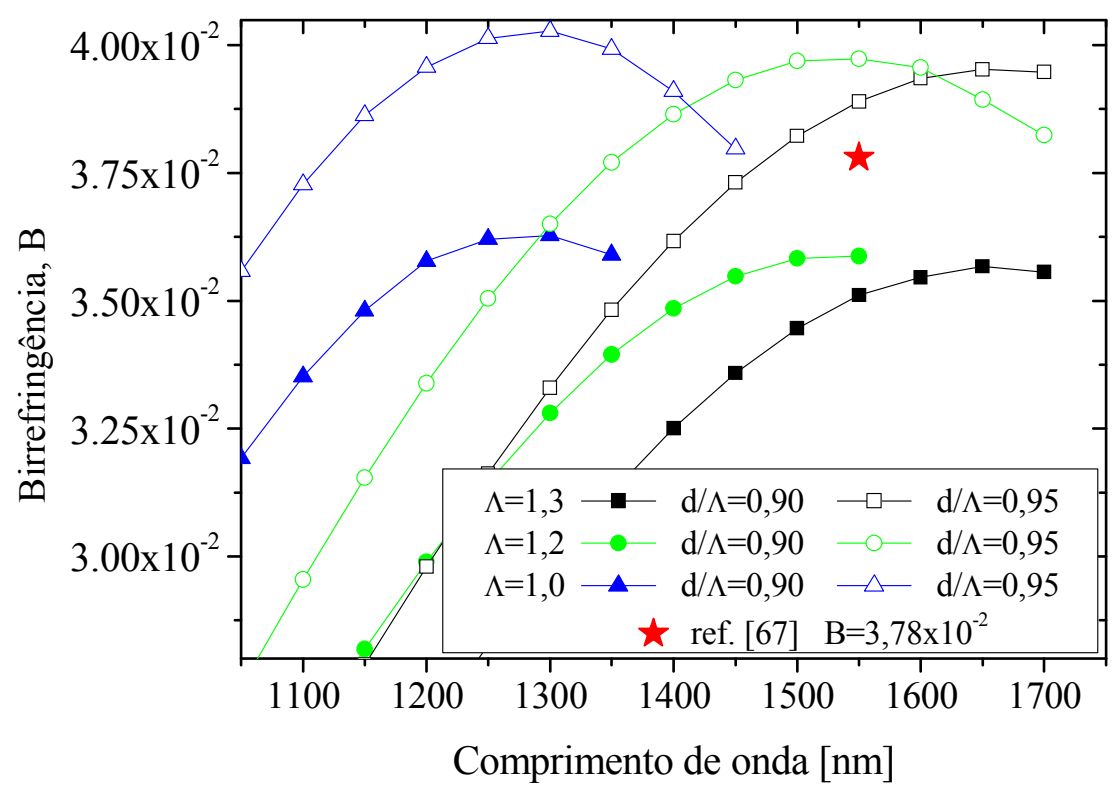

Figura 39. Cálculo da birrefringência para D-MOF com posição do corte em $\delta=0$ e: $\Lambda=1,3 \mu \mathrm{m}$ (preta), $\Lambda=1,2 \mu \mathrm{m}$ (verde), $\Lambda=1,0 \mu \mathrm{m}$ (azul) para $\mathrm{d} / \Lambda=0,90$ (símbolos cheios) e $\mathrm{d} / \Lambda=0,95$ (símbolos vazados).

Analisando os resultados apresentados na Figura 39, verifica-se que com a fibra DMOF, $\delta=0, \Lambda=1,3 \mu \mathrm{m}$ e $\Lambda=1,2 \mu \mathrm{m}$ é possível obter uma birrefringência, no comprimento de onda de $1550 \mathrm{~nm}$, respectivamente igual a $3,89 \times 10^{-2}$ e $3,97 \times 10^{-2}$. Estes valores de birrefringência são maiores que o valor de B apresentado em [67], o qual, até o presente momento, era o maior valor de B obtido com uma fibra óptica microestruturada. Portanto, as fibras ópticas microestruturadas com perfil tipo D tornam-se uma excelente alternativa no projeto de fibras altamente birrefringentes.

Ainda visando o aumento da birrefringência, este trabalho apresenta uma nova geometria para as fibras MOFs tipo D, onde a região da casca é formada por capilares em formato elíptico. Estas fibras são definidas como ED-MOFs, ou, mais especificamente, como $\mathrm{x}$-ED-MOF e y-ED-MOF, quando o maior eixo do capilar elíptico estiver ordenado ao longo da direção x ou ao longo da direção y, respectivamente.

A associação de MOF tipo D e capilares elípticos tem como objetivo acentuar a assimetria da fibra na região do núcleo e, por sua vez, aumentar o efeito da birrefringência pois, utilizar a geometria tipo $\mathrm{D}$ ou capilares elípticos tendem a tornar a fibra mais 
birrefringente. Assim, espera-se que a associação desses dois artifícios produza um aumento da birrefringência.

A seção transversal das duas disposições dos capilares elípticos assim como as dimensões do capilar estão apresentadas nas Figuras 40(a) e (b), respectivamente, para a EDMOF com o maior eixo do capilar elíptico alinhado ao longo da direção x, e para a ED-MOF com o maior eixo do capilar elíptico alinhado ao longo da direção y.
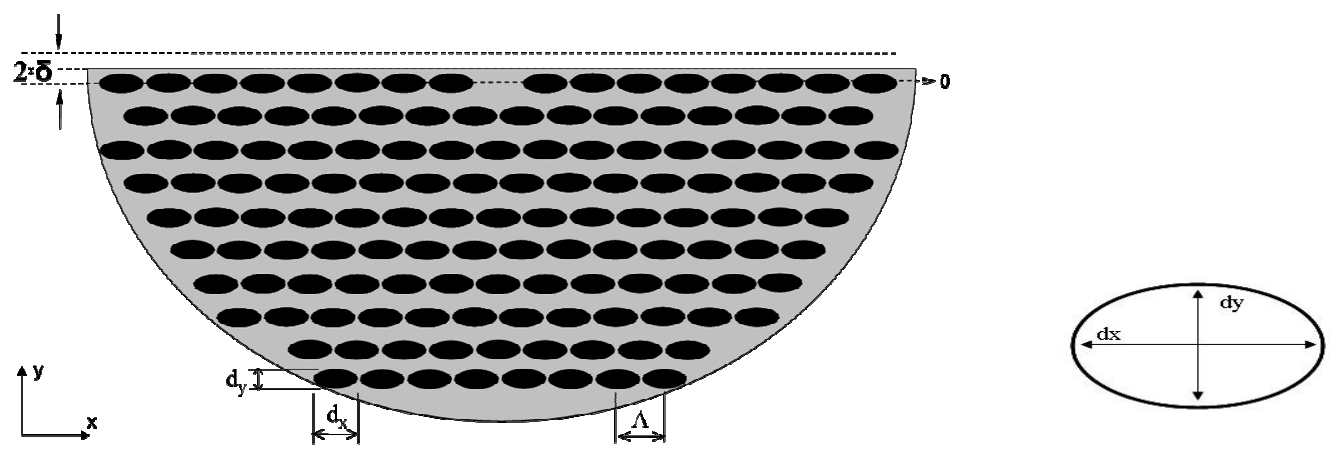

(a)
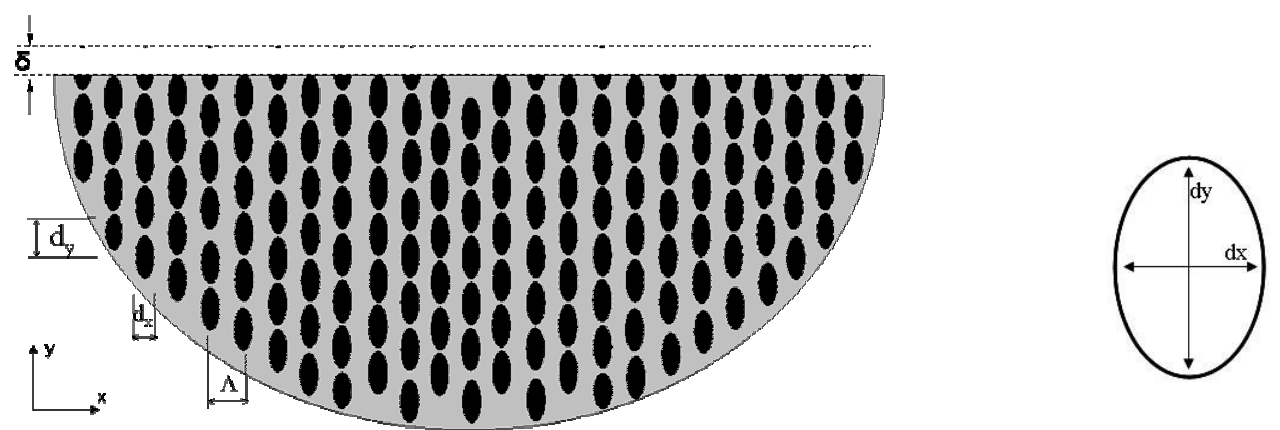

(b)

Figura 40. (a) Fibra x-ED-MOF - capilares elípticos dispostos horizontalmente; (b) Fibra y-EDMOF - capilares elípticos dispostos verticalmente. Figura na lateral mostra as dimensões de um capilar elíptico.

Como apresentado na Figura 40, os parâmetros geométricos que definem a estrutura das ED-MOFs são: o espaçamento, $\Lambda$, o diâmetro da elipse no eixo horizontal e no eixo vertical, respectivamente, $d_{x}$ e $d_{y}$, e o parâmetro $\delta$, o qual define a distância do corte da fibra em relação ao seu eixo central. Uma das vantagens apresentadas no projeto das fibras x-EDMOF com o corte acima da posição $d_{\mathrm{y}} / 2$, observada na Figura 40(a), é a de preservar a região do núcleo e os capilares da fileira central, o que pode facilitar a montagem da preforma da 
fibra e, consequentemente, o processo de fabricação, mas, por outro lado, diminui ligeiramente a birrefringência.

A primeira análise é feita de forma a verificar a magnitude da birrefringência nas fibras microestruturadas tipo D com capilares elípticos. O gráfico da Figura 41 compara o valor da birrefringência entre as $\mathrm{x}$-ED-MOFs (linhas em preto com símbolos vazados) com as y-EDMOFs (linhas em vermelho com símbolos cheios). Nestes casos, a relação $d / \Lambda$ foi mantida em 0,875 , com o espaçamento igual a: $\Lambda=1,0 \mu \mathrm{m}$ (quadrado), $\Lambda=1,2 \mu \mathrm{m}$ (triângulo), $\Lambda=1,6 \mu \mathrm{m}$ (estrela) e $\Lambda=2,3 \mu \mathrm{m}$ (diamante).

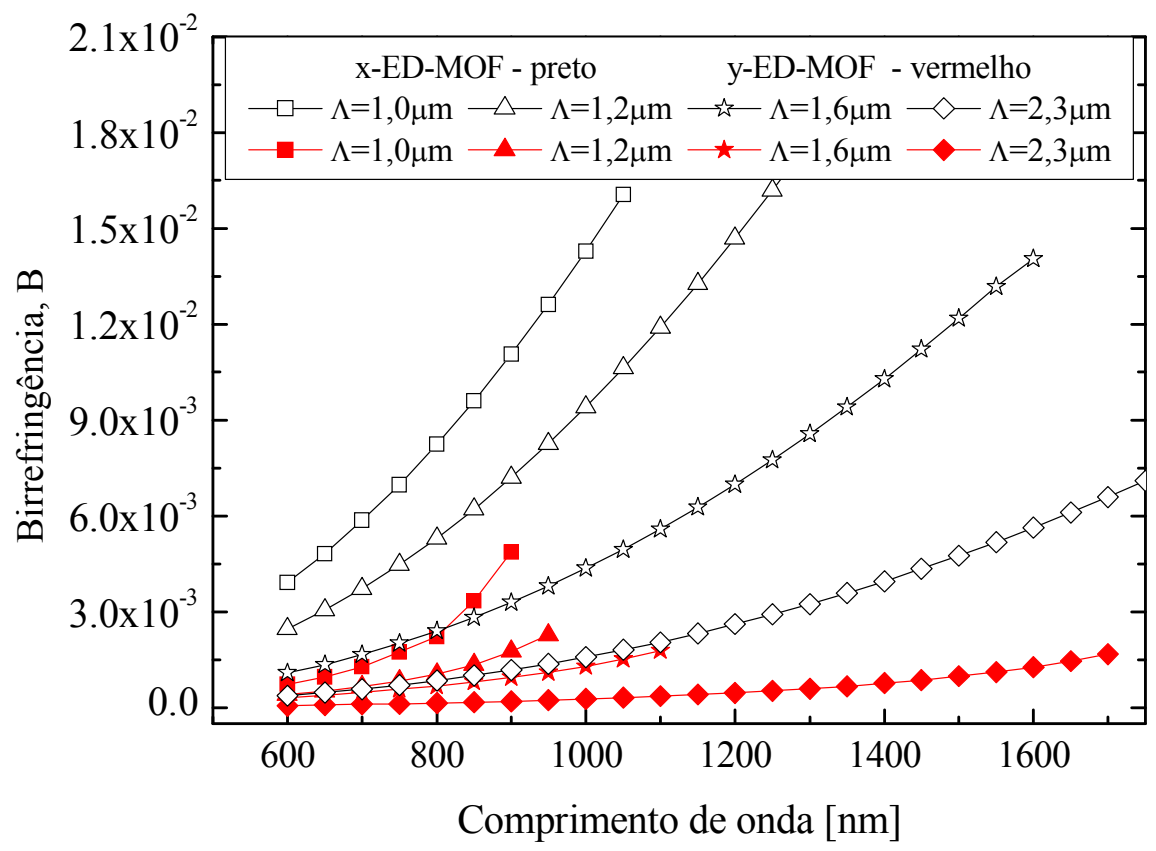

Figura 41. Cálculo da birrefringência para x-ED-MOF linhas em preto e símbolos vazados e para y-ED-MOFs linhas em vermelho com símbolos cheios; $\Lambda=1,0 \mu \mathrm{m}$ (quadrado), $\Lambda=1,2 \mu \mathrm{m}$ (triângulo), $\Lambda=1,6 \mu \mathrm{m}$ (estrela) e $\Lambda=2,3 \mu \mathrm{m}$ (diamante).

Pelo gráfico da Figura 41, nota-se que com o eixo maior da elipse ordenado na direção $\mathrm{x}$ (linhas em preto) as fibras ED-MOFs apresentam uma maior birrefringência se comparadas às mesmas estruturas com o eixo maior da elipse orientado na direção y (linhas em vermelho). As $\mathrm{x}$-ED-MOFs apresentam o valor de $\mathrm{B}$ da ordem de $10^{-2}$ enquanto as $\mathrm{y}$-ED-MOFs possuem $\mathrm{B}$ da ordem de $10^{-3}$. Ademais, verifica-se que reduzir as dimensões das fibras y-ED-MOFs, 
diminui a região espectral onde o confinamento modal é mantido, conforme pode ser observado pelas linhas em vermelho.

Nas fibras x-ED-MOFs o campo permanece mais confinado na região do núcleo e tem um maior contato com a assimetria da estrutura, conforme Figura 42(a). Por isso, apresentam uma maior diferença entre os modos ortogonais da fibra. Adicionalmente, conforme comentado acima, as x-ED-MOFs apresentam a vantagem adicional da região do núcleo e dos capilares da primeira fileira não serem afetados pelo corte, o que pode facilitar a montagem da preforma. Por outro lado, as fibras y-ED-MOFs apresentam uma maior área efetiva do núcleo e um menor confinamento de campo, consequentemente, uma menor birrefringência. Estes efeitos comentados acima, podem ser verificados na Figura 42(a) e (b) que apresentam a distribuição da componente de campo magnético $\mathrm{H}_{\mathrm{x}}$ para as fibras x-ED-MOFs e y-EDMOFs, respectivamente.

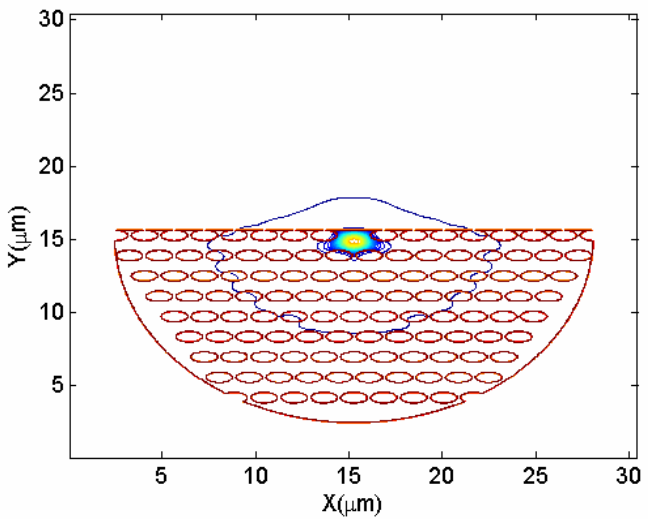

(a)

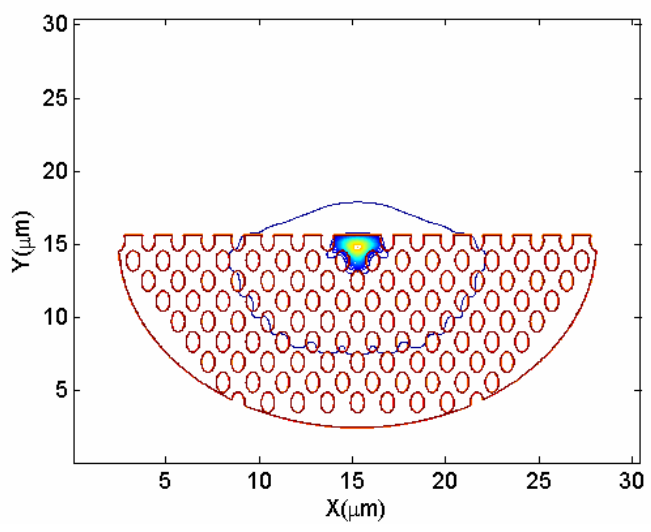

(b)

Figura 42. Distribuição da componente de campo magnético fundamental $H_{x} ; \Lambda=1,6 \mu m$,

$$
\mathrm{d} / \Lambda=0,875 \text { e } \lambda=1,0 \mu \mathrm{m} \quad \text { (a) } x \text {-ED-MOF } \quad \text { (b) } y \text {-ED-MOF. }
$$

Por fim, a Figura 43 traz uma comparação entre os valores de B obtidos com as fibras D-MOFs com capilares circulares e as fibras ED-MOFs com capilares elípticos ordenados na direção x. Nesta comparação, nas fibras D-MOFs com capilares circulares o corte foi mantido na posição $\delta=0$, pois com o corte assim posicionado a fibra apresenta sua maior birrefringência. Por outro lado, nas fibras x-ED-MOFs o corte foi considerado na posição $\delta=\mathrm{d}_{\mathrm{y}} / 2$, pois, nessa posição o corte não afeta o núcleo e os capilares da primeira fila. Assim, 
podem-se comparar os valores de $\mathrm{B}$ obtidos no melhor caso das D-MOFs com a melhor distribuição geométrica das X-ED-MOFs.

Na Figura 43, as linhas em azul com símbolos vazados representam as D-MOFs com capilares circulares e as linhas em preto com símbolos cheios as D-MOFs com capilares elípticos ordenados na direção x. Em todos os casos a relação d/ $\Lambda$ foi mantida igual a 0,875 ,

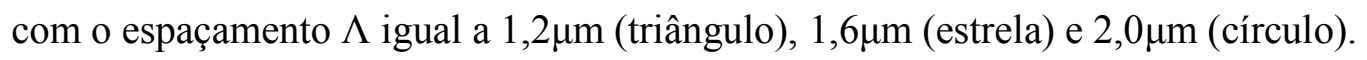

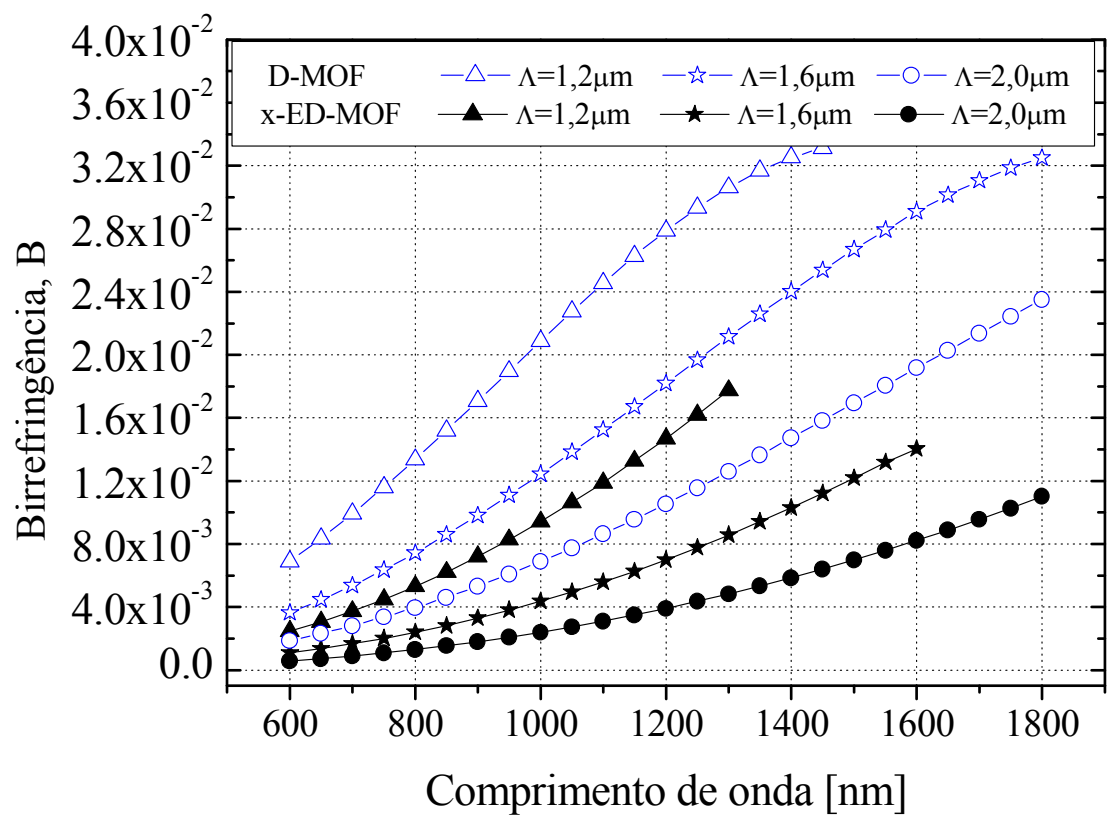

Figura 43. Cálculo da birrefringência para as D-MOFs linhas em azul com símbolos vazados e xED-MOFs linhas em preto com símbolos cheios; $d / \Lambda=0,875$ e $\Lambda=1,2 \mu \mathrm{m}$ (triângulo), $\Lambda=1,6 \mu \mathrm{m}$ (estrela) e $\Lambda=2,0 \mu \mathrm{m}$ (circulo).

Comparando os resultados da birrefringência obtidos no projeto das fibras D-MOFs com capilares circulares com as x-ED-MOFs com capilares elípticos, é possível observar que, em ambos os projetos, a birrefringência permanece na ordem de $10^{-2}$ para uma longa faixa de comprimentos de onda. As D-MOFs com o corte $\delta=0$ têm a vantagem de produzir um maior valor de birrefringência, com a desvantagem de reduzir a área do núcleo, $\mathrm{A}_{\mathrm{eff}} \approx 1,25 \mu \mathrm{m}^{2} \mathrm{em}$ $\lambda=1550 \mathrm{~nm}$. Por outro lado, as $\mathrm{x}$-ED-MOFs com o corte na posição $\delta=\mathrm{d}_{\mathrm{y}} / 2$, apresentam uma birrefringência ligeiramente menor, mas ainda na mesma ordem de grandeza, com a vantagem de manter os capilares e o núcleo inalterados pelo corte. Logo, possuem uma maior área efetiva, $\mathrm{A}_{\mathrm{eff}} \approx 2,50 \mu \mathrm{m}^{2}$ em $\lambda=1550 \mathrm{~nm}$, podendo, portanto, facilitar o acoplamento modal e o 
processo de fabricação. Entretanto, reduzir as dimensões físicas da fibra x-ED-MOF diminui a região espectral onde o confinamento modal é mantido. Conforme pode ser observado nas curvas em preto com símbolos em triângulo e estrela, o confinamento modal é preservado, respectivamente, até próximo ao comprimento de onda de $1350 \mathrm{~nm}$ e $1600 \mathrm{~nm}$. Já, as y-EDMOFs apresentam um menor confinamento modal (Figura 42b), com a área efetiva, $\mathrm{A}_{\mathrm{eff}} \approx 3,70 \mu \mathrm{m}^{2}$ em $1550 \mathrm{~nm}$ e, portanto, uma menor birrefringência.

De fato, os valores de birrefringência obtidos para os casos analisados das D-MOFs e das $\mathrm{x}$-ED-MOFs são duas ordens de grandeza maiores do que os valores das fibras ópticas convencionais birrefringentes [50], [51] e da mesma ordem de grandeza $\left(B=10^{-2}\right)$ das MOFs projetadas para alta birrefringência [67]-[70]. Adicionalmente, as D-MOFs e x-ED-MOFs apresentam a vantagem de serem projetadas com sílica pura (não-dopada) e de possuírem uma estrutura geométrica menos complexas se comparadas às geometrias propostas em [68] e [70]. Por fim, o projeto da fibra D-MOF, $\delta=0, \Lambda=1,2 \mu \mathrm{m}, \mathrm{d} / \Lambda=0,95$ apresenta o maior valor de birrefringência descrito na literatura até o presente momento, com $\mathrm{B}$, em $1550 \mathrm{~nm}$, igual a $3,97 \times 10^{-2}$. Logo, as fibras ópticas microestruturadas com perfil tipo D tornam-se uma excelente alternativa no projeto de fibras altamente birrefringentes.

\subsection{D-MOF com preenchimento}

Essa subseção investiga o comportamento das D-MOFs quando a região de ar é preenchida por diferentes materiais. Como comentando anteriormente, as fibras ópticas microestruturadas de núcleo sólido apresentam guiamento por diferença de índice [4]. Estas fibras, conforme T. Monro e co-autores sugeriram em 1999 [37], permitem explorar a interação da luz com a região de ar por meio do campo evanescente.

Desde então, devido às facilidades oferecidas pela sua geometria, pesquisadores estão propondo preencher as regiões de ar da fibra com diferentes materiais [113]-[120]. O objetivo deste preenchimento é alterar as características ópticas das fibras e, dessa forma, utilizá-las nas mais diversas aplicações. Como as fibras D-MOFs apresentam uma maior região de ar acima do corte (túnel), pode-se preencher esse túnel com o material de interesse, resultando em uma 
maior região de interação entre o campo evanescente e o material. Esta possibilidade de preenchimento tornam as fibras D-MOFs atraentes no projeto de sensores, o qual pode ser objeto de estudos futuros. Especificamente neste trabalho, são investigados os casos de fibras compensadoras de dispersão e fibras altamente birrefringentes.

Nas duas subseções anteriores foram apresentados, respectivamente, um projeto de fibra capaz de compensar o efeito da dispersão simultaneamente nas bandas $\mathrm{S}, \mathrm{C}$ e L, porém com birrefringência da ordem de $10^{-3}$, e um outro projeto de fibra altamente birrefringente, com $B=3,97 \times 10^{-2}$, e dispersão de aproximadamente $-500 \mathrm{ps} /(\mathrm{nm} \mathrm{km}) \mathrm{em} 1550 \mathrm{~nm}$. Nesta seção, busca-se desacoplar esses efeitos, ou seja, ou projetar uma fibra compensadora de dispersão com baixa birrefringência, ou, de forma contrária, projetar uma fibra com dispersão plana próxima de zero e com alta birrefringência, para aplicações, por exemplo, na geração de luz supercontínua, dispositivos mantedores do estado de polarização, sensores, entre outras [70].

Pode-se dividir as fibras ópticas microestruturadas preenchidas em três configurações específicas [113]. Na primeira categoria estão as fibras ópticas microestruturadas com núcleo sólido, sendo os capilares da região de casca preenchidos com o material de interesse. Em 2003 Y.L. Hoo [114] e co-autores propuseram a fibra MOF atuando como sensor de acetileno ou metano, investigando a sensibilidade relativa e dinâmica da difusão destes gases preenchendo os capilares da fibra. A segunda categoria apresenta o núcleo vazado por ar. Neste caso, o material a ser estudado é inserido no núcleo da fibra e, por apresentar índice de refração maior que o da região da casca, o mecanismo de guiamento é regido pela diferença de índice. Com essa configuração, no ano de 2004, J.M. Fini [115] propôs uma MOF projetada para atuar como sensor de gás e líquido. A terceira configuração possível também diz respeito às fibras com núcleo de ar, porém, o núcleo é preenchido com algum tipo de gás ou líquido de índice de refração menor que o da região da casca, apresentando, assim, guiamento por banda fotônica proibida. Com esse tipo de estrutura, T. Ritari e co-autores [116] em 2004 propuseram uma fibra atuando como sensor de gás metano e amônia. Para uma maior interação entre a luz e o material, essa fibra foi projetada com o diâmetro do núcleo de aproximadamente $11 \mu \mathrm{m}$. Pode-se mencionar que parte das fibras investigadas como sensores estão sendo fabricadas em polímeros, pelo fato de apresentarem potenciais facilidades no processo de fabricação e custos reduzidos [113]. 
Ao longo dos anos, surgiram poucas aplicações para as fibras microestruturadas preenchidas atuando em sistemas de comunicações ópticas. Entre as aplicações investigadas para as fibras preenchidas encontram-se na literatura as fibras desenvolvidas para compensar dispersão [117], as fibras com dispersão plana [118], e as MOFs com acentuado efeito nãolinear [119], [120].

Com relação à dispersão cromática, S. Yang e co-autores [117], em 2006, mostraram teoricamente que a dispersão de uma fibra microestruturada de sílica pode ser modificada, de forma a apresentar um coeficiente de dispersão negativo, simplesmente preenchendo um anel dos capilares com polímero. No caso específico, Yang simulou uma fibra com o terceiro anel preenchido com acrilato $\left(\mathrm{n}_{\mathrm{r}}=1,434\right)$. Esta fibra apresentou, além de um coeficiente de dispersão negativo em torno de -400 ps/(nm $\mathrm{km})$, a vantagem de poder sintonizar a faixa de comprimento de onda (1520nm -1580nm) conforme ajuste do índice de refração do polímero.

Recentemente, em julho de 2006, K.M. Gundu e co-autores [118], através de uma técnica de preenchimento seletivo dos anéis de ar, projetaram uma fibra microestruturada, núcleo sólido, com anéis preenchidos por líquido $\left(\mathrm{n}_{1}=1,3975\right)$, apresentando dispersão plana em uma larga faixa de comprimentos de onda (de 1300nm a 1900nm). A fibra foi projetada com 4 anéis, sendo apenas os dois anéis mais internos preenchidos com líquido.

Por outro lado, dependendo do material a ser inserido na região de ar, as fibras preenchidas também podem apresentar acentuado efeito não-linear. Um grupo de pesquisadores franceses [119] utilizando uma fibra microestruturada com o núcleo preenchido por líquido de índice de refração 1,36, demonstrou a possibilidade de aumentar a eficiência do espalhamento Raman estimulado. Este primeiro experimento também mostrou que o resultado pode ser estendido para outros efeitos não-lineares, como efeito Kerr, conversão paramétrica, espalhamento Brillouin, entre outros.

Este trabalho propõe investigar uma nova configuração possível para as fibras ópticas microestruturadas preenchidas, isto é, as D-MOFs preenchidas. Estas fibras apresentam como vantagem a possibilidade de se preencher não somente os capilares da região da casca, mas também a região do túnel acima do corte. A seguir serão analisadas separadamente algumas das possíveis configurações para as D-MOFs. 


\section{A) Somente túnel preenchido}

Neste primeiro caso investigado apenas a região do túnel é preenchida por materiais com índice de refração variando entre $1,0<\mathrm{n}_{\text {túnel }}<1,4$, com a região dos capilares mantida sem preenchimento, conforme Figura 44. Nas simulações a parede do túnel foi mantida com dimensões menores que $2 \mu \mathrm{m}$ para garantir que o campo permanecesse confinado na região do núcleo.
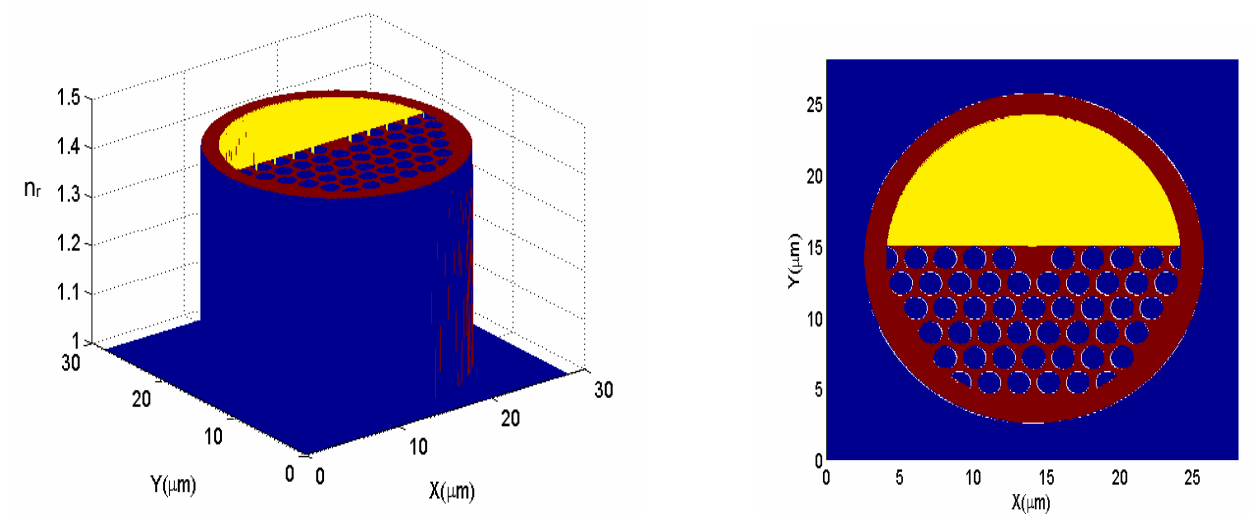

Figura 44. Perfil de índice de refração da D-MOF com a região do túnel preenchida e anéis vazados.

No estudo das D-MOFs preenchidas existe uma enorme liberdade de projeto, pois é possível alterar o material a ser utilizado no preenchimento das regiões de ar, o espaçamento entre os capilares $\Lambda$, a razão $\mathrm{d} / \Lambda$ e a distância do corte, $\delta$. Devido a essa grande flexibilidade de projeto, foram investigadas todas as variações possíveis, listadas na Tabela 5. 


\section{Tabela 5: Variação dos parâmetros de investigação.}

\begin{tabular}{|c|c|}
\hline $\begin{array}{c}\text { Índice de refração do } \\
\text { material de } \\
\text { preenchimento }\end{array}$ & $1,0<\mathrm{n}_{\text {túnel }}<1,4$ \\
\hline Espaçamento, $\boldsymbol{\Lambda}[\boldsymbol{\mu m}]$ & $1,0<\Lambda<10$ \\
\hline Relação $\mathbf{d} / \boldsymbol{\Lambda}$ & $0,5<\mathrm{d} / \Lambda<0,9$ \\
\hline Distância do corte, $\boldsymbol{\delta}$ & $0<\delta<2 \Lambda$ \\
\hline
\end{tabular}

O índice de refração do material de preenchimento foi escolhido variando desde o índice de refração do ar $\left(n_{t}=1,0\right)$ até próximo o índice de refração da sílica $\left(n_{t}=1,40\right)$. $O$ espaçamento, $\Lambda$, e a relação, $\mathrm{d} / \Lambda$, foram escolhidos considerando as dimensões práticas de fabricação das MOF encontradas na literatura. $\mathrm{O}$ corte, $\delta$, foi investigado para uma região do núcleo da fibra reduzida à metade $(\delta=0)$, até um corte onde a região do núcleo é preservada completamente $(\delta=2 \Lambda)$.

Neste ponto faz-se necessário comentar que em estruturas com o espaçamento $\Lambda$ maior que $4 \mu \mathrm{m}$ (maior dimensão geométrica) e materiais de preenchimentos com índice de refração abaixo de 1,3 (mais próximos do índice do ar) não apresentaram boas características para o projeto de fibras com dispersão plana e alta birrefringência.

Inicialmente, a Figura 45 apresenta a variação do índice efetivo em função do comprimento de onda. A fibra D-MOF investigada apresenta 8 anéis, espaçamento entre os capilares, $\Lambda=2 \mu \mathrm{m}$, e índice de refração do material de preenchimento da região do túnel, $\mathrm{n}_{\text {túnel }}$ $=1,4$. O parâmetro $\mathrm{d} / \Lambda$ e a distância do corte em relação ao centro, $\delta$, foram modificados, variando entre $0,5<\mathrm{d} / \Lambda<0,9$ e $0<\delta<2 \Lambda$, respectivamente. 


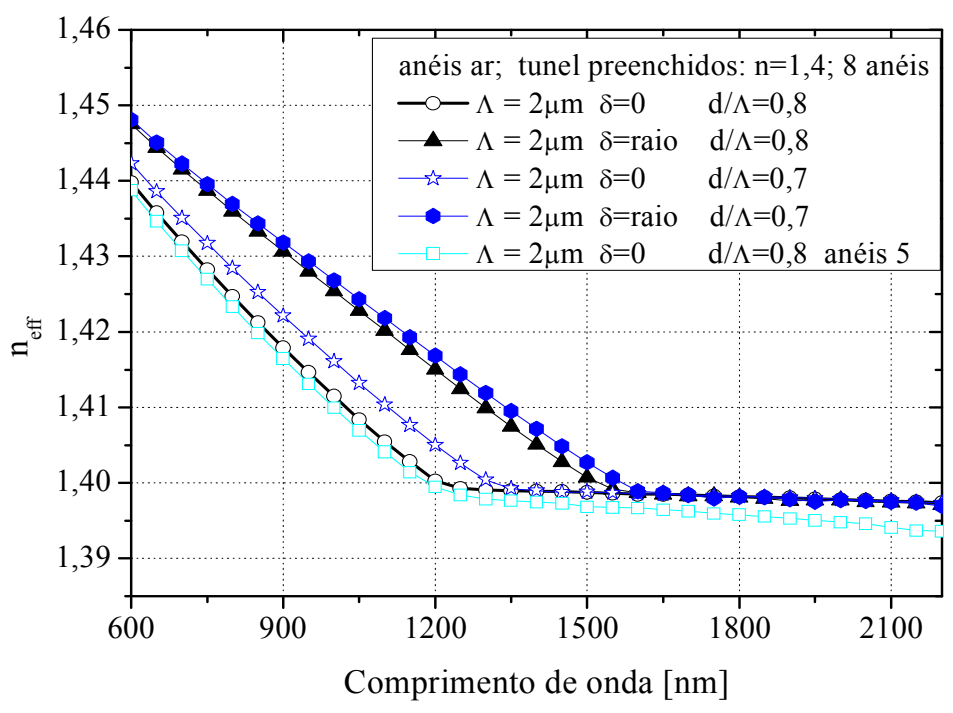

Figura 45. Índice efetivo em função do comprimento de onda para a D-MOF com apenas a região do túnel preenchida.

A Figura 45 apresenta cinco situações distintas investigadas para a fibra D-MOF com a região do túnel preenchida. As curvas com símbolos vazados $(\delta=0)$ são as curvas onde o corte do túnel passa exatamente no eixo central da fibra. As curvas com os símbolos cheios ( $\delta$ = raio) são os casos onde o núcleo foi mantido inteiro. Outra situação investigada refere-se à alteração na relação d/ $\Lambda$ e na mudança no número de anéis da fibra.

Analisando o gráfico da Figura 45, nota-se que ocorre uma mudança na inclinação da curva do índice efetivo em função do comprimento de onda. Essa mudança é causada pela presença do material na região do túnel. Em comprimentos de onda curtos, a energia do modo está confinada na região do núcleo, em comprimentos de onda longos, a energia do modo passa a ser guiada na região do túnel, conforme pode ser visualizado na Figura 46(a) e (b).

Ainda com relação ao gráfico da Figura 46, comparando-se as curvas pretas (ou azuis), nota-se que aumentando a distância do corte, $\delta$, em relação ao centro é possível deslocar o ponto onde ocorre a mudança na inclinação da curva. A mudança na relação $d / \Lambda$ também é capaz de deslocar esse ponto onde ocorre a mudança na inclinação. Já a mudança no número de anéis (curva azul clara) não acarreta uma variação significativa no valor do índice efetivo. 


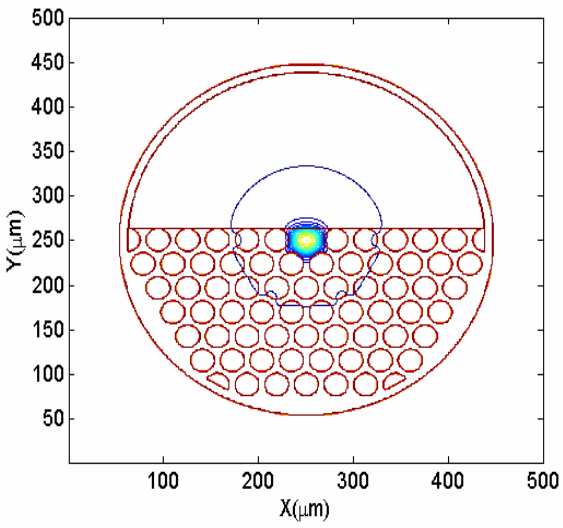

(a)

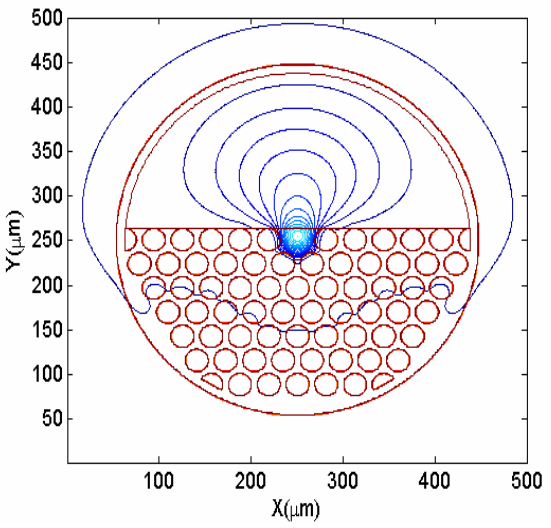

(b)

Figura 46. Componente de campo magnético $H_{x}$ do modo fundamental. (a) $\lambda=1000 \mathrm{~nm}$; (b)

$$
\lambda=1800 \mathrm{~nm} \text {. }
$$

Essa mudança na inclinação da curva do índice efetivo em função do comprimento de onda é fundamental no projeto de fibras ópticas compensadoras de dispersão. Calculando a segunda derivada dessa função em relação ao comprimento de onda, ou seja, a dispersão, verifica-se um acentuado aumento do seu valor no ponto onde ocorre a mudança da inclinação. Este fato resulta em um aumento no pico da dispersão, conforme mostrado na Figura 47.

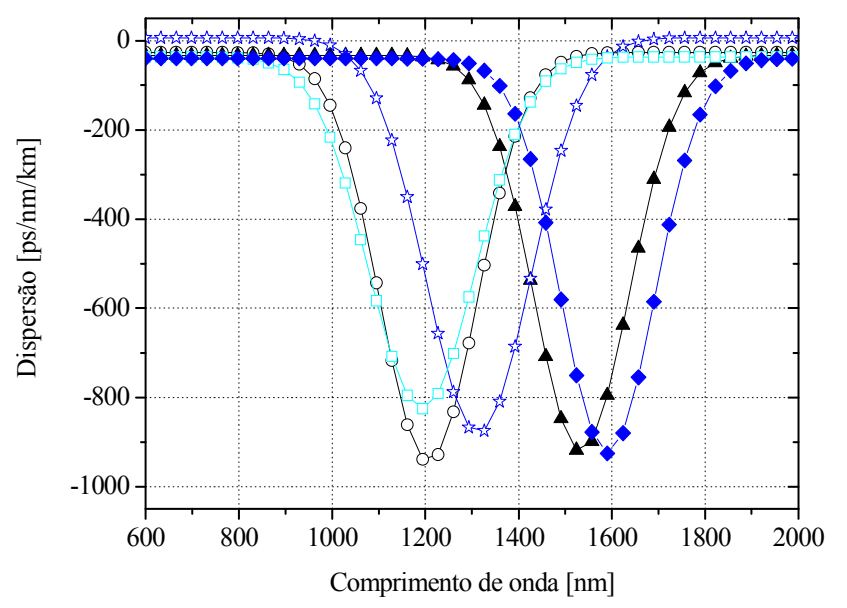

$$
\begin{array}{ll}
\text { anéis ar; tunel preenchidos: } \mathrm{n}=1,4 ; 8 \text { anéis } \\
-\Lambda=2 \mu \mathrm{m} \mathrm{dd}=0 & \mathrm{~d} / \Lambda=0,8 \\
-\Lambda=2 \mu \mathrm{m} \mathrm{dd}=\text { raio } & \mathrm{d} / \Lambda=0,8 \\
-\Lambda=2 \mu \mathrm{m} \mathrm{dd}=0 & \mathrm{~d} / \Lambda=0,7 \\
-\Lambda=2 \mu \mathrm{m} \mathrm{dd}=\text { raio } & \mathrm{d} / \Lambda=0,7 \\
-\Lambda=2 \mu \mathrm{m} \mathrm{dd}=0 & \mathrm{~d} / \Lambda=0,8 \text { anéis } 5
\end{array}
$$

Figura 47. Dispersão cromática para a fibra D-MOF com túnel preenchido. 
Portanto, com as fibras ópticas microestruturadas tipo $\mathrm{D}$ com a região do túnel preenchida, é possível projetar fibras compensadoras de dispersão, na região de $1550 \mathrm{~nm}$, cujo pico de dispersão negativo é de aproximadamente $-1000 \mathrm{ps} /(\mathrm{nm} \mathrm{km})$. Com 100nm de largura de banda $(1490 \mathrm{~nm}-1590 \mathrm{~nm})$, essa fibra apresenta uma dispersão negativa de aproximadamente $-800 \mathrm{ps} /(\mathrm{nm} \mathrm{km})$.

Uma outra fibra D-MOF com a região do túnel preenchida foi também investigada. Neste caso, foram mantidos os mesmos parâmetros simulados anteriormente, apenas o material utilizado no preenchimento do túnel foi modificado. No caso particular, foi utilizado um material com índice de refração igual a 1,38. Os valores obtidos para a dispersão nessa fibra foram comparados ao caso anterior e são apresentados na Figura 48.

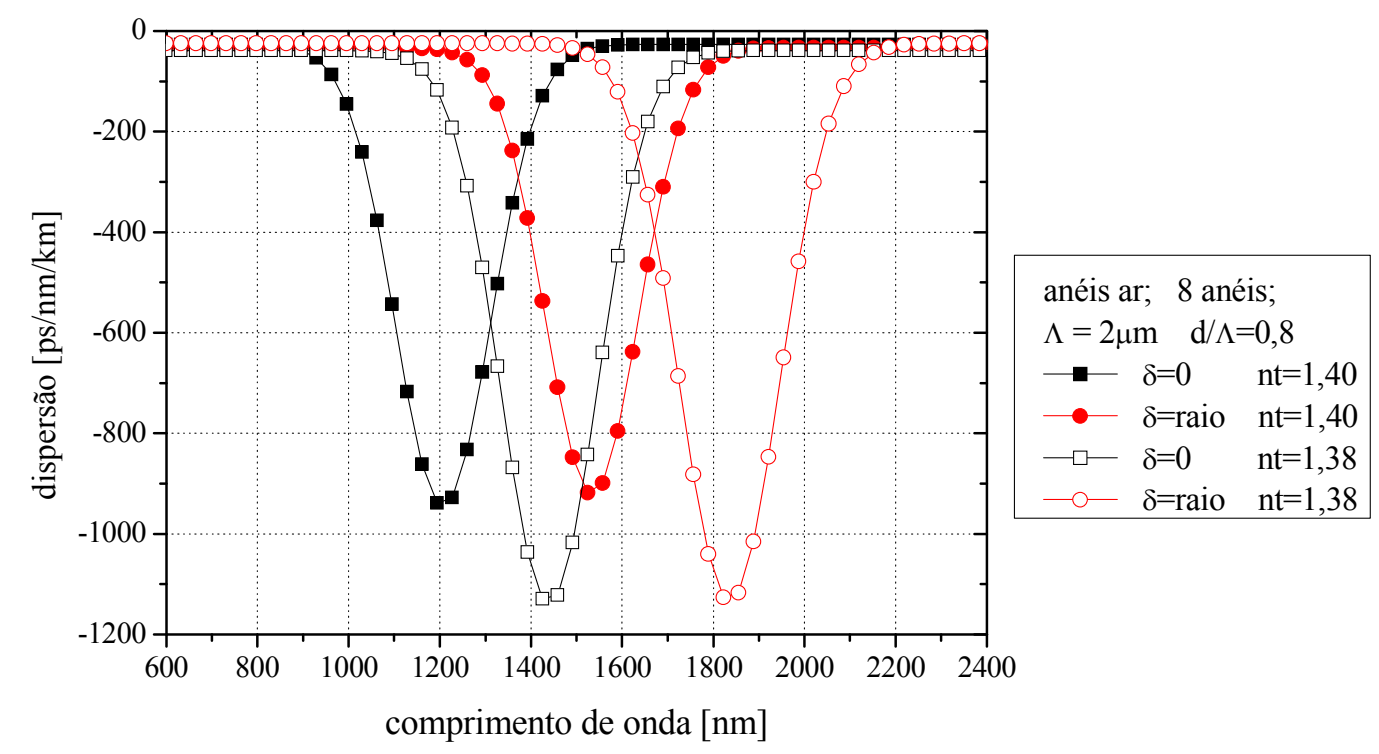

Figura 48. Dispersão cromática para a fibra D-MOF com túnel preenchido por materiais de índice de refração: $n=1,40$ e $n=1,38$.

Conforme demonstrado na Figura 48, utilizando um material de preenchimento com índice de refração menor, verifica-se que é possível obter um coeficiente de dispersão ainda mais negativo. Isto ocorre devido ao aumento no degrau de índice de refração entre o núcleo e a região do túnel. Esse maior contraste de índice acarreta em uma maior inclinação da curva 
do índice efetivo. Fisicamente, ocorre uma mudança mais abrupta na região de guiamento, ou seja, o modo que estava confinado na região do núcleo passa a ser guiado na região do túnel.

\section{B) Túnel e anéis preenchidos}

Nesta subseção, são investigadas as fibras D-MOF onde a região do túnel e os capilares são preenchidos com materiais de índice de refração variando entre 1,0 $<\mathrm{n}_{\text {túnel }}, \mathrm{n}_{\text {ané }}<1,4$, conforme Figura 49
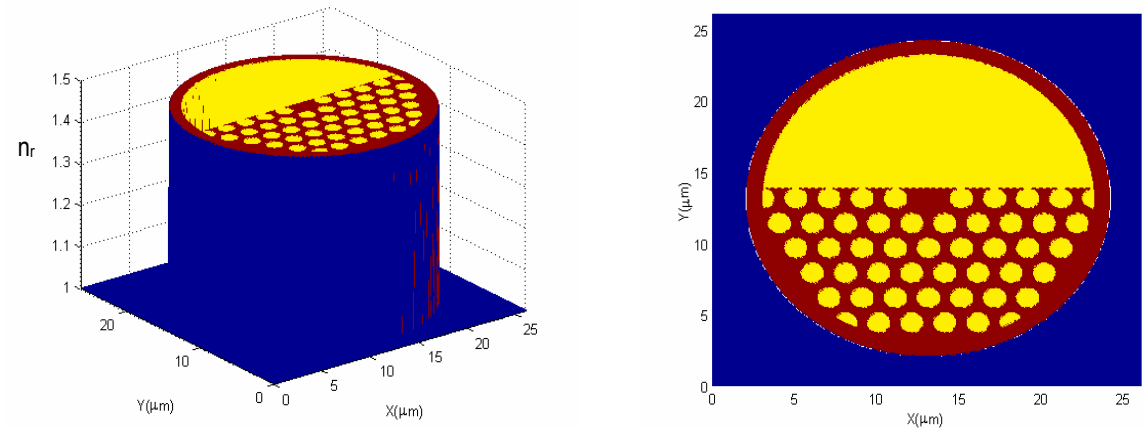

Figura 49. Perfil de índice de refração da D-MOF com a região do túnel e os anéis preenchidos.

Os parâmetros de variação no projeto dessa fibra $\left(\Lambda, d / \Lambda, \delta\right.$ e $\left.n_{\text {túnel }}\right)$ são os mesmos listados na Tabela 5 na subseção anterior. Com isso, é possível manter um padrão de preenchimento, e analisar as variações entre as fibras apresentadas no subitem anterior (onde apenas a região do túnel é preenchida) com estas estruturas (onde toda a região de ar foi preenchida).

A Figura 50 apresenta a variação do índice efetivo em função do comprimento de onda mantendo-se a relação $\mathrm{d} / \Lambda$ fixa, igual a 0,8 , o corte $\delta$, igual a $\mathrm{d} / 2$, para duas fibras, respectivamente, com $\Lambda=2 \mu \mathrm{m}$ (símbolos cheios) e $\Lambda=3 \mu \mathrm{m}$ (símbolos vazados). Neste caso, investigou-se a variação do material de preenchimento, utilizando materiais com índice de refração igual a 1,40 (quadrado), 1,38 (estrela) e 1,30 (triângulo). 


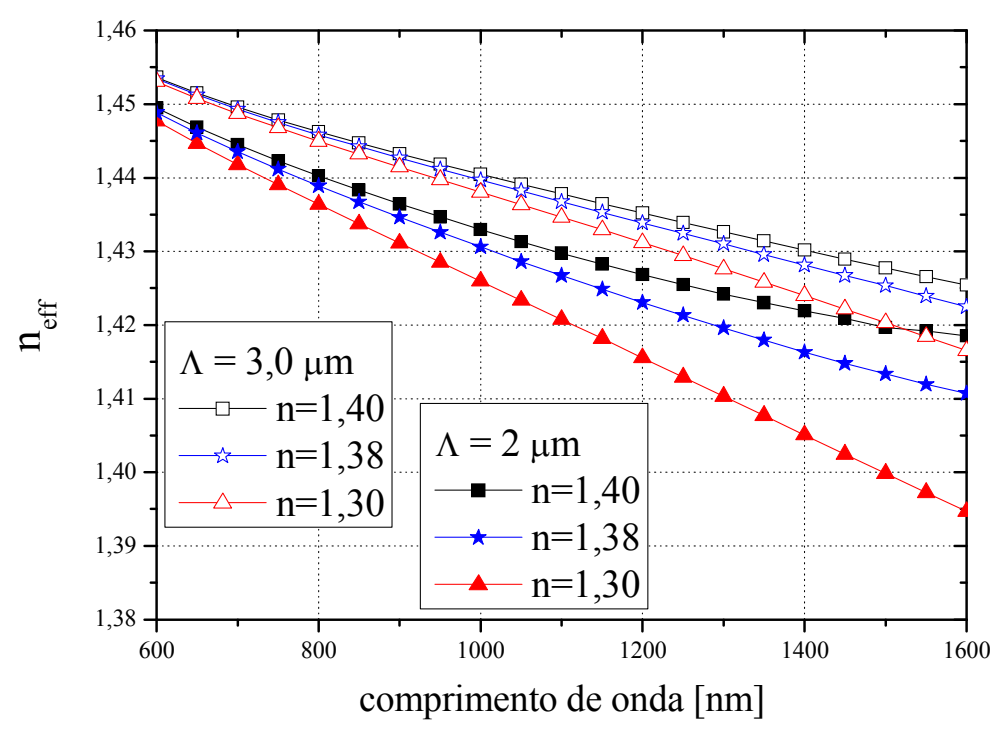

Figura 50. Índice efetivo em função do comprimento de onda para a D-MOF com $\mathrm{d} / \Lambda=0,8$, $\delta=d / 2$ e região do túnel e anéis preenchidos com material de índice de refração igual a 1,40 (quadrado), 1,38 (estrela) e 1,30 (triângulo).

Analisando o gráfico da Figura 50, verifica-se um comportamento semelhante entre as curvas, com o valor do índice efetivo diminuindo com o aumento do comprimento de onda. Justifica-se esse comportamento nas D-MOFs pelo fato do modo propagante permanecer sempre confinado na região do núcleo e, em comprimentos de onda mais longos, penetrar mais fortemente na região dos anéis preenchidos. Este comportamento é semelhante ao ocorrido em uma fibra microestruturada convencional.

O fato de preencher a região de ar com diferentes materiais diminui o contraste de índice de refração entre o núcleo e a casca, diminuindo o confinamento na região do núcleo e, portanto, conforme já discutido, tornando a fibra menos birrefringente. Para os casos investigados apresentados na Figura 51, o valor da birrefringência B permaneceu na ordem de $10^{-4}$. Vale lembrar que a fibra D-MOF sem preenchimento, ou seja, com grande confinamento modal, apresenta elevados valores de $\mathrm{B}$, da ordem de $10^{-2}$. Com relação à dispersão cromática para os casos apresentados na Figura 51, observa-se que aumentar o espaçamento, $\Lambda$, ou aumentar o índice de refração do material de preenchimento, torna a dispersão menos negativa, mais plana e mais próxima de zero. Para melhor observar estas características, a 
Figura 51 apresenta essas curvas de dispersão na região do espectro óptico de interesse, entre $1300 \mathrm{~nm}$ e $1600 \mathrm{~nm}$.

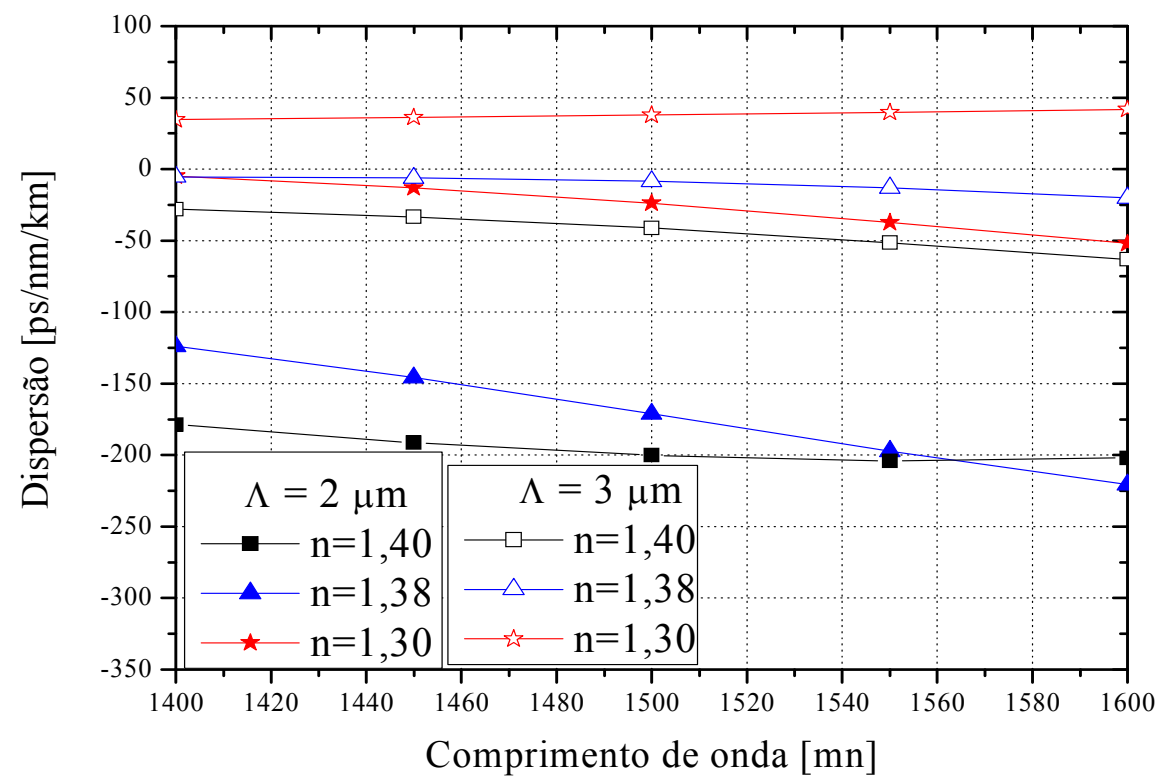

Figura 51. Dispersão cromática em função do comprimento de onda. $\Lambda=2$ linhas com símbolos cheios e $\Lambda=3$ linhas com símbolos vazados. Índice de refração do material de preenchimento igual a 1,40 (quadrado), 1,38 (triângulo) e 1,30 (estrela).

Analisando o comportamento das curvas de dispersão para os casos selecionados acima, verifica-se que é possível projetar fibras com dispersão plana e próxima de zero ( $\Lambda=3 \mu \mathrm{m}, \mathrm{n}=1,38$ - curva azul símbolos vazados), ou ainda, fibras com dispersão negativa em toda a banda óptica $(\Lambda=2 \mu \mathrm{m}, \mathrm{n}=1,40$ - curva azul com símbolos cheios), cobrindo desde a banda O (1260-1360nm) até a banda L (1560-1630nm). Neste caso específico, pode-se utilizar a fibra com dispersão plana e negativa para compensar a dispersão cromática residual.

Para finalizar esse estudo, foram investigados os casos onde tanto o espaçamento $\Lambda$, $(\Lambda=3 \mu \mathrm{m})$ quanto o material de preenchimento $\left(\mathrm{n}_{\mathrm{m}}=1,36\right)$ é mantido fixo, com a relação $\mathrm{d} / \Lambda$ sendo modificada. Neste caso, obteve-se uma dispersão mais plana e próxima de zero, Figura 52(a) com a birrefringência na ordem de $10^{-4}$ Figura 52(b). 


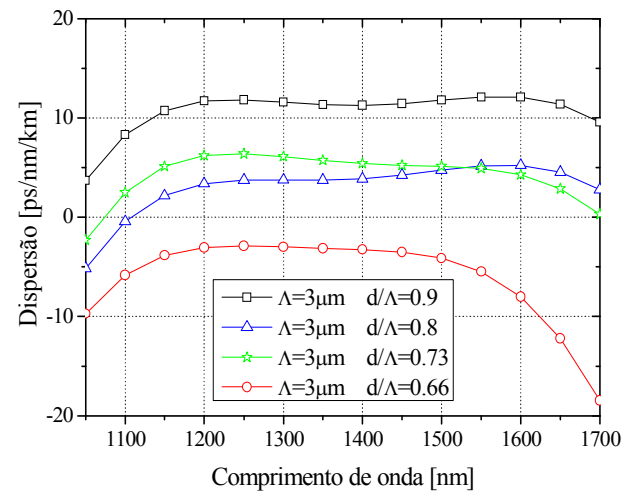

(a)

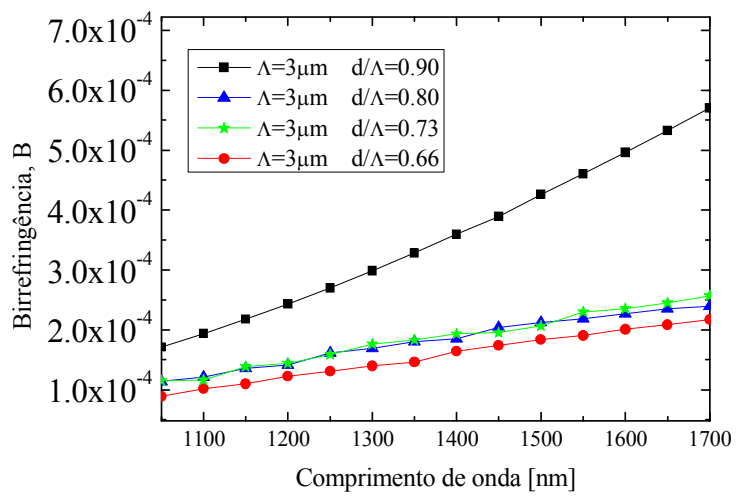

(b)

Figura 52. (a) Dispersão cromática em função do comprimento de onda. (b) Birrefringência em função do comprimento de onda. Linhas: preto $d / \Lambda=0,90$, verde $d / \Lambda=0,80$, azul $d / \Lambda=0,73 \mathrm{e}$ vermelho $\mathrm{d} / \Lambda=0,66$.

Portanto, buscou-se nesta subseção preencher a região de ar e investigar o comportamento modal das D-MOFs. Com o preenchimento das D-MOFs foi possível projetar fibras com dispersão plana e próxima de zero. Porém, devido ao menor contraste entre o índice de refração núcleo e casca, a birrefringência para todos os casos das fibras preenchidas investigadas manteve-se na ordem de $10^{-4}$, ou seja, apresentam, ainda, elevada birrefringência, porém, duas ordens de grandeza menores que das fibras D-MOFs altamente birrefringentes projetadas na seção anterior. 


\section{Conclusão}

Neste trabalho, foram investigados novos arranjos geométricos para as fibras ópticas microestruturadas (MOFs), visando a sua utilização como fibras compensadoras de dispersão cromática e como fibras altamente birrefringentes. Particularmente, investigou-se as MOFs convencionais, as MOFs de dois núcleos e as MOFs tipo D.

Para isso, foi necessário desenvolver, inicialmente, ferramentas numéricas capazes de simular as estruturas propostas. Foram, então, implementados e aferidos os métodos numéricos SOR e IRAM. Os resultados obtidos com os métodos SOR e IRAM, comparados com os resultados das estruturas padrão encontrados na literatura, para três guias de ondas diferentes, confirmaram a validação dos métodos. Foi verificado, também, que o método IRAM é capaz de fornecer a distribuição modal não só do modo fundamental mas também de todos os modos de ordem superior.

A primeira fibra óptica microestruturada analisada neste trabalho foi uma fibra capaz de apresentar, simultaneamente, os efeitos de compensação de dispersão e amplificação Raman. Foram feitos os testes experimentais nesta MOF, verificando-se espalhamento Raman ao redor do comprimento de onda em $1583 \mathrm{~nm}$, com um coeficiente de dispersão negativo $\mathrm{D}=$ $-124,31 \mathrm{ps} /(\mathrm{nm} \mathrm{km})$ em 1560nm. Portanto, esta fibra MOF é adequada ao projeto específico de uma fibra óptica apresentando simultaneamente compensação de dispersão e ganho Raman.

Em seguida, visto o grande interesse dos pesquisadores nas fibras ópticas microestruturadas de dois núcleos, atuando como fibras compensadoras de dispersão, foi feito um estudo teórico do comportamento modal dessas fibras MOFs de dois núcleos. Neste estudo, foi proposta uma nova interpretação do comportamento modal, pois verificou-se que o modo estritamente confinado no núcleo interno ou no núcleo externo não existe. $\mathrm{O}$ que realmente ocorre é a existência do modo com parcelas de energia distribuídas simultaneamente, em diferentes quantidades, entre os dois núcleos. Conseqüentemente, os dois supermodos nas vizinhanças do comprimento de onda de corte não podem ser estudados independentemente.

$\mathrm{Na}$ terceira parte deste trabalho foram apresentados os resultados obtidos para as MOFs com geometria tipo D. Foram desenvolvidos três projetos: 
1) fibra compensadora de dispersão em banda larga: projetou-se uma fibra microestruturada tipo $\mathrm{D}$, otimizada para compensação de dispersão em banda larga $(\Lambda=1,6 \mu \mathrm{m}$, $\mathrm{d} / \Lambda=0,6875, \mathrm{r}_{\mathrm{c}}=0,10 \mathrm{r}$ ), apresentando dispersão negativa, no comprimento de onda de $1550 \mathrm{~nm}$, de aproximadamente $-690 \mathrm{ps} /(\mathrm{nm} \mathrm{km})$. A dispersão residual permaneceu abaixo de $1,0 \mathrm{ps} /(\mathrm{nm}$ $\mathrm{km}$ ), demonstrando, portanto, a eficiência da fibra D-MOF atuando na compensação da dispersão cromática nas bandas S, C e L. Assim, aproximadamente 2,5km dessa fibra D-MOF são capazes de compensar a dispersão imposta em um enlace de 100km da fibra SMF-28.

2) fibra altamente birrefringente: foram projetadas fibras com elevada birrefringência, com o valor de B mantendo-se em torno de $10^{-2} \mathrm{em}$ uma larga faixa espectral. Particularmente, as D-MOFs com $\mathrm{d} / \Lambda=0,95, \delta=0, \Lambda=1,3 \mu \mathrm{m}$ e $\Lambda=1,2 \mu \mathrm{m}$, respectivamente, apresentaram o valor da birrefringência, no comprimento de onda de $1550 \mathrm{~nm}$, iguais a $3,89 \times 10^{-2}$ e $3,97 \times 10^{-2}$. Estes valores de birrefringência, até o presente momento, são os maiores valores de B obtidos numericamente com uma fibra óptica microestruturada. Ademais, foi proposta uma nova geometria para as fibras MOFs tipo $\mathrm{D}$, com a região da casca formada por capilares em formato elípticos, definidas como x-ED-MOF e y-ED-MOF. Particularmente, as x-ED-MOFs apresentam uma maior birrefringência se comparadas às mesmas estruturas com o eixo maior da elipse orientado na direção y, com a vantagem adicional da região do núcleo e dos capilares da primeira fileira não serem afetados pelo corte. As x-ED-MOFs apresentaram o valor de $\mathrm{B}$ da ordem de $10^{-2}$ enquanto as y-ED-MOFs possuem B da ordem de $10^{-3}$.

3) fibra com dispersão plana e alta birrefringência: para se obter estas características, as D-MOFs foram preenchidas por diferentes materiais e investigadas em diferentes configurações geométricas. Por meio do preenchimento, buscava-se descoplar os efeitos de alta birrefringência e dispersão negativa, ou seja, ou projetar uma fibra compensadora de dispersão com baixa birrefringência, ou, de forma contrária, projetar uma fibra com dispersão plana próxima de zero e com alta birrefringência. Foi possível projetar fibras com dispersão plana e próxima de zero $\left(\Lambda=3 \mu \mathrm{m}, \mathrm{d} / \Lambda=0,8, \mathrm{n}_{\text {material }}=1,38\right)$, com a birrefringência na ordem de $10^{-4}$, ou ainda, fibras com dispersão negativa em toda a banda óptica $(\Lambda=2 \mu \mathrm{m}, \mathrm{d} / \Lambda=0,8$ $\left.\mathrm{n}_{\text {material }}=1,40\right)$, cobrindo desde a banda $\mathrm{O}(1260-1360 \mathrm{~nm})$ até a banda L (1560-1630nm). 
Por fim, alguns tópicos que podem dar continuidade a este trabalho são: investigar novos materiais no preenchimento das fibras D-MOFs; propor e investigar novas aplicações para as D-MOFs, tais como, na geração de supercontínuo, na aplicação como sensores, entre outros. 


\section{Publicações}

\section{Periódicos - Artigos publicados:}

1) E.R. Martins, D.H. Spadoti, M.A. Romero e B.-H.V. Borges, "Theoretical Analysis of Supercontinuum Generation in a Highly Birefringent D-shaped Microstructured Optical Fiber", Optics Express, Vol. 15, no. 22, pp. 14335 - 14347, Novembro 2007.

2) S.P.N. Cani, C.A. De Francisco, D.H. Spadoti, V.E. Nascimento , B.-H.V. Borges, L.C. Calmon and M.A. Romero, "Requirementes for Efficient Raman amplification and dispersion compensation using Photonic Crystal Fiber”, Fiber and Integrated Optics, Vol. 26, no. 5, pp. 255 270, Setembro 2007.

3) C.A. De Francisco, K. Digweed-Lyytikainen, D.H. Spadoti, A.A. Juriollo, J.B. Rosolem, J.B.M. Ayres Neto, B.V. Borges, J. Canning and M.A. Romero, "Photonic Crystal Optical Fibers for Dispersion Compensation and Raman Amplification: Design and Experiment", Microwave and Optical Technology Letters, Vol. 49, no. 4, pp. 872-874, Abril 2007.

4) D.H. Spadoti, C.A. De Francisco, V. Nascimento, B.-H.V. Borges, M.A. Romero, "Fullvectorial to scalar FD-SOR formulations for optical waveguide modelling: a comparative study", International Journal of Numerical Modelling: Electronic Networks, Devices and Fields, Vol. 19, no. 6, pp. 507-520, Novembro/Dezembro 2006.

5) V.E. Nascimento, C.A. De Francisco, D.H. Spadoti, M.A. Romero, B.-H.V. Borges, "Use of a novel wide-angle FD-BPM for loss performance assessment in randomly perturbed photonic crystal fibers", Microwave and Optical Technology Letters, Vol. 45, no. 6, pp. 568-573, Junho 2005.

\section{Congressos - Trabalhos aceitos/publicados:}

1) Emiliano R. Martins, Danilo H. Spadoti, Murilo A. Romero, and Ben-Hur V. Borges, "Influence of Pump Location on the Supercontinuum Generation in a Highly Birefringent Microstructured Fiber", The $13^{\text {th }}$ Biennial IEEE Conference on Electromagnetic Field Computation CEFC 2008 - Maio de 2008, PA. 4-8, Atenas, Grécia. 
2) D.H. Spadoti, B.-H.V. Borges, and M.A. Romero, "Novel Microstructured Optical Fiber Design for Broadband Dispersion Compensation”, 2007 SBMO/IEEE MTT-S - IMOC-2007 International Microwave and Optoelectronics Conference, Outubro de 2007, Salvado-BA, Brasil.

3) D.H. Spadoti, K. Digweed-Lyytikainen, C.A. De Francisco, A.A. Juriollo, J.B. Rosolem, J.B.M. Ayres Neto, B.V. Borges, J. Canning and M. A. Romero, "Resultados Experimentais Preliminares para Fibras Ópticas Microestruturadas em Compensação de Dispersão e Amplificação Raman (trabalho convidado)", XII Simpósio Brasileiro de Microondas e Optoeletrônica - MOMAG'06, Agosto de 2006, Belo Horizonte-MG, Brasil.

4) K. Digweed-Lyytikainen, C.A. De Francisco, D. Spadoti, A.A. Juriollo, J.B. Rosolem, J.B.M. Ayres Neto, B.V. Borges, J. Canning and M.A. Romero, "Towards Microstructured Silica Optical Fibers for Dispersion Compensation and Raman Amplification: Design and Preliminary Experimental Results”, WorkPof-2006 - International Workshop on Polymer Optical Fibers and International Workshop on Micro-Structured Polymer Optical Fibers, Abril 2006, Campinas-S.P, Brasil.

5) De Francisco, C.A.; Lyytikainen, K.D.; Spadoti, D.; Juriollo, A.A; Rosolem, J.B.; Ayres Neto, J.B.M.; Borges, B.V. ; Canning, J.; Romero, M.A., "Photonic Crystal Optical Fibers for Dispersion Compensation and Raman Amplification: Design and Preliminary Experimental Results", Australian Conference on Optical Fibre Technology - ACOFT'06, 2006, Melbourne, Austrália.

6) S.P.N. Cani, L.C. Calmon, C.A. De Francisco, D.H Spadoti, B. V. Borges e M.A. Romero, "Performance Evaluation of Simultaneous Dispersion Compensation and Raman Amplification using Microstructured Optical Fibers", 2005 SBMO/IEEE MTT-S - IMOC-2005 - International Microwave and Optoelectronics Conference, Julho de 2005, Brasília, Brasil. 


\section{Referências}

[1] E. Yablonovitch, "Inhibited Spontaneous Emission in Solid-State Physics and Electronics", Physical Review Letters, vol. 58, no. 20, p. 2060 -2062, Maio 1987.

[2] J.C. Knight, T.A. Birks, P.St.J. Russell, D.M. Atkin, "All-silica single-mode optical fiber with photonic crystal cladding”, Optics Letters, 21, no. 19, p. 1547-1549, Outubro 1996.

[3] R.F. Cregan, , B.J. Mangan, J.C. Knight, T.A. Birks, P.St.J. Russell, "Single-Mode Photonic Band Gap Guidance of Light in Air", Science, vol. 285, p. 1537-1539, Setembro 1999.

[4] F. Brechet, J. Marcou, D.Pagnoux, P. Roy, "Complete Analysis of the Characteristics of Propagation into Photonic Crystal Fibers, by the Finite Element Method", Optical Fiber Technology 6, p. 181-191, 2000.

[5] K. Saitoh e M. Koshiba, "Numerical Modeling of Photonic Crystal Fibers", J. of Light. Techno. Lett., vol. 23 no. 11, novembro de 2005.

[6] J. Broeng, D. Mogilevstev, S.E. Barkou, A. Bjarklev, "Photonic Crystal Fibers: A New Class of Optical Waveguides”, Optical Fiber Technology 5, p. 305-330, 1999.

[7] T.F. Krauss, R.M. De La Rue, "Photonic crystal in the optical regime - past, present and future", Progress in Quantum Electronics 23, p.51-96.

[8] T.A. Birks, J.C. Knigh, P.St.J. Russell, "Endlessly single-mode photonic crystal fiber", Optics Letters, v. 22, no. 13, p. 961-963, Julho 1997.

[9] N.A. Mortensen, "Effective area of photonic crystal fibers", Optics Express, v. 8, no. 7, Abril 2002.

[10] Agrawal, G.P, “Fiber-Optic Communication Systems”, 2ª edição, John Wiley, 1992.

[11] A.M. Zheltikov, "Holey Fibers", Physics-Uspekhi 43 (11), p. 1125-1136.

[12] F. Poli, A. Cucinotta, M. Fuochi, S. Selleri e L. Vincetti, "Characterization of microstructured optical fibers for wideband dispersion compensation ”, J. of Opt. Soc. Am., vol. 20 no. 10, Outubro de 2003.

[13] A. Ortigosa-Blanch, J. C. Knight, W. J. Wadsworth, J. Arriaga, B. J. Mangan, T. A. Birks, e P. St. J. Russell, "Highly birefringent photonic crystal fibers", Optics Letters, vol. 25, no. 18, pp. 1325-1328, Setembro de 2000.

[14] M.L. Rocha, “Tutorial 1 - Dispesão”, http://www.kyatera.fapesp.br/portal/pesquisa/tutoriais 
[15] M. Nishimura, "Optical fibers and fiber dispersion compensators for high-speed optical communication", Journal of Optical and Fiber Communications Report vol. 2, pp. 115-139, 2005.

[16] J.B. Rosolem, “Amplificadores ópticos de dupla passagem incorporando fibras compensadoras de dispersão", Tese de doutorado da Escola de Engenharia de São Carlos -USP.

[17] B.P. Pal, K. Pande, "Optimization of a dual-core dispersion slope compensating fiber for DWDM transmission in the 1480-1610 nm band through G.652 single-mode fibers", Optics Communications vol. 201, pp. 335-344, janeiro de 2002.

[18] V. A. Semenov, A. V. Belov, E. M. Dianov, A. A. Abramov, M. M. Bubnov, S. L. Semjonov, A.G. Shchebunjaev, V. F. Khopin, A. N. Guryanov, e N. N. Vechkanov, "Broadband dispersioncompensating fiber for high-bit-rate transmission network use", Applied Optics, vol. 34, no. 24, Agosto de 1995.

[19] G. Keiser, “Optical Fiber Communications”, 2a edição, Inc. McGraw Hill, pp 97-113.

[20] G.P. Agrawal, "Nonlinear Fiber Optics", $2^{a}$ edição, Inc. Academic Press, pp 7-15.

[21] J. L. Auguste, J. M. Blondy, J. Maury, J. Marcou, B. Dussardier, G. Monnom, R. Jindal, K. Thyagarajan, B. P. Pal, "Conception, Realization, and Characterization of a Very High Negative Chromatic Dispersion Fiber”, Optical Fiber Technology, vol. 8, pp. 89-105, 2002.

[22] L. Grüner-Nielsen, M. Wandel, P. Kristensen, C.Jørgensen, L.V. Jørgensen, B. Edvold, B. Pálsdóttir, D. Jakobsen, "Dispersion-Compensating Fibers", Journal of Lightwave Technology, vol 23, no. 11, novembro 2005.

[23] C. Lin, H. Kogelnik, L. G. Cohen, "Optical-pulse equalization of low dispersion transmission in single-mode fibers in the 1.3-1.7 $\mu \mathrm{m}$ spectral region," Opt. Lett., vol. 5, no. 11, pp. 476-478, Novembro 1980.

[24] J. M. Dugan, A. J. Price, M. Ramadan, D. L. Wolf, E. F. Murphy, A. J. Antos, D. K. Smith, D. W. Hall, "All-optical, fiber-based $1550 \mathrm{~nm}$ dispersion compensation in a $10 \mathrm{~Gb} / \mathrm{s}, 150 \mathrm{~km}$ transmission experiment over $1310 \mathrm{~nm}$ optimized fiber," presented at the Optical Fiber Communication (OFC), San Jose, CA, 1992, Paper PD14.

[25] B. Jopson, A. Gnauck, "Dispersion Compensation for Optical Fiber Systems", IEEE Communications Magazine Junho de 1995.

[26] K. Oh., S. Choi, Y. Jung, J.W. Lee, "Novel Hollow Optical Fibers and Their Applications in Photonic Devices for Optical Communications”, Journal of Lightwave Technology, vol 23, no. 2, fevereiro 2005.

[27] A.M. Vengsarkar, "Dispersion compensating fibers", Optical Fiber Communication - OFC'97 Technical Digest, pp. 233 - 234, 1997. 
[28] L. P. Shen, W.-P. Huang, G. X. Chen, e S. S. Jian, "Design and Optimization of Photonic Crystal Fibers for Broad-Band Dispersion Compensation”, Photonic Technology Letters. vol. 15, no 4, Abril de 2003.

[29] K. Thyagarajan, R.K. Varsney, P. Palai, A.K. Ghatak, I.C. Goyal, "A novel design of a dispersion compensating fiber”, IEEE Photonics Technol. Lett., vol 8, no. 11, 1996.

[30] J.-L. Auguste, R. Jindal, J.-M. Blondy, M. Clapeau, J. Marcou, B. Dussardier, G. Monnom, D.B. Ostrowsky, B.P. Pal and K. Thyagarajan, “ $-1800 \mathrm{ps} /(\mathrm{nm} \mathrm{km})$ chromatic dispersion at $1.55 \mathrm{pm}$ in dual concentric core fibre”, Electron. Letters, vol. 36, no. 20, pp. 1689-1691, setembro de 2000.

[31] T.A. Birks, D. Mogilevtsev, J.C. Knigh, P.St.J. Russell, "Dispersion compensation using single material fiber”, IEEE Photonic Technology Letters, vol. 11, junho de 1999.

[32] D. Mogilevtsev, T. A. Birks, e P. S. J. Russell, "Group-velocity dispersion in photonic crystal fibers," Optics Letters, 23, pp. 1662-1664, 1998.

[33] M. J. Gander, R. McBride, J. D. C. Jones ,D. Mogilevts ev, T. A. Birks ,J. C. Knight, e P. S. J. Russell, "Experimental measurement of group velocity dispersion in photonic crystal fibers," Electronic Letters, Vol. 35, pp. 63-64, 1999.

[34] T. M. Monro, D. J. Richardson, G. R. Broderick, e P. J. Bennet, "Holey Optical Fibers: An Efficient Modal Model”, Journal of Lightwave Technology, vol 17, no 6, Junho de 1999.

[35] A. Ferrando, E. Silves tre, J. J. Miret, e P. Andrés, "Nearly zero ultraflattened dispersion in photonic crystal fibers," Optics Letters, 25, pp. 790-792, 2000.

[36] M. Fuochi, F. Poli, S. Selleri, A. Cucinotta e L. Vincetti, "Study of Raman amplification properties in triangular photonic crystal fibers", Journal of Lightwave Technology, Vol. 21 no. 10, Outubro de 2003.

[37] T. M. Monro, D. J. Richardson, e P. J. Bennett, "Developing holey fibers for evanescent field devices”, Electronic Letters, Vol 35, pp. 1188-1189, 1999.

[38] C.A. de Francisco, "Fibras ópticas microestruturadas: modelagem e aplicação", Tese de doutorado, Escola de Engenharia de São Carlos -USP - 2004.

[39] Yi Ni, L. Zhang, L. An, J. Peng e C. Fan, "Dual-Core Photonic Crystal Fiber for Dispersion Compensation”, IEEE Photonic Technology Letters, vol. 16, no 6, Junho de 2004.

[40] F. Gerome, J.L. Auguste, J.M. Blondy, "Very high negative chromatic dispersion in a dual concentric core photonic crystal fiber”, Optical Fiber Communication-WA2, pp 1-3, 2004.

[41] B.J. Mangan, F. Couny, L. Farr, A. Langford, P.J. Roberts, D.P. Williams, M. Banham, M.W. Mason, D.F. Murphy, E.A.M. Brown, H. Sabert, T.A. Birks, J.C. Knight, e P.St.J. Russel, "Slope-matched dispersion compensating photonic crystal fibre," Proceedings of Conference on Lasers and Electro-Optics, paper CPDD3, San Francisco, CA, (2004). 
[42] F. Gerome, J.L. Auguste, J.M. Blondy, "Design of dispersion compensation fibers base on a dual concentric core photonic crystal fiber", Optics Letters, vol. 29, no. 23, Dezembro de 2004.

[43] Ni Yi, "Large Negative Dispersion in Square Solid Photonic Bandgap Fibers", IEEE J. Quantum Electronics, vol. 41, no 5, Maio de 2005.

[44] A. Huttunen, P. Törmä, "Optimization of dual core and microstructure fiber geometries for dispersion compensation and large mode area”, Optics Express, vol. 13, no. 2, Janeiro de 2005.

[45] S. Yang, Y. Zhang, X. Peng, Y. Lu, S. Xie, J. Li, W. Chen, Z. Jiang, J. Peng, H. Li, “ Theoretical study and experimental fabrication of high negative dispersion photonic crystal fiber with large area mode field", Optics Express, vol. 14, no. 7, Abril de 2006.

[46] T. Fujisawa, K. Saitoh, K. Wada, e M. Koshiba, "Chromatic dispersion profile optimization of dual-concentric-core photonic crystal fibers for broadband dispersion compensation", Optics Express, vol. 14, no 2, Janeiro de 2006.

[47] F. Gérôme, S. Février, J.-L. Auguste, R. Jamier, J.-M. Blondy, M. E. Likhachev, M. M. Bubnov, S. L. Semjonov, E. M. Dianov, V. F. Khopin, M. Y. Salganskii, A. N. Guryanov, "Dispersion Compensating Photonic Bandgap Fibre", 32nd European Conference on Optical Communication (ECOC), We4.4.3, 2006.

[48] T. Matsui, K. Nakajima, I. Sankawa, "Dispersion Compensation Over All the Telecommunication Bands With Double-Cladding Photonic-Crystal Fiber” Journal of Lightwave Technology, vol 25, no 3, Marco de 2007.

[49] C.-L. Chen, "An Analysis of High Birefringence Fibers”, Journal of Lightwave Technology, vol. LT5, no 1, Janeiro de 1987

[50] T. Hosaka, K. Okamoto, T. Miya, Y. Sasaki, e T. Edahiro, "Low-loss single polarization fibers with asymmetrical strain birefringence," Electron. Letters, Vol. 17, pp.530-531, 1981.

[51] M. P. Varnham, D. N. Payne, R. D. Birch, e E. J. Tarbox, "Single-polarization operation of highly birefringent bow-tie optical fibers," Electronic Letters, Vol. 19, pp. 246-247, 1983.

[52] Vide referência 13.

[53] M. J. Steel e R. M. Osgood Jr., "Elliptical-hole photonic crystal fibers," Optics Letters, Vol. 26, no. 229, Fevereiro de 2001.

[54] T. P. Hansen, J. Broeng, S. E. B. Libori, E. Knudsen, A. Bjarklev, J. R. Jensen, e H. Simonsen, "Highly birefringent index-guiding photonic crystal fibers," IEEE Photonic Technology Letters, Vol. 13, pp. 588-590, Junho de 2001.

[55] S. B. Libori, J. Broeng, E. Knudsen, A. Bjarklev, e H. R. Simonsen, "High-birefringent photonic crystal fiber," in Proc. Optical Fiber Communication Conference 2001, Vol. 54 of OSA Proceedings Series, pp. TuM2-1 -TuM2-3. 
[56] K. Suzuki, H. Kubota, S. Kawanishi, M. Tanaka, M. Fujita, "Optical properties of a low-loss polarization-maintaining photonic crystal fiber,” Optics Express, Vol 9, pp. 676-680, Dezembro de 2001.

[57] K. Saitoh e M. Koshiba, "Single-Polarization Single-Mode Photonic Crystal Fibers", IEEE Photonic Technology Letters, Vol. 15, no. 10, Outubro de 2003.

[58] C.-L. Zhao, C. Lu, X. Zhou, X. Yang, P.R. Chaudhuri, X. Wang, J. Lou, L. Qin, e C. Qing, "Asymmetric core photonic crystal fibers with high birefringence", Microwave and Optical Technology Letters, Vol. 42, No. 6, Setembro de 2004.

[59] N. A. Issa, M. A. Van-Eijkelenborg, M. Fellew, F. Cox, G. Henry, e M. C. J. Large, "Fabrication and study of microstructured optical fibers with elliptical holes," Optics Letters, Vol. 29, pp. 1336-1338, Junho de 2004

[60] A. Ortigosa-Blanch, A. Diez, M. Delgado-Pinar, J.L. Cruz, e M.V. Andres, "Ultrahigh birefringent nonlinear microstructured fiber," Photonics Technology Letters, Vol. 16, pp. 16671669, Julho de 2004.

[61] Y.C. Liu e Y. Lai, "Optical birefringence and polarization dependent loss of square- and rectangular-lattice holey fibers with elliptical air holes: numerical analysis", Optics Express, Vol. 13, no. 1, Janeiro de 2005.

[62] M. Szpulak, G. Statkiewicz, J. Olszewski, T. Martynkien, W. Urbanczyk, J. Wójcik, M. Makara, J. Klimek, T. Nasilowski, F. Berghmans, e H. Thienpont, "Experimental and theoretical investigations of birefringent holey fibers with a triple defect”, Applied Optics. Vol. 44, no. 13, Maio de 2005.

[63] J. Wang, C. Jiang, W. Hu, M. Gao, "High birefringence photonic bandgap fiber with elliptical air holes", Optical Fiber Technology, Vol. 12, pp 265-267, 2006.

[64] Y. Yue, G. Kai, Z. Wang, Y.Li, C. Zhang, Y. Lu, T. Sun, L. Jin, J. Liu, Y. Liu, S. Yuan, X. Dong, "Phase and group modal birefringence of an index-guiding photonic crystal fibre with helical air holes", Optics Communications 268, pp. 46-50, Julho de 2006.

[65] D.C. Zografopoulos, E.E. Kriezis e T.D. Tsiboukis "Photonic crystal-liquid crystal fibers for single-polarization or high-birefringence guidance", Optics Express, Vol. 14, no. 2, Janeiro de 2006.

[66] Y. Yue, G. Kai, Z. Wang, Y. Lu, C. Zhang, T. Sun, Y.Li, L. Jin, J. Liu, Y. Liu, S. Yuan, e X. Dong "Highly Birefringent Elliptical-Hole Photonic Crystal Fiber With Two Big Circular Air Holes Adjacent to the Core", Photonics Technology Letters, Vol. 18, no. 24, Dezembro 2006. 
[67] Y. Yue, G. Kai, Z. Wang, T. Sun, L. Jin, Y. Lu, C. Zhang, J. Liu, Y. Li, Y. Liu, S. Yuan e X. Dong, "Highly birefringent elliptical-hole photonic crystal fiber with squeezed hexagonal lattice", Optics Letters, Vol. 32, no. 5, Março 2007.

[68] Y.-S. Sun, Y.-F. Chau, H.-H. Yeh, L.-F. Shen, T.-J. Yang e D.P. Tsai, "High birefringence photonic crystal fiber with a complex unit cell of asymmetric elliptical air hole cladding", Applied Optics, Vol. 46, no. 22, Agosto 2007.

[69] D. Chen e L. Shen, "Highly Birefringent Elliptical-Hole Photonic Crystal Fibers With Double Defect", Journal of Lightwave Technology, Vol. 25, no. 9, Setembro de 2007.

[70] H. Ademgil e S. Haxha, "Highly Birefringent Photonic Crystal Fibers with Ultralow Chromatic Dispersion and Low Confinement Losses”, Journal of Lightwave Technology, Vol. 26, no. 4, Fevereiro de 2008.

[71] E.R Martins, D.H Spadoti; M.A Romero; B.-H.V Borges, "Theoretical analysis of supercontinuum generation in a highly birefringent D-shaped microstructured optical fiber", Optics Express, Vol. 15 no. 22, pp.14335-14347, Dezembro de 2007.

[72] E.R Martins, "Modelagem de geração de luz supercontínua", Tese de doutorado da Escola de Engenharia de São Carlos-USP, 2008.

[73] http://www.caam.rice.edu/software/ARPACK/

[74] D.H. Spadoti, "Análise de fibras ópticas microestruturadas pelo método da sobrerelaxação sucessiva”, dissertação de mestrado, Escola de Engenharia de São Carlos -USP - 2004.

[75] J. Yamauchi, G. Takahashi, H. Nakano, "Full-Vectorial Beam-Propagation Method Based on the McKee-Mitchell Scheme with Improved Finite-Difference Formulas", Journal of Lightwave Technology, vol. 16, no. 12, Dezembro 1998.

[76] M.S. Stern, "Semivectorial polarized H field solutions for dielectric waveguides with arbitrary index profiles", IEE Proceedings, vol. 135, pp 333-338, 1998.

[77] J. Yamauchi, G. Takahashi, e H. Nakano, "Modified Finite-Difference Formula for Semivectorial H-Field Solutions of Optical Waveguides”, IEEE Photon. Technology Letters, vol. 10, no. 8, pp. 1127-1129, Agosto 1998.

[78] Y.-P. Chiou, Y.-C. Chiang, H.-C. Chang, "Improved Three-Point Formulas Considering the Interface Conditions in the Finite-Difference Analysis of Step-Index Optical Devices”, Journal of Lightwave Technology, vol. 18, no. 2, Fevereiro 2000.

[79] J.D. Faires, R.L. Burden, "Numerical Methods”, Publishing Company Boston, p. 242-269.

[80] R.S. Varga, "Matrix Iterative Analysis", Editora Prentice-Hall, ed. 1, 1962.

[81] D.M. Young, "Iterative Solution of Large Linear Systems - Computer Science and Applied Mathematics", Editora Academic Press, ed. 1, 1971. 
[82] W.H. Press, B.P. Flannery, S.A. Teukolsky, W.T. Vetterling, "Numerical Recipes - the art of scientific computing”, Cambridge University Press, pp-335-377,615-659.

[83] W. Huang, H.A. Hauss, "Analysis of Buried-Channel Waveguides and Couplers: Scalar Solution and Polarization Correction", Journal of Lightwave Technology, vol. 8, no. 5, Maio 1990.

[84] C.A. De Francisco, B.-H. V. Borges, M.A. Romero, "A Semivectorial Method for the Modeling of Photonic Crystal Fibers", Microwave and Optical Technology Letters, vol. 38, no. 5, pp. 418 421, Setembro 2003.

[85] M.C.C. Cunha, "Métodos Numéricos”, Editora Unicamp, ed. 2, pp. 58- 66, 2003.

[86] P.R. Chaudhuri, C. Lu, W. Xiaoyan, "Scalar model and exact vectorial description for the design analysis of hollow optical fiber components", Optics Communications, Vol. 228, no. 4-6, pp. 285-293, 2003.

[87] S. Choi, T.J. Eom, J.W. Yu, B.H. Lee, K. Oh, "Novel All-Fiber Bandpass Filter Based on Hollow Optical Fiber", Photonics Technology Letters, Vol. 14, no. 12, dezembro 2002.

[88] S. Choi, K. Oh, W. Shin, C.S. Park, U.C. Paek, K.J. Park, Y.C. Chung, G.Y. Kim, Y.G. Lee, "Novel Mode Converter Based on Hollow Optical Fiber for Gigabit LAN Communication", Photonics Technology Letters, Vol. 14, no. 12, fevereiro 2002.

[89] S. Choi, W. Shin, K. Oh, "Higher-order-mode dispersion compensation technique based on mode converter using hollow optical fiber" Optical Fiber Communication Conference - OFC 2002, pp. 177-178.

[90] P.B. Hansen, G. Jacobovitz-Veselka, L. Gruner-Nielsen e A.J. Stentz, "Raman amplification for loss compensation in dispersion compensating fibre modules", Electronic Letters, Vol. 34, pp. 1136-1137, Maio 1998.

[91] B.J. Mangan, F. Couny, L. Farr, A. Langford, P.J. Roberts, D.P. Wiliams, M. Banham, M.W. Manson, D.F. Murphy, E.A.M. Brown, H. Sabert, T.A. Birks, J.C. Knight e P.S.J. Russell. "Slope Matched Dispersion Compensation Photonic Crystal Fibre", Proceedings of the CLEO’04, pp. 1069-1070, Maio 2004.

[92] Z. Yusoff, J. H. Lee, W. Belarti, T. M. Monro, P. C. Teh e D. J. Richardson, "Raman Effects in a Highly Nonlinear Holey Fiber: Amplification and Modulation”, Optics Letters, vol. 27, pp. 424426, Março 2002.

[93] S.K. Varshney, T. Fujisawa, K. Saitoh e M. Koshiba, "Novel design of inherently gain-flattened discrete highly nonlinear photonic crystal fiber Raman amplifier and dispersion compensation using a single pump in C-band", Optics Express, Vol. 13, pp. 9516-9526, Novembro 2005.

[94] S.P.N. Cani , C.A. De Francisco, D.H. Spadoti, V.E. Nascimento , B.-H. V. Borges, L.C. Calmon, M. A. Romero, "Requirements for Efficient Raman Amplification and Dispersion 
Compensation Using Microstructured Optical Fibers”, Fiber and Integrated Optics - Vol. 26, no. 5, Junho 2007.

[95] K.J. Lyytikainen, "Control of Complex Structural Geometry in Optical Fibre Drawing”, Ph.D. Thesis, University of Sydney, 2004.

[96] F. Gérôme, J.-L. Auguste, J. Maury, J.-M. Blondy, e J. Marcou, “Theoretical and Experimental Analysis of a Chromatic Dispersion Compensating Module Using a Dual Concentric Core Fiber" J. Lightwave Technology, vol. 24, no. 1, Janeiro 2006.

[97] D. Marcuse, "Directional Couplers Made of Nonidentical Asymmetric Slabs. Part I: Synchronous Couplers", J. of Lightwave Technology, vol. 1t-5, no. 1, Janeiro 1987.

[98] D. Marcuse, "Directional Couplers Made of Nonidentical Asymmetric Slabs. Part II: Gratingassisted Couplers", J. of Lightwave Technology, vol. 1t-5, no. 2, Fevereiro 1987.

[99] S. Yang, Y. Zhang, J. Li, W. Chen, L. He, e S. Xie, "Experimental Study of Mode Field Evolution of Dual-Core Photonic Crystal Fiber", Photonics Technology Letters, Vol. 19, no. 19, Outubro 2007.

[100] W. Jin, G. Stewart, M. Wilkinson, B. Culshaw, F. Muhammad, S. Murray, e J. 0. W. Norris, "Compensation for Surface Contamination in a D-Fiber Evanescent Wave Methane Sensor", Journal of Lightwave Technology, vol. 13, no 6, Junho 1995.

[101] N-K. Chen, S. Chi, "Evanescent Wave Photonic Crystal Fiber Tunable Filter Using Dispersive Optical Polymers", Optical Fiber Communication Conference - OFC'05, OWD3 -2005.

[102] N.-K. Chen, S. Chi "Influence of a holey cladding structure on spectral characteristics of sidepolished endlessly single-mode photonic crystal fibers", Optics Letters, Vol. 31, no. 15, pp. 2251-2253, Agosto 2006.

[103] H. Kim, J. Kim, U.-C. Paek, B.H. Lee, K.T. Kim "Tunable photonic crystal fiber coupler based on a side-polishing technique”, Optics Letters, vol. 29, no. 11, pp. 1194-1196, Junho 2004.

[104] P.St.J. Russell, "Photonic-Crystal Fibers" J. of Lightwave Technology, Vol. 24, no. 12, dezembro 2006.

[105] K. Digweed-Lyytikainen, C. A. de Francisco, D. Spadoti, A. A. Juriollo, J. B. Rosolem, J. B. M. Ayres Neto, B. V. Borges, J. Canning, e M. A. Romero, "Photonic crystal optical fibers for dispersion compensation and Raman amplification: design and experiment," Microwave. Optical. Technology Letters, Vol. 49, pp. 872-874, Abril 2007.

[106] J. Lægsgaard e A. Bjarklev, "Microstructured optical fibers-fundamentals and applications," J. of American Ceramic Society. vol. 89, pp 2-12, Janeiro 2006.

[107] J. Fini e R. Bise. "Progress in fabrication and modeling of microstructured optical fiber," Japanese J. of Applied Physics. Vol. 43, pp. 5717-5730, Agosto 2004. 
[108] S.K. Varshney, T. Fujisawa, K. Saitoh, e M. Koshiba, "Design and analysis of a broadband dispersion compensating photonic crystal fiber Raman amplifier operating in S-band”, Optics Express, Vol. 14, no. 817, Abril 2006.

[109] J. Dudley, G. Genty, S. Coen "Supercontinuum generation in photonic crystal fiber", Reviews of Modern Physics, vol. 78, Outubro -Dezembro 2006.

[110] K. Saitoh, N. Florous, e M. Koshiba "Ultra-flattened chromatic dispersion controllability using a defected-core photonic crystal fiber with low confinement losses”, Optics Express, Vol. 13, n. 21, Outubro, 2005.

[111] W.J. Bock, J. Chen, T. Eftimov e W. Urbanczyk, "A Photonic Crystal Fiber Sensor for Pressure Measurements", Transactions on Instrumentation and Measurement, Vol. 55, no. 4, Agosto 2006.

[112] M. Nakazawa, "Highly efficient Raman amplification in a polarization-preserving optical fiber," Appl. Phys. Lett. 46, 628-630 (1985).

[113] C.M. B. Cordeiro, M.A. R. Franco, G. Chesini, E.C. S. Barretto, R. Lwin, C.H.B. Cruz e M.C.J. Large "Microstructured-core optical fibre for evanescent sensing applications", Optics Express, Vol. 14, n. 26, Dezembro de 2006.

[114] Y.L. Hoo, W. Jin, C. Shi, H.L. Ho, D.N. Wang e S.C. Ruan "Design and modeling of a photonic crystal fiber gas sensor", Applied Optics, Vol. 42, n. 18, Junho de 2003.

[115] J.M Fini, "Microstructure fibres for optical sensing in gases and liquids", Meas. Sci. Technol., Vol. 15, p. 1120-1128, 2004.

[116] T. Ritari, J. Tuominen, e H. Ludvigsen , J. C. Petersen, T. Sørensen, T. P. Hansen, H. R. Simonsen, "Gas sensing using air-guiding photonic bandgap Fibers", Optics Express, Vol. 12, n. 17, Agosto de 2004.

[117] S. Yang, Y. Zhang e S. Xie, "Transformation of a Single Mode Photonic Crystal Fiber into a Tunable Dispersion Compensator”, ECOC 2006.

[118] K.M. Gundu, M. Kolesik, J.V. Moloney e K.S. Lee, "Ultra-flattened-dispersion selectively liquid-filled photonic crystal fibers”, Optics Express, Vol. 14, n. 15, Julho de 2006.

[119] S. Yiou, P. Delaye, A. Rouvie, J. Chinaud, R. Frey, G. Roosen, P. Viale, S.Février, P. Roy, J.-L. Auguste, J.-M. Blondy "Stimulated Raman scattering in an ethanol core microstructured optical fiber”, Optics Express, Vol. 13, n. 12, Junho de 2005.

[120] R. Zhang, J. Teipel, H. Giessen, "Theoretical design of a liquid-core photonic crystal fiber for supercontinuum generation", Optics Express, Vol. 14, no. 15, Julho 2006. 


\section{I.1. Apêndice - Obtenção da Equação Vetorial de Helmholtz.}

A partir das equações de Maxwell, será deduzida a equação vetorial de Helmholtz.

As equações de Maxwell são:

$$
\left\{\begin{array}{lll}
\nabla \times \vec{E}=-\frac{\partial \vec{B}}{\partial t} & (1 a) & \nabla \cdot \vec{D}=\rho \\
\nabla \times \vec{H}=\vec{J}+\frac{\partial \vec{D}}{\partial t} & (2 a) & \nabla \cdot \vec{B}=0
\end{array}\right.
$$

No domínio da freqüência

$\left\{\begin{array}{l}\nabla \times \vec{E}=-j \omega \vec{B} \\ \nabla \times \vec{H}=j \omega \vec{D}+\vec{J}\end{array}\right.$

Considerando o meio isotrópico $\left\{\begin{array}{l}\vec{D}=\varepsilon \vec{E} \\ \vec{B}=\mu \vec{H}\end{array}\right.$

Como: $\mu=\mu_{0}$

$$
n=\sqrt{\varepsilon / \varepsilon_{0}} \Rightarrow D=n^{2} \varepsilon_{0} \vec{E}
$$

Substituindo (6) em (4); como $\vec{J}$ e $\rho=0$ (meio dielétrico e região sem fontes), temse:

$\nabla \times \vec{H}=j \omega \varepsilon_{0} n^{2} \vec{E}$

Aplicando o operador rotacional $(\nabla \times)$ em ambos os lados da equação acima:

$\nabla \times \nabla \times \vec{H}=j \omega \varepsilon_{0}\left(\nabla \times n^{2} E\right)$

Utilizando a identidade vetorial: $\quad \nabla \times(\phi \vec{F})=\phi \nabla \times \vec{F}+\nabla \phi \times \vec{F}$ 


$$
\nabla \times \nabla \times \vec{H}=j \omega \varepsilon_{0}\left(n^{2} \nabla \times \vec{E}\right)+j \omega \varepsilon_{0}\left(\nabla n^{2} \times \vec{E}\right)
$$

Substituindo a equação (3) na equação acima:

$$
\nabla \times \nabla \times \vec{H}=j \omega \varepsilon_{0}\left(-n^{2} j \omega \vec{B}\right)+j \omega \varepsilon_{0}\left(\nabla n^{2} \times \vec{E}\right)
$$

Agora, substituindo (6) em (4):

$$
\nabla \times \vec{H}=j \omega \varepsilon_{0} n^{2} \vec{E} \quad \Rightarrow \quad \vec{E}=\frac{\nabla \times \vec{H}}{j \omega \varepsilon_{0} n^{2}}
$$

Substituindo as equações (5b) e (8) na equação (7):

$$
\begin{gathered}
\nabla \times \nabla \times \vec{H}=\omega^{2} n^{2} \varepsilon_{0} \mu \vec{H}+j \omega \varepsilon_{0}\left(\nabla n^{2} \times \frac{\nabla \times \vec{H}}{j \omega \varepsilon_{0} n^{2}}\right) \\
\nabla \times \nabla \times \vec{H}=\omega^{2} n^{2} \varepsilon_{0} \mu \vec{H}+\nabla n^{2} \times\left(\frac{1}{n^{2}} \nabla \times \vec{H}\right)
\end{gathered}
$$

Operando por partes, primeiro expandindo o lado direito de (9):

O termo: $\quad \nabla n^{2} \times\left(\frac{1}{n^{2}} \nabla \times \vec{H}\right)$ da equação (9), fica:

$$
\left(\hat{i} \frac{\partial n^{2}}{\partial x}+\hat{j} \frac{\partial n^{2}}{\partial y}+\hat{k} \frac{\partial n^{2}}{\partial z}\right) \times\left[\left(\hat{i} \frac{1}{n^{2}}\left(\frac{\partial H z}{\partial y}-\frac{\partial H y}{\partial z}\right)\right)+\left(\hat{j} \frac{1}{n^{2}}\left(\frac{\partial H x}{\partial z}-\frac{\partial H z}{\partial x}\right)\right)+\left(\hat{k} \frac{1}{n^{2}}\left(\frac{\partial H y}{\partial x}-\frac{\partial H x}{\partial y}\right)\right)\right]=
$$

Efetuando a multiplicação vetorial 


$$
\begin{aligned}
& \hat{i}[\overbrace{\frac{\partial n^{2}}{\partial y}}^{\text {ESCALAR }} \overbrace{\left(\frac{1}{n^{2}} \frac{\partial H y}{\partial x}\right)}^{\text {VETOR }}-\frac{\partial n^{2}}{\partial y}\left(\frac{1}{n^{2}} \frac{\partial H x}{\partial y}\right)-\frac{\partial n^{2}}{\partial z}\left(\frac{1}{n^{2}} \frac{\partial H x}{\partial z}\right)+\frac{\partial n^{2}}{\partial z}\left(\frac{1}{n^{2}} \frac{\partial H z}{\partial x}\right)] \\
& \hat{j}\left[-\frac{\partial n^{2}}{\partial x}\left(\frac{1}{n^{2}} \frac{\partial H y}{\partial x}\right)+\frac{\partial n^{2}}{\partial x}\left(\frac{1}{n^{2}} \frac{\partial H x}{\partial y}\right)+\frac{\partial n^{2}}{\partial z}\left(\frac{1}{n^{2}} \frac{\partial H z}{\partial y}\right)-\frac{\partial n^{2}}{\partial z}\left(\frac{1}{n^{2}} \frac{\partial H y}{\partial z}\right)\right] \\
& \hat{k}\left[-\frac{\partial n^{2}}{\partial y}\left(\frac{1}{n^{2}} \frac{\partial H z}{\partial y}\right)+\frac{\partial n^{2}}{\partial y}\left(\frac{1}{n^{2}} \frac{\partial H y}{\partial z}\right)+\frac{\partial n^{2}}{\partial x}\left(\frac{1}{n^{2}} \frac{\partial H x}{\partial z}\right)-\frac{\partial n^{2}}{\partial x}\left(\frac{1}{n^{2}} \frac{\partial H z}{\partial x}\right)\right]
\end{aligned}
$$

Trabalhando apenas as coordenadas transversais $(i, j)$ e utilizando a identidade:

$$
\frac{\partial(\phi \hat{F})}{\partial u}=\phi \frac{\partial \hat{F}}{\partial u}+\frac{\partial \phi \hat{F}}{\partial u} \Rightarrow \frac{\partial \phi \hat{F}}{\partial u}=-\phi \frac{\partial \hat{F}}{\partial u}+\frac{\partial(\phi \hat{F})}{\partial u}
$$

Se o índice de refração varia lentamente em z, pode-se desprezar os termos que contém $\frac{\partial n^{2}}{\partial z}, \log 0 \frac{\partial n^{2}}{\partial z} \equiv 0$

A equação (10) fica:

$$
\hat{i}\left[-n^{2} \frac{\partial}{\partial y}\left(\frac{1}{n^{2}} \frac{\partial H y}{\partial x}\right)+\frac{\partial}{\partial y}\left(n^{2} \frac{1}{n^{2}} \frac{\partial H y}{\partial x}\right)+\frac{n^{2} \partial}{\partial y}\left(\frac{1}{n^{2}} \frac{\partial H x}{\partial y}\right)-\frac{\partial}{\partial y}\left(n^{2} \frac{1}{n^{2}} \frac{\partial H x}{\partial y}\right)\right]
$$

Cancelando os termos, tem-se:

$$
\hat{i}\left[-n^{2} \frac{\partial}{\partial y}\left(\frac{1}{n^{2}} \frac{\partial H y}{\partial x}\right)+\frac{\partial^{2} H y}{\partial y \partial x}+n^{2} \frac{\partial}{\partial y}\left(\frac{1}{n^{2}} \frac{\partial H x}{\partial y}\right)-\frac{\partial^{2} H x}{\partial y^{2}}\right]
$$

A equação (11) fica:

$$
\hat{j}\left[n^{2} \frac{\partial}{\partial x}\left(\frac{1}{n^{2}} \frac{\partial H y}{\partial x}\right)-\frac{\partial}{\partial x}\left(n^{2} \frac{1}{n^{2}} \frac{\partial H y}{\partial x}\right)-n^{2} \frac{\partial}{\partial x}\left(\frac{1}{n^{2}} \frac{\partial H x}{\partial y}\right)+\frac{\partial}{\partial x}\left(n^{2} \frac{1}{n^{2}} \frac{\partial H x}{\partial y}\right)\right]
$$

Cancelando os termos, tem-se:

$$
\hat{j}\left[n^{2} \frac{\partial}{\partial x}\left(\frac{1}{n^{2}} \frac{\partial H y}{\partial x}\right)-\frac{\partial^{2} H y}{\partial x^{2}}-n^{2} \frac{\partial}{\partial x}\left(\frac{1}{n^{2}} \frac{\partial H x}{\partial y}\right)+\frac{\partial^{2} H x}{\partial x \partial y}\right]
$$

Agora, trabalhando o lado esquerdo da equação (9):

Usando a identidade $\nabla \times \nabla \times \vec{H}=\nabla(\nabla \cdot \vec{H})-\nabla^{2} \vec{H}$ 
De $(2 b) \nabla \cdot \vec{H}=0$

Expandindo o termo: $-\nabla^{2} \vec{H}$

$$
\begin{gathered}
-\nabla^{2} \vec{H}=-\frac{\partial^{2}}{\partial x^{2}}(\hat{i} H x, \hat{j} H y, \hat{k} H z)-\frac{\partial^{2}}{\partial y^{2}}(\hat{i} H x, \hat{j} H y, \hat{k} H z)-\frac{\partial^{2}}{\partial z^{2}}(\hat{i} H x, \hat{j} H y, \hat{k} H z) \\
\text { em } \hat{i}: \quad-\frac{\partial^{2} H x}{\partial x^{2}}-\frac{\partial^{2} H x}{\partial y^{2}}-\frac{\partial^{2} H x}{\partial z^{2}} \\
\text { em } \hat{j}:-\frac{\partial^{2} H y}{\partial x^{2}}-\frac{\partial^{2} H y}{\partial y^{2}}-\frac{\partial^{2} H y}{\partial z^{2}}
\end{gathered}
$$

Supondo o campo como sendo uma onda plana e escrevendo o campo como uma parte com variação lenta e uma parte de variação rápida em z (aproximação de envelope lento) pode-se escrever:

$$
H=H_{t} e^{-j \beta z}
$$

onde o termo $H_{t}$ descreve a variação lenta do campo transversal e o termo $e^{-j \beta z}$ descreve a variação rápida do campo (variação de fase). A primeira e segunda derivadas em relação a $\mathrm{z}$ podem então ser descritas como:

$$
\frac{\partial \vec{H}}{\partial z}=-j \beta \vec{H} \quad \Rightarrow \quad \frac{\partial^{2} \vec{H}}{\partial z^{2}}=-\beta^{2} \vec{H}
$$

A equação (9) era: $\nabla \times \nabla \times \vec{H}=\omega^{2} n^{2} \varepsilon_{0} \mu \vec{H}+\nabla n^{2} \times\left(\frac{1}{n^{2}} \nabla \times \vec{H}\right)$, após substituir os termos expandidos torna-se

Na direção $\hat{i}$ : nas equações (13) e (15) substitui-se as derivadas em z pela equação (17), considerando $\kappa_{0}=\omega \sqrt{\mu_{0} \varepsilon_{0}}, \operatorname{logo}$ :

$-\frac{\partial^{2} H x}{\partial x^{2}}-\frac{\partial^{2} H x}{\partial y^{2}}-\frac{\partial^{2} H x}{\partial z^{2}}=\kappa^{2} n^{2} \vec{H} x-n^{2} \frac{\partial}{\partial y}\left(\frac{1}{n^{2}} \frac{\partial H y}{\partial x}\right)+\frac{\partial^{2} H y}{\partial y \partial x}+n^{2} \frac{\partial}{\partial y}\left(\frac{1}{n^{2}} \frac{\partial H x}{\partial y}\right)-\frac{\partial^{2} H x}{\partial y^{2}}$

Rearranjando, isolando $\mathrm{H}_{\mathrm{x}}$ e multiplicando por (-1):

$$
\left[\frac{\partial^{2}}{\partial x^{2}}+n^{2} \frac{\partial}{\partial y}\left(\frac{1}{n^{2}} \frac{\partial}{\partial y}\right)+\kappa_{0}^{2} n^{2}-\beta^{2}\right] H_{x}=\left[n^{2} \frac{\partial}{\partial y}\left(\frac{1}{n^{2}} \frac{\partial}{\partial x}\right)-\frac{\partial^{2}}{\partial y \partial x}\right] H_{y}
$$


Na direção $\hat{j}$ : nas equações (14) e (16) substitui-se as derivadas em z pela equação (17) obtendo-se :

$$
-\frac{\partial^{2} H y}{\partial x^{2}}-\frac{\partial^{2} H y}{\partial y^{2}}-\frac{\partial^{2} H y}{\partial z^{2}}=\kappa^{2} n^{2} \vec{H} y+n^{2} \frac{\partial}{\partial x}\left(\frac{1}{n^{2}} \frac{\partial H y}{\partial x}\right)-\frac{\partial^{2} H y}{\partial x^{2}}-n^{2} \frac{\partial}{\partial x}\left(\frac{1}{n^{2}} \frac{\partial H x}{\partial y}\right)+\frac{\partial^{2} H x}{\partial x \partial y}
$$

Rearranjando, isolando $\mathrm{H}_{\mathrm{y}}$ e multiplicando por (-1):

$$
\left[\frac{\partial^{2}}{\partial y^{2}}+n^{2} \frac{\partial}{\partial x}\left(\frac{1}{n^{2}} \frac{\partial}{\partial x}\right)+\kappa_{0}^{2} n^{2}-\beta^{2}\right] H_{y}=\left[n^{2} \frac{\partial}{\partial x}\left(\frac{1}{n^{2}} \frac{\partial}{\partial y}\right)-\frac{\partial^{2}}{\partial x \partial y}\right] H_{x}
$$

As equações (18) e (19) são as equações vetoriais de Helmholtz. 